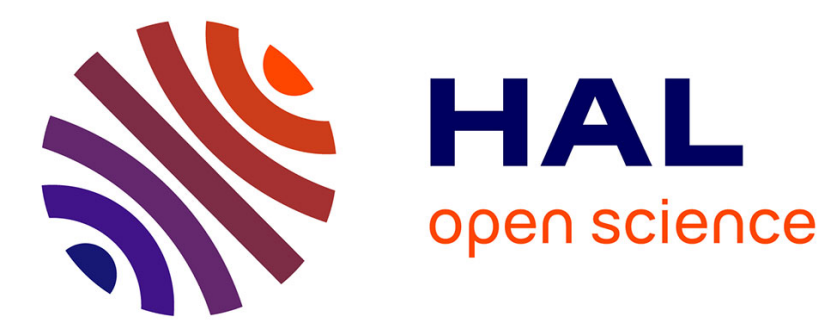

\title{
Relationships between type I and type II chondrules: Implications on chondrule formation processes
}

\author{
Johan Villeneuve, Guy Libourel, Camille Soulié
}

\section{To cite this version:}

Johan Villeneuve, Guy Libourel, Camille Soulié. Relationships between type I and type II chondrules: Implications on chondrule formation processes. Geochimica et Cosmochimica Acta, 2015, 160, pp.277305. 10.1016/j.gca.2015.03.033 . insu-01139842

\section{HAL Id: insu-01139842 \\ https://hal-insu.archives-ouvertes.fr/insu-01139842}

Submitted on 29 Apr 2015

HAL is a multi-disciplinary open access archive for the deposit and dissemination of scientific research documents, whether they are published or not. The documents may come from teaching and research institutions in France or abroad, or from public or private research centers.
L'archive ouverte pluridisciplinaire HAL, est destinée au dépôt et à la diffusion de documents scientifiques de niveau recherche, publiés ou non, émanant des établissements d'enseignement et de recherche français ou étrangers, des laboratoires publics ou privés. 


\section{Accepted Manuscript}

Relationships between type I and type II chondrules: Implications on chondrule formation processes

Johan Villeneuve, Guy Libourel, Camille Soulié

PII: S0016-7037(15)00185-4

DOI: http://dx.doi.org/10.1016/j.gca.2015.03.033

Reference: GCA 9198

To appear in:

Geochimica et Cosmochimica Acta

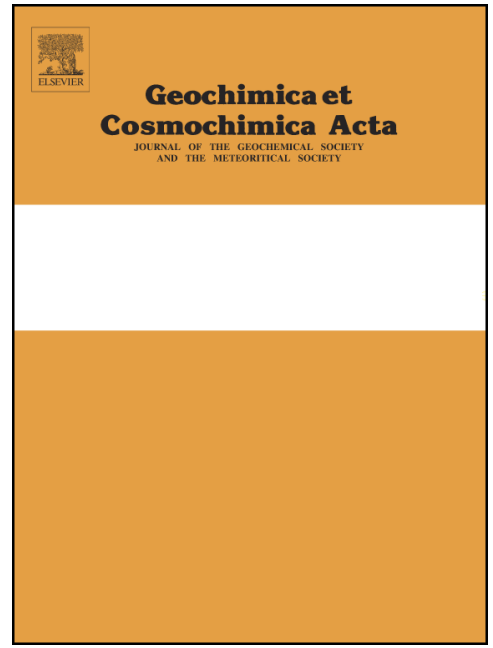

Received Date: $\quad 8$ April 2013

Accepted Date: $\quad 27$ March 2015

Please cite this article as: Villeneuve, J., Libourel, G., Soulié, C., Relationships between type I and type II chondrules: Implications on chondrule formation processes, Geochimica et Cosmochimica Acta (2015), doi: http://dx.doi.org/ 10.1016/j.gca.2015.03.033

This is a PDF file of an unedited manuscript that has been accepted for publication. As a service to our customers we are providing this early version of the manuscript. The manuscript will undergo copyediting, typesetting, and review of the resulting proof before it is published in its final form. Please note that during the production process errors may be discovered which could affect the content, and all legal disclaimers that apply to the journal pertain. 


\section{Relationships between type I and type II chondrules: implications on chondrule formation processes.}

$\underline{\text { Johan Villeneuve }}^{a, b, c, d,{ }^{*}}$ Guy Libourel ${ }^{a, e, f}$, Camille Soulié $^{a}$

${ }^{a}$ CRPG-Université de Lorraine, CNRS, UMR 7358, 15 Rue Notre-Dame des Pauvres, BP20,

545401 Vandoeuvre-lès-Nancy, France

'Université d'Orléans, ISTO, UMR 7327, 45071 Orléans, France.

${ }^{\mathrm{C} C N R S / I N S U, ~ I S T O, ~ U M R ~ 7327, ~} 45071$ Orléans, France.

${ }^{d}$ BRGM, BP 36009, 45060 Orléans, France.

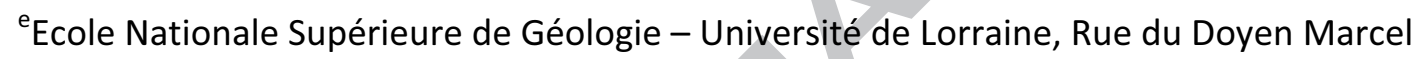
Roubault, BP40, 54501, Vandoeuvre-lès-Nancy, France.

fGeoazur, OCA, Université de Nice - Sophia Antipolis, CNRS/IRD, 250 rue Albert Einstein, Sophia Antipolis, 06560 Valbonne, France.

*Corresponding author. 1A rue de la férollerie, 45071 Orléans cedex 2.

Johan.villeneuve@cnrs-orleans.fr (+33)2 38255213

Abstract: 469 words

Main text: 11941 words

Figures: 22

Table: $\quad 3$

Keywords: Chondrules, oxidation experiments, kinetics, chondrule formation processes. 


\begin{abstract}
In unequilibrated chondrites, the ferromagnesian silicates in chondrules exhibit wide ranges of $\mathrm{mg \#}=\mathrm{Mg} /(\mathrm{Mg}+\mathrm{Fe})$, allowing to sub-divide porphyritic chondrules into either type I (mg\# > 0.9) or type II (mg\# < 0.9). Although both chondrule types formed under oxidizing conditions relative to the canonical solar nebula, it is generally inferred that type II chondrules formed in more oxidizing conditions than type I. In order to check whether this redox difference was established during chondrule formation, or reflects differences in their precursors, we have undertaken a set of experiments aimed at heating type I olivine-rich (A) chondrule proxy, i.e. forsterite + Fe metal + Ca-Mg-Si-Al glass mixtures, under oxidizing conditions. We show that high temperature (isothermal) oxidation of type IA-like assemblages is a very efficient and rapid process (e.g., few tens of minutes) to form textures similar to type IIA chondrules. Due to the rapid dissolution of Fe metal blebs, a FeO increase in the melt and in combination with the dissolution of magnesian olivine allows the melt to reach ferroan olivine saturation. Crystallization of ferroan olivine occurs either as new crystal in the mesostasis or as overgrowths on the remaining unresorbed forsterite grains (relicts). Interruption of this process at any time before its completion by rapid cooling allows to reproduce the whole range of textures and chemical diversity observed in type $A$ chondrules, i.e., from type I to type II.
\end{abstract}

Several implications on chondrule formation processes can be inferred from the presented experiments. Type I chondrules or fragments of type I chondrules are very likely the main precursor material involved in the formation of most type II chondrules. Formation of porphyritic olivine type II chondrules is very likely the result of processes generating crystal growth by chemical disequilibrium at high temperature rather than processes 
generating crystallization only by cooling rates. This questions the reliability of chondrule thermal history (e.g., cooling rate values) hitherto inferred for producing porphyritic textures from dynamical cooling rate experiments only. Type A chondrule formation can be a very fast process. After periods of sub-isothermal heating or slow cooling $(<50 \mathrm{~K} / \mathrm{h})$ as short as several tens of minutes and no longer than few hundreds of minutes at $1500-1800^{\circ} \mathrm{C}$, type $\mathrm{A}$ chondrules terminates their formation by a fast cooling $\left(>10^{3}-10^{4} \mathrm{~K} / \mathrm{h}\right)$ in order to preserve their glassy mesostasis. Such inferred thermal history being at odds with nebular shock models, we thus advocate that impacts on planetesimals causing rapid melting and vaporization may provide the high density and highly volatile-enriched gaseous environments required to form chondrules. In this scenario, chondrules and their diversity should result from various degrees of interaction of the ejected fragments with the impact vapor plume; the most oxidizing conditions recorded in type IIA chondrules being very likely the closest to those imposed by the impact vapor plume. 


\section{INTRODUCTION}

Chondrules, millimeter-sized igneous spheres containing olivine, pyroxene, metal, sulfide and glass, are the most abundant constituents of chondritic meteorites. Formed up to 2-3 Ma after CAls (Amelin et al., 2002; Kita et al., 2005; Russell et al., 2006; Wadhwa et al., 2007; Connelly et al., 2008; Villeneuve et al., 2009, Connelly et al., 2012), chondrules may provide some of the most powerful constraints on conditions in the solar protoplanetary disk, if the processes that led to their heating, melting and recrystallization can be understood.

Porphyritic ferro-magnesian chondrules, the most abundant type in most chondritic meteorites (Scott and Krot, 2003), are generally classified as olivine-rich (>80\%, A), pyroxene-rich $(>80 \%, B)$ and intermediate $(A B)$ according to their olivine and pyroxene modal abundances (Jones et al., 2005). Based on textural and chemical observations, it is generally inferred that porphyritic chondrules formed during brief, possibly repetitive, heating events resulting in partial melting of solid precursors (dust and large grains) followed by rapid cooling (e.g. Jones et al., 2005). In details, however, no clear consensus emerges on how chondrules formed and on the number of chondrule formation processes (e.g. Alexander and Ebel, 2012). The origin of chondrules precursors is also a key question. Did current chondrule precursors form from condensate dusts and/or liquid condensates from the nebula gas, from the recycling of previous generations of chondrules or chondrule-like materials, or from disrupted planetesimals (see reviews in Wood, 1996; Zanda, 2004; Lauretta et al., 2006; Jones et al., 2005; Hewins et al., 2005; Libourel and Krot, 2007; Ruzicka et al., 2008; Hewins and Zanda, 2012; Ruzicka, 2012)? The other central question of whether the heating mechanism was an astrophysical process or a planetary process is still a matter of debate, though heating by nebular shock (e.g., Desch and Connolly 2002; Ciesla, 2005; 
Morris and Desch, 2010; Desh et al., 2012; Morris et al., 2012) is currently one of the most favored mechanisms. Although whether or not chondrules formed in an open-system environment is still highly debated (e.g. Sears et al., 1996; Hewins et al., 2005; Jones et al., 2005; Alexander et al., 2008; Hewins et al., 2012; Alexander and Ebel, 2012; Hewins and Zanda, 2012), a number of arguments based on chemical (e.g. Matsunami et al., 1993; Nagahara et al., 1999; Libourel et al., 2003; Libourel et al., 2006; Krot et al., 2004), isotopic (e.g. Thiemens, 1996; Clayton, 2004; Chaussidon et al., 2008; Libourel and Chaussidon, 2011) and experimental (e.g. Yu and Hewins, 1998; Tissandier et al., 2002; Yu et al., 2003) observations strongly suggest that chondrules interacted with their gaseous surrounding environment during the period when they were molten.

Also debated is the nature of the relationships between type I and type II chondrules (e.g. Sears et al., 1996; Jones et al., 2005; Ruzicka et al., 2008 and 2012). Large heterogeneities among type I and type II chondrules of ordinary chondrites, particularly in terms of their olivine compositions (Fig. 1) and their bulk chemical compositions (Fig. 2), mean that there is no clear hiatus but rather a progressive transition between these two types of chondrules (e.g. Jones et al., 2005; Hewins et al., 2005). Such a continuum, together with the higher enrichment of type II chondrules in volatiles and moderately volatile elements, i.e. $\mathrm{Na}, \mathrm{K}$, $\mathrm{Mn}, \mathrm{Cr}, \mathrm{Si}$, and $\mathrm{Fe}$, and the larger average size of type II chondrules together with the occurrence of dusty relict olivines in some type I chondrules, have led several workers (e.g. Sears et al., 1996; Jones et al., 2005; Hewins et al., 2005 and refs therein) to suggest that type I chondrules could have been derived from type II chondrules by evaporation and reduction processes during heating events (see also Ruzicka, 2012). In addition, reduction experiments, conducted on chondrule proxies containing ferroan olivines, have shown that reduction processes are able to reproduce not only the forsteritic olivines observed in type I 
chondrules but also some dusty olivine assemblages (e.g. Connolly et al., 1994; Libourel and Chaussidon, 1995; Jones and Danielson, 1997; Lemelle et al., 2001; Leroux et al., 2003).

However, several observations have pointed out that if an evaporation/reduction scenario could have existed, it cannot explain the formation of the majority of chondrules. For instance (i) isotopic fractionation for volatile and moderately volatile elements that would have been induced by evaporation/reduction processes are not observed in chondrules (e.g. Alexander et al., 2000; Alexander and Wang, 2001; Yu et al., 2003; Lauretta et al., 2006; Alexander et al., 2008; Fedkin et al., 2012), (ii) metal grains in dusty olivines (Nipoor) and metal in type I chondrules (Ni-rich) do not have the same origin and thus could not have been formed simultaneously by an evaporation/reduction process (e.g. Rambaldi and Wasson, 1981; Leroux et al., 2003; Hewins et al., 2005), (iii) chemical gradients of volatiles and moderately volatiles elements in chondrule mesostasis and occurrence of mineralogical zoning in some chondrules argue in favor of condensation rather than evaporation processes (Matsunami et al., 1993; Nagahara et al., 1999; Libourel et al., 2003, Libourel et al., 2006; Krot et al., 2004; Alexander et al. , 2008; Hewins et al., 2012).

Recently, it has been shown that the formation of chondrules both of type I and type II is incompatible with canonical nebula conditions and most probably occurred in regions with high oxidation enhancement, i.e., circa 5-6 log units more oxidizing than solar (Grossman et al., 2008), due to either dust (e.g. Hewins et al., 2005; Jones et al., 2005; Grossman et al., 2008; Alexander et al., 2008; Grosmann, 2010) or ice (Ciesla and Cuzzi, 2006; Grosmann, 2010; Grosmann et al., 2012; Fedkin et al., 2012) enrichments. For instance, $\mathrm{fO}_{2}$ measured in type II chondrules can only be achieved with dust enrichments higher than 500 times the solar nebula abundance (e.g. Yu and Hewins, 1998; Grossman et al., 2008). However, the 
fact that type II chondrules contain fayalitic olivine phenocrysts with relict forsteritic cores (Jones, 1990; Wasson and Rubin, 2003; Ruzicka et al., 2007) and trivalent Ti (Simon et al., 2008, Simon et al., 2011), suggests that their precursors (or part of the precursor material) were formed in more reduced conditions. In the standard view, type I and type II chondrules appear thus to originate from different nebular reservoirs (e.g. Jones et al., 2005; Hewins and Zanda, 2012).

Recent studies have shown that (i) type I and type II chondrules formed almost contemporaneously, based on ${ }^{26} \mathrm{Al}$ systematics (e. g. Kita et al., 2005; Kurahashi et al., 2008; Villeneuve et al., 2009 and 2012), (ii) both types are close to chondritic bulk compositions (Jones et al., 2005) and (iii) type I phases (forsterite, metal) are often preserved as relicts in type II chondrules (Wasson and Rubin, 2003; Ruzicka et al., 2007; Schrader et al., 2008). Accordingly, the present study is aimed to investigate the possibility of an alternative chemical pathway to the classical view of formation of type I and type II chondrules from different nebular reservoirs. Recent studies (Connolly et al., 2008; Schrader et al., 2008; Ruzicka et al., 2008) have shown that type II chondrules could have been derived from type I chondrules by oxidation. We have conducted a set of experiments aimed at heating type I chondrule proxies under oxidizing conditions to test whether this pathway is feasible.

We survey the chemical and the petrological evolution with time of type IA proxies consisting of an assemblage of forsterite + iron metal $+\mathrm{CaO}-\mathrm{MgO}-\mathrm{Al}_{2} \mathrm{O}_{3}-\mathrm{SiO}_{2}$ (CMAS hereafter) glass exposed to oxidizing conditions between Iron-Wustite (IW) and $\mathrm{Ni}-\mathrm{NiO}$ (NNO) buffer curves under isothermal conditions at $1450^{\circ} \mathrm{C}$ and $1500^{\circ} \mathrm{C}$ (Fig. 3). In particular, we explore the possibility that FeO in type II chondrules could be the result of the oxidation of Fe metal from type I chondrules, according to the simple chemical reaction: $\mathrm{Fe}_{(\text {metal })}+$ 
$1 / 2 \mathrm{O}_{2 \text { (gas) }}=\mathrm{FeO}_{\text {(silicate/mesostasis) }}$. With experimental conditions compatible with chondrule formation (Hewins et al., 2005; Grossman, 2010; Grossman et al., 2008 and 2012), these experiments are designed to put new constraints on (i) textural and mineralogical changes that might result from an evolution from type I to type II chondrules, (ii) the kinetics of formation of type II chondrules by this process, and (iii) a more general understanding of chondrule formation processes, their timing and their associated redox conditions.

\section{EXPERIMENTAL}

Experiments were performed in a muffle furnace and in a $1 \mathrm{~atm}$ vertical furnace GERO HTVR 70-250 (Fig. 4) at the CRPG, for pre-synthesis and experimental runs, respectively. $\mathrm{CaO}-\mathrm{MgO}-\mathrm{Al}_{2} \mathrm{O}_{3}-\mathrm{SiO}_{2}$ (CMAS) glasses were synthetized from oxide and carbonate powders $\left(\mathrm{CaCO}_{3}, \mathrm{MgCO}_{3}, \mathrm{Al}_{2} \mathrm{O}_{3}\right.$ and $\left.\mathrm{SiO}_{2}\right)$, melted at $1500{ }^{\circ} \mathrm{C}$ for 60 min and pulverized. Then the obtained CMAS powder was melted again at $1500^{\circ} \mathrm{C}$ and pulverized again. Pure forsterite monocrystals, produced by zone melting crystallization, were crushed and sieved in two different powders with grain size ranging from 20-500 $\mu \mathrm{m}$ and 10-150 $\mu \mathrm{m}$. Iron metal was added in the form of iron filings (sub-spherical particles) ranging from 50 to $80 \mu \mathrm{m}$, a good analogue for representing metal blebs in chondrules. Experiments were run in a vertical furnace adjusted for both dwell oxygen fugacity and temperature (see below). Samples consisted of $\approx 2-3 \mathrm{~mm}$ diameter pellets of a mixture of starting materials and polyvinyl alcohol, were fixed on platinum (Pt) loops, and placed in the hot spot of the furnace by using a simple alumina rod or an alumina multistage rod equipped with a $\mathrm{PtRh} \mathrm{h}_{10}$-Pt thermocouple

(Fig. 4). The multistage rod is also equipped with a multi-quench device allowing to dropquench five samples at different durations of heating in the course of the same experiment 
(Fig. 4). Samples were quenched into air and collected into a transparent quenching container (Fig. 4).

Typical type IA chondrules in chondritic meteorites are mainly composed of forsteritic olivines \pm Fe-Ni metal blebs set in a glassy mesostasis (Jones and Scott, 1989). For this study, type IA proxies were produced from two types of starting materials (Table 1): Series A, in which a forsterite + CMAS glass assemblage was crystallized from a CMAS melt, then mixed with various proportions of iron filings, and Series B consisted of several mechanical mixtures of forsterite grains, fine glass chips and iron filings.

- Series $A$ : Starting with a CMAS glass with a bulk composition (hereafter $\mathrm{G}_{\mathrm{A}}$, Table 1) corresponding to the $\mathrm{SiO}_{2}$-rich end-member of type IA chondrules from Semarkona (Jones and Scott, 1989), we synthetized a forsterite + glass assemblage by applying the following thermal path: stage $1\left(1580^{\circ} \mathrm{C}\right.$ for $\left.1 \mathrm{~h}\right)-\operatorname{ramp}\left(10^{\circ} \mathrm{C} / \mathrm{h}\right)-$ stage $2\left(1450^{\circ} \mathrm{C}\right.$ for $\left.4 \mathrm{~h}\right)-$ quench. This thermal path allows us to obtain a final assemblage that contains $\approx 40 \%$ of forsteritic olivines with grain sizes ranging from 25 to $200 \mu \mathrm{m}$ and $\approx 60 \%$ of mesostasis $\left(\mathrm{G}_{\mathrm{A} \text { cryst., }}\right.$ Table 1). The bulk composition of $G_{A}$ cryst matches well with the composition of $G_{A}$ (Table 1 ). Surfaces of these assemblages were then sprinkled with a mixture of iron filings and polyvinyl alcohol, the abundance of which is not well controlled, in order to mimic the trend of bulk compositions of type I A and type II A chondrules from Semarkona (Fig. 5; Jones and Scott, 1989; Jones, 1990). Relative abundances of iron compared to silicates cannot be estimated for this series. In this series, magnesian olivine and mesostasis are initially in equilibrium. Thus, any chemical disequilibrium will only come from the oxidation of the Fe metal. This assemblage mimics a type IA in which magnesian olivine and mesostasis are in equilibrium. 
- Series B: Six different starting materials (CO to C4 and $\mathrm{C}^{\prime}$ ) were prepared by mixing in different proportions: fine chips of a CMAS glass (hereafter $\left.G_{B}\right)$, forsterite powder $\left(F_{o_{100}}\right)$ and iron filings (Table 1 and Fig. 5). The composition of the CMAS glass $\left(G_{B}=24.09\right.$ wt\% CaO, 6.44 wt\% $\mathrm{MgO}, 29.65 \mathrm{wt} \% \mathrm{Al}_{2} \mathrm{O}_{3}$ and $39.77 \mathrm{wt} \% \mathrm{SiO}_{2}$ ) corresponds to the most Ca-Al-rich mesostasis composition of type IA chondrules measured in Semarkona (Jones and Scott, 1989), which can be interpreted as the composition of chondrules that interacted the least with the surrounding environment during their formation (Libourel et al., 2006). As shown in Table 1, C0 to C4 mixtures contain from 0 to $20 \mathrm{wt} \%$ of iron metal. Forsterite grain sizes are in the range of 20 to $500 \mu \mathrm{m}$. The C3' starting composition is equivalent to C3, but differs from it in its smaller forsterite grain size between 10 and $150 \mu \mathrm{m}$. In this series, forsteritic grains are neither in equilibrium with the glass nor with the metal phase. This assemblage mimics a type IA chondrule in which magnesian olivine and mesostasis are not in chemical equilibrium.

In our experiments, there is a concern that Fe can be lost by reduction to the Pt wire (Bowen and Schairer, 1932). Unfortunately, unsuccessful trials with rhenium loops forced us to use Pt loops to hang our samples. In our experiments and irrespective of the sample used, maximum iron losses seem to have occurred in runs at $1500^{\circ} \mathrm{C}$ and $\mathrm{IW}+1$. From measured modal abundances and average chemical compositions of phases, we estimated $\approx 30 \%$ loss after $90 \mathrm{~min}, \approx 50 \%$ loss after $360 \mathrm{~min}$ and $\approx 55 \%$ after $1440 \mathrm{~min}$ (Table 3 ). Fe losses were not estimated at $1500^{\circ} \mathrm{C}$ and $\mathrm{NNO}$ but since this $\mathrm{fO}_{2}$ is higher than IW+1 the Fe losses must be less important. Because the initial amount of Fe metal is not well controlled for the series it is not possible to estimate Fe losses. However, since mass balance calculations are not involved in the following, these losses did not affect the main results of this study. 
The $\mathrm{fO}_{2}$ within the vertical furnace was controlled by flowing a $\mathrm{CO}-\mathrm{CO}_{2}$ gas mixture at a rate of $300 \mathrm{~cm}^{3} \cdot \mathrm{min}^{-1}$ and was adjusted at IW+1 or NNO buffers depending on the experiment, i.e. $\log \mathrm{fO}_{2}=-7.7$ and -8.1 for $\mathrm{IW}+1$ at respectively $1500^{\circ} \mathrm{C}$ and $1450^{\circ} \mathrm{C}, \log \mathrm{fO}_{2}=$ -4.7 for NNO at $1500^{\circ} \mathrm{C}$ (Figs. 3, 6). Experiments were terminated by drop quenching samples to room temperature in the furnace atmosphere at a cooling rate around a few hundreds of ${ }^{\circ} \mathrm{C} / \mathrm{s}$ (Fig. 6). Samples were studied for their mineralogy and petrography by backscattered secondary electrons (BSE) imaging using the JEOL-JSM-6510 scanning electron microscope at CRPG-CNRS and the Cameca SX-100 electron microprobe at Université Henri Poincaré of Nancy. Chemical analyses were performed by EPMA with a primary beam of $10 \mathrm{nA}$ intensity and $15 \mathrm{kV}$ accelerating voltage. Counting times on peaks and backgrounds were $20 \mathrm{~s}$ for all elements. Spot and line profile analyses on olivines were conducted with a focused beam (1$2 \mu \mathrm{m})$, while analyses in mesostasis were performed with a square defocused beam $(30 \times 30$ $\mu \mathrm{m})$. A set of well-known silicates and oxides were used as standards and matrix corrections were applied by using a PAP software routine. Detections limits in wt \% were: MgO - 0.03; $\mathrm{SiO}_{2}, \mathrm{Al}_{2} \mathrm{O}_{3}-0.04 ; \mathrm{CaO}-0.05 ; \mathrm{FeO}-0.07$

\section{RESULTS}

\subsection{Mineralogy and textures}

\section{Series A:}

Samples of series A were heated from $15 \mathrm{~min}$ to $1320 \mathrm{~min}$ ( 5 time steps) at $1450^{\circ} \mathrm{C}$ and IW+1 (Fig. 6; Table 2). Representative examples of textures and mineralogy obtained for this series are shown in Fig. 7. Iron filings are rapidly oxidized and dissolved into the melt. During 
the first minutes of heating, the iron-enriched mesostasis leads to crystallisation of euhedral ferroan olivines as overgrowths around forsterite grains and very likely as distinct crystals (Fig. 7a). With increasing experiment duration, magnesian olivines relicts progressively disappear in favor of euhedral ferroan olivines and are almost completely resorbed after 480 min (Fig. 7b). Dendritic olivines in the mesostasis very likely crystallized during the quench of the samples and their abundance might be correlated with the FeO content of the liquid (Fig. 7). The average size of olivine increases with time (Fig. 8a), e.g. $\approx 80 \%$ of crystals have diameters $<50 \mu \mathrm{m}$ after $15 \mathrm{~min}$ and $\approx 65 \%$ of crystals have diameters $>75 \mu \mathrm{m}$ after 1320 min. Crystal sizes tend to reach a maximum size in the range of $\approx 75-150 \mu$ m diameter (Fig. 8a). Ferroan olivines reach FeO abundances up to $\approx 26$ wt\% (Table 2 ). Lower FeO abundances measured in the longest experiment $(<10 \mathrm{wt} \%$, Table 2$)$ is certainly due to Fe loss to the $\mathrm{Pt}$ wire.

\section{Series B:}

At NNO redox conditions, all the series B samples were exposed at $1500^{\circ} \mathrm{C}$ for three durations: $15 \mathrm{~min}, 90 \mathrm{~min}$ and $165 \mathrm{~min}$ (Fig. 6, Table 3). Disappearance of fine grains and the rounding of large crystals in the shortest runs indicate that dissolution is an efficient process in all the samples (Fig. 9). For iron bearing samples (C1 to C4), most of the forsterite grains are mantled by sub-euhedral to euhedral ferroan olivines, even in the shortest runs, suggesting a rapid attainment of iron-rich olivine saturation in the melt. Numerous crystals of ferroan spinels either in the mesostasis or poikilitically enclosed in ferroan olivines overgrowths are also observed. The abundance of these spinels is correlated with the initial Fe amount (Fig. 9). 
For experiments at $1500^{\circ} \mathrm{C}$ and $\mathrm{IW}+1$, five time steps from $1.5 \mathrm{~min}$ to $1440 \mathrm{~min}$ were performed for $\mathrm{CO}$ to C4 starting materials, while six time steps were carried out for C3' (Fig. 6, Table 3). Representative examples of textures and mineralogy of the samples are shown in Fig. 10. As for samples ran at NNO, experiments show a significant dissolution of magnesian olivines with time, resulting in the disappearance of fine grains and the rounding of large forsterite crystals. This dissolution is a fast process since it is observed after $1.5 \mathrm{~min}$ of heating (Fig. 10) with ferroan olivines overgrowing rounded forsterites in all runs (excepted for $\mathrm{CO}$ ). The evolution of the $\mathrm{C} 1$ to $\mathrm{C} 4$ samples with time is similar with series A: (i) crystallization of ferroan olivines and progressive disappearance of forsterite grains, (ii) crystallization of dendritic ferroan olivines ( \pm iron oxide) in the melt during quenching and their lower abundance with time and (iii) increase of ferroan olivine size (Fig. 10). The evolution of C3' samples present the same features as those observed in C1 to C4 samples, except that the final grain size is smaller and more homogeneous (Fig. 10). As for series A, the size of olivines increases with time (Fig. 8b) and the final grain size is strongly controlled by the initial grain size (Figs. 8b, 10). FeO contents of ferroan olivine rims reach values up to 12 wt\% and decrease with time probably due to Fe loss to the Pt (Table 3).

Figure 11 shows that the abundance of olivine relicts decreases rapidly in short time and then the rate of decrease slows down for longer durations. The percentage of olivine relicts is correlated to two other parameters: the initial amount of Fe filings and the initial grain size of the magnesian olivines. Increasing the amount of iron filings to be oxidized from CO to C4 significantly decreases the percentage of olivine relicts remaining for the same duration of experiment, e.g. $\approx 80 \%$ of relicts remaining for $\mathrm{C} 1$ and $\approx 20 \%$ for C4 after $1440 \mathrm{~min}$ (Fig. 11 ). The smaller the initial grain size of magnesian olivines, the lower the abundance of olivine relicts remaining. For instance, in C3 (20 to $500 \mu \mathrm{m}$ forsterite) experiments more than $50 \%$ 
relicts grains still remain after $2 \mathrm{~h}$ of oxidation, compared with less than $10 \%$ for the same duration for C3' (10 to $150 \mu \mathrm{m}$ forsterite) or series A (25 to $200 \mu \mathrm{m}$ forsterite).

\subsection{Chemistry}

Bulk olivine (which is an estimation of the average composition of olivine, both magnesian and ferroan - see Table 2 caption for details), olivine rim and mesostasis compositions for series A are given in Table 2. In Figure 12a, mesostasis composition in each sample is recalculated on a FeO-free basis, since the initial amounts of Fe filings added is not constrained. Because $\mathrm{CaO}$ and $\mathrm{Al}_{2} \mathrm{O}_{3}$ are incompatible in olivine, their concentrations provide a good marker of the chemical evolution of the mesostasis during these oxidation experiments. The bulk composition of the mesostasis evolves due to the entrance of FeO but apart from that the fact that abundances of $\mathrm{CaO}$ and $\mathrm{Al}_{2} \mathrm{O}_{3}$ remain constant with time and the fact that the abundances of $\mathrm{MgO}$ and $\mathrm{SiO}_{2}$ remain more or less constant with time suggests that the decrease of magnesian olivine abundance is balanced by the crystallization of ferroan olivine (Fig. 12a). The occurrence of FeO zonation within olivines delineates distinctly the boundary between the overgrowths of ferroan olivines and ferroan olivines formed by net inward Fe-Mg interdiffusion in the forsterite relicts (Fig. 12b). Both widths of overgrowths and distances of FeO diffusion increase with the heating duration.

For series B (except for experiments at NNO buffer for which only average compositions of mesostasis are given), average compositions of mesostasis, bulk olivine and olivine rims are given in Table 3. In figure 13, mesostasis compositions are not recalculated on a FeO-free base as for the previous figure. The dissolution of Fe metal filings, due to oxidation, is more or less instantaneous and leads to a sharp increase of FeO in mesostasis compared with the 
starting CMAS glass (Fig. 13a). This increase is correlated with the initial amount of Fe. At the same time, MgO shows a significant increase in response to the dissolution of magnesian olivines (Fig. 13b). As ferroan olivine crystallisation proceeds, the $\mathrm{FeO}$ content in the mesostasis decreases as expected (Fig. 13a), while $\mathrm{CaO}\left(\mathrm{Al}_{2} \mathrm{O}_{3}\right.$ as well), after an initial decrease due to $\mathrm{FeO}$ and $\mathrm{MgO}$ entrance in the mesostasis, follow a complementary path as expected from its incompatibility (Fig. 13c). Part of the FeO decrease is certainly due to Fe loss to the Pt wire. As well, the fact that the MgO content continues to slightly increase with time, while the opposite would be expected with olivine crystallisation, is very likely due to Fe loss (Fig. 13b). Zoning profiles of $\mathrm{CaO}, \mathrm{Al}_{2} \mathrm{O}_{3}$ and $\mathrm{FeO}$ in olivines from $\mathrm{C} 2, \mathrm{C} 4$ and $\mathrm{C}^{\prime}$ samples allow us to distinguish easily the ferroan olivine overgrowths from their forsteritic host (Figs. 14, 15). Ca and Al, which are both enriched in the ferroan olivine overgrowths and have low diffusion coefficients in olivine (except that, as expected, Ca shows more diffusion than $\mathrm{Al}$ ), help in this task by marking the original interface between the forsterite and the fayalitic overgrowth. In contrast Fe zoning penetrates further into the forsterite relicts in agreement with its higher diffusivity (Figs. 14, 15). In a similar manner as series A, widths of overgrowths and distances of diffusion are correlated with heating duration. $\mathrm{Ca}$ and $\mathrm{Al}$ contents of the overgrowths are slightly higher than those usually encountered in type II chondrules because of the starting CMAS material is more Ca-Al-rich than typical type II chondrule mesostasis. Partition coefficients for $\mathrm{Ca}$ and $\mathrm{Al}$ between overgrowths and mesostasis after 1440 min vary respectively from $\approx 0.02$ to $\approx 0.07$ and from $\approx 0.015$ to $\approx$ 0.027 in agreement with values from the literature (Kennedy et al., 1993; Libourel, 1999).

Depending on the starting materials, the run duration and the melt composition, olivines show a broad range of composition from $\mathrm{Fa}_{0}$ to around $\mathrm{Fa}_{30}$. We calculated a parameter to indicate the track toward equilibration with time which is a ratio of $\mathrm{FeO}$ and $\mathrm{MgO}$ between 
bulk olivine and mesostasis: $\mathrm{PTE}=(\mathrm{FeO} / \mathrm{MgO})_{\text {b.ol. }} /(\mathrm{FeO} / \mathrm{MgO})_{\text {mes }}$. For our experimental samples, this parameter varies from 0.003 to 0.34 (Fig. 16a, Tables 2, 3). For a given initial composition, PTE increases with the square root of the time from very low values far from the equilibrium value, i.e. from 0.003 to 0.01 for the shortest duration, $1.5 \mathrm{~min}$, to values closer to the $0.3 \pm 0.03 K_{D}$ equilibrium value (Roeder and Emslie, 1970), i.e. from 0.19 to 0.34 for the longest runs, $1320 \mathrm{~min}$ or $1440 \mathrm{~min}$ (Fig. 16a, Tables 2, 3). The starting materials with the smaller forsterite grain size ( $C 3^{\prime}$ and series $A$ ) reach near equilibrium conditions at shorter duration than those with larger initial forsterite grain size. The $\mathrm{C} 4$ iron rich starting material is the slowest to reach equilibrium, with a PTE of 0.19 after 24 hours of run duration. Effective $K_{D}$ values calculated for olivine rims - mesostasis pairs vary from 0.12 to 0.34 (Fig. 16b).Olivine rims approach near equilibrium $K_{D}$ values in runs of durations as short as 200 and 400 minutes.

\section{DISCUSSION}

Our results show how chemical disequilibrium induced by (isothermal) oxidation of Fe metal blebs leads to drastic changes in texture, mineralogy, modal abundance and chemical composition of the constituent phases of a chondrule proxy, i.e., olivine, metal blebs and CMAS glass. Before describing potential applications of these results to chondrule formation, reactive mechanisms taking place during this oxidation will be first discussed.

\subsection{Kinetic considerations}


Depending on the imposed oxygen fugacity conditions (NNO or IW+1), Fe metal filings are oxidized into the silicate melt as ferrous or ferric iron. We calculated the ferric/ferrous ratio in the mesostasis using the equation given by Kilinc et al. (1983) for our 1450 and $1500^{\circ} \mathrm{C}$ runs. At IW+1, $\mathrm{XFe}_{2} \mathrm{O}_{3} / \mathrm{XFeO}$ is systematically below 0.03 and, at $\mathrm{NNO}, \mathrm{XFe}_{2} \mathrm{O}_{3} / \mathrm{XFeO}$ is between 0.10 and 0.15 . Such high $\mathrm{XFe}_{2} \mathrm{O}_{3}$ in the $\mathrm{B}$ series melts run at $1500^{\circ} \mathrm{C}$ and $\mathrm{NNO}$ redox conditions is very likely the explanation for co-crystallization of ferroan spinel and ferroan olivine (Fig. 9). At more reduced conditions (IW+1), the activity of $\mathrm{Fe}_{2} \mathrm{O}_{3}$ in the melt is too low to promote the precipitation of ferroan spinel (Fig. 10).

From the shortest runs (Table 2,3$)$, one can infer that the oxidation of iron filings $(\varnothing=$ $50-80 \mu \mathrm{m} ; \mathrm{m} \approx 1 \mu \mathrm{g}$ ) in silicate melts must be almost an instantaneous process. This is in agreement with metallurgical data (e.g., Gaye and Riboud, 1977), that have shown that the kinetics of oxidation of iron alloy drops in slags are of the order of 0.007 to $0.035 \mathrm{~g} / \mathrm{s}$. Similarly, forsterite dissolution in the iron-rich melt must also be a fast process, according to the significant increase of $\mathrm{MgO}$ content in the melt at short oxidation times and the corresponding fast decrease in forsteritic relict proportion in the charges (Figs. 11, 13). Dissolution kinetics can be estimated roughly at about tens of $\mu \mathrm{m} / \mathrm{min}$ at these temperatures, consistent with olivine dissolution rates from the literature (Kuo and Kirkpatrick, 1990; Soulié et al., 2012 and references therein). This high rate of olivine dissolution is also consistent with the fact that the shortest runs (1min30) show already some fayalitic overgrowth covering rounded forsterite grains (Fig. 10).

As evidenced by these experiments, the crystallization of ferroan olivine overgrowth on forsterite grains in all the runs (Figs. 9, 10) is the response of the system to the chemical disequilibrium induced by the sudden oxidation of Fe and can be accounted for by the coupling of the following reactions: 


$$
\begin{aligned}
& \mathrm{Fe}_{\text {(metal) }}+1 / 2 \mathrm{O}_{2 \text { (gas) }}=\mathrm{FeO}_{\text {(liquid) }} \\
& \mathrm{Mg}_{2} \mathrm{SiO}_{4 \text { (forsterite) }}+\mathrm{FeO}_{\text {(liquid) }}=2 \mathrm{MgO}_{\text {(liquid) }}+\mathrm{SiO}_{2 \text { (liquid) }}+\mathrm{FeO}_{\text {(liquid) }} \\
& x \mathrm{MgO}_{\text {liq }}+(1-\mathrm{x}) \mathrm{FeO}_{\text {liq }}+\mathrm{SiO}_{2 \text { liq }}=\left(\mathrm{x}^{\prime} \mathrm{Mg},\left(1-\mathrm{x}^{\prime}\right) \mathrm{Fe}\right)_{2} \mathrm{SiO}_{4 \text { (ferroan olivine) }}
\end{aligned}
$$

The reaction rate for crystallization of ferroan olivine overgrowth on forsterite grains is:

$$
v=d \xi / d t=-d F e O(m e l t) / d t=d(F e, M g)_{2} \mathrm{SiO}_{4} / d t
$$

in moles by time unit, with $\xi$ the extent of reaction and $d X / d t$ the derivative of the abundance of $X$ with time. Basically, this equation states that the reaction rate depends on the variation of the abundance of the elements, i.e. (i) high FeO abundance in the melt will lead to rapid crystallization of ferroan olivine and (ii) the crystallisation of ferroan olivine has a negative feedback by decreasing the reaction rate. In addition to this compositional effect, the initial grain size of forsterite seems also to have a significant influence on reaction rate since widths of overgrowths are on average smaller for C3' (initial grain size of forsterite $\approx$ $10-150 \mu \mathrm{m}$ ) than for C3 (initial grain size of forsterite $\approx 20-500 \mu \mathrm{m}$ ), e.g. after $360 \mathrm{~min}$, from $\approx 20$ to $50 \mu \mathrm{m}$ for C3 and from $\approx 15$ to $30 \mu \mathrm{m}$ for C3' (Fig. 17a; Table 3); the same trend is observable for series A.

The kinetics of ferroan olivine overgrowth formation (Fig. 17a) in our experiments is best approximated by a parabolic rate law of the form:

$$
x=k \cdot t^{1 / 2}
$$

in which $\mathrm{x}$ is the average olivine overgrowth thickness $(\mu \mathrm{m}), \mathrm{k}$ is the rate constant (Arrhenius type) and $\mathrm{t}$ is the time $(\min )$. $\mathrm{k}$ varies between $\approx 1$ and $\approx 2 \mu \mathrm{m} \cdot \mathrm{min}^{-0.5}$ for iron poor (C1) to iron rich composition (C4), respectively, and has a value around 2.15 for the starting material with the smaller grain size ( $\mathrm{C3}^{\prime}$ and series A). Even if these values are subject to large uncertainties (see min. and max. values in Table 2, 3), they show nevertheless that ferroan growth rate is on average a relatively fast process with a minimum growth rate of the order 
$\mathrm{k} \approx 1 \mu \mathrm{m} \cdot \mathrm{min}^{-0.5}$. That this overgrowth is a linear function of the square root of the time is not surprising since the rate-controlling processes for crystal growth is diffusion in the melt (long or short range).

As for the overgrowths, the length of diffusion of $\mathrm{FeO}$ in relict magnesian olivines is correlated with the duration of the experiment (Fig. 17b, Tables 2, 3). For instance, FeO diffusion for $\mathrm{C} 4$ occurred on a length of $<1 \mu \mathrm{m}$ after $1 \mathrm{~min} 30$, of $\approx 5$ to $\approx 15 \mu \mathrm{m}$ after $15 \mathrm{~min}$, of $\approx 20$ to $\approx 30 \mu \mathrm{m}$ after $90 \mathrm{~min}$, of $\approx 30$ to $\approx 60 \mu \mathrm{m}$ after $360 \mathrm{~min}$ and a length of $\approx 55$ to $\approx 95$ $\mu \mathrm{m}$ after $1440 \mathrm{~min}$ (Fig. 17b, Table 3). Since the $\mathrm{D}^{\mathrm{Fe}-\mathrm{Mg}}$ changes with the crystallographic orientation (e.g. Dohmen and Chakraborty, 2007; Tachibana et al., 2013) and because orientations of our olivines are not known, $\mathrm{D}^{\mathrm{Fe}-\mathrm{Mg}}$ cannot be determined accurately. Moreover, the fact that Fe-Mg profiles are not necessarily performed orthogonally to the olivine faces may lead to an overestimation of the length of diffusion. It turns out however that $\mathrm{D}^{\mathrm{Fe}-\mathrm{Mg}}$ decreases with time at long durations, i.e. $24 \mathrm{~h}$ (Fig. 17b), very likely in response to changes in the $\mathrm{FeO}$ gradient between the overgrowth and the relict, due to either iron losses (see experimental) or complete disappearance of relict forsterites. If we exclude these long runs, we found that Fe-Mg interdiffusion coefficient in the olivines vary from $\mathrm{D}^{\mathrm{Fe}-\mathrm{Mg}}{ }_{\min .}=$ $0.0127 \mu \mathrm{m}^{2} / \mathrm{s}$ to $\mathrm{D}^{\mathrm{Fe}-\mathrm{Mg}}{ }_{\text {max. }}=0.0444 \mu \mathrm{m}^{2} / \mathrm{s}$ with an average value of $\mathrm{D}_{\mathrm{ae}-\mathrm{Mg} .}=0.0338 \mu \mathrm{m}^{2} / \mathrm{s}$ (Fig. 17b, Tables 2, 3). These results are in fair agreement with some Fe-Mg data of the literature extrapolated to our conditions of temperature, i.e. from $0.006 \mu \mathrm{m}^{2} / \mathrm{s}$ to 0.048 $\mu \mathrm{m}^{2} / \mathrm{s}$ at $1500^{\circ} \mathrm{C}$ (Fig. $17 \mathrm{~b}$, Jurewicz and Watson, 1988) and on average slightly higher than more recent data performed at $1500^{\circ} \mathrm{C}$ and similar $\mathrm{fO}_{2}$, i.e. from $0.004 \mu \mathrm{m}^{2} / \mathrm{s}$ to $0.025 \mu \mathrm{m}^{2} / \mathrm{s}$ (Tachibana et al., 2013). Accordingly, Fe-Mg interdiffusion in olivines at the overgrowth/relict interface is thus a fast process at these temperatures or above $\left(>1450^{\circ} \mathrm{C}\right)$. 


\subsection{Application of experiments to chondrule formation}

\subsubsection{Textural and chemical analogies}

Figure 18 portrays the textural changes of a metal-forsterite-glass assemblage typical of a type I A chondrule that would occur during an isothermal oxidation event at $1500^{\circ} \mathrm{C}$ $(I W+1)$. Based on our experiments, we predict that the type I chondrule would undergo progressive evolution towards porphyritic olivine type IIA-like texture. Depending on the duration of the heating event, this evolution can be interrupted at any time before its completion by rapid cooling (as in our experiments), thus preserving various proportions of forsterite relict grains inside ferroan olivine cores (Fig. 18). The same observation can be made in chondrules since relict forsterites in type II chondrules are almost ubiquitous in most of the chondrite groups (Rambaldi, 1981; Miyamoto, et al. 1986; Steele, 1986; Jones, 1990; Wasson and Rubin, 2003; Ruzicka et al., 2007, 2008). Wasson and Rubin (2003) have shown for instance that, in CO 3.0 chondrites, $91 \%$ of type II chondrules have low-FeO olivine relicts. Forsterite relicts in type II chondrules have compositions similar to those observed in type I chondrules (e.g., Jones, 1996; Jones and Carey, 2006; Wasson and Rubin, 2003; Ruzicka et al., 2007 and 2008). It is possible to find a suite of type I to type II chondrules with decreasing modal abundances of forsterite grains that mimics almost perfectly the textural evolution observed in our experiments (Fig. 19 versus Figs. 9, 10). Olivine overgrowths in our oxidation experiments have compositions up to $\mathrm{Fa}_{30}$ (Table 2, 3), a range that matches those measured in type II chondrules from ordinary chondrites. Even if these textural and compositional similarities are striking, they cannot alone demonstrate that such an oxidation process is viable for linking genetically type II chondrules to type $I_{\text {. }} K_{D}$ 
variations in chondrules and chemical zoning in relict forsterite grains provide other compelling evidence that are described in the following.

\section{Olivine-liquid Fe/Mg partitioning in meteoritic chondrules}

Previous works on the olivine-liquid $\mathrm{Fe} / \mathrm{Mg}$ partitioning in chondrules have shown significant departure from equilibrium value in highly unequilibrated ordinary and carbonaceous chondrites (see Fig. 2 of Symes and Lofgren, 1999). Low to very low $K_{D}<<0.3$ are commonly documented in type IA chondrules of ordinary chondrites, e.g. from 0.027 to 0.225 in LL3.0 Semarkona chondrite (Jones and Scott, 1989; Taylor and Cirlin, 1986), from 0.131 to 0.28 in LL3.1 Bishunpur, from 0.10 to 0.18 in LL3.2 Krymka, from 0.019 to 0.09 in LL3.4 Chainpur (Taylor and Cirlin, 1986; Lofgren and Le, 1998), or of carbonaceous chondrites from 0.06 to 0.26 (Taylor and Cirlin, 1986). In contrast, $K_{D}$ values in type IIA chondrules mainly scatter between $\approx 0.2$ to $\approx 0.5$ at around near equilibrium values or higher up to $\approx 0.9$ (Taylor and Cirlin, 1986; Jones, 1990; Symes and Lofgren, 1999). For comparison, $K_{D}<0.2$ is hardly documented in terrestrial volcanic rocks (Roeder and Emslie, 1970).

Attempts to create non-equilibrium olivine-liquid $\mathrm{Fe} / \mathrm{Mg}$ partitioning have shown that rapid cooling during crystallization drives $K_{D}$ below 0.3 . However, rapidly cooled experiments result only in $K_{D}$ values moderately different or similar to 0.3 , i.e. from 0.10 to 0.30 $\left(1000^{\circ} \mathrm{C} / \mathrm{hr}\right.$ : Nettles et al., $2006 ; 1874^{\circ} \mathrm{C} / \mathrm{hr}$ : Taylor and Cirlin, $1986 ; 2100^{\circ} \mathrm{C} / \mathrm{hr}$; Symes and Lofgren, $1999 ; 2190^{\circ} \mathrm{C} / \mathrm{hr}$ : Kennedy et al., 1993). The kinetic effect of rapid cooling alone cannot thus account for the most significant deviations from $K_{D}=0.3$ seen in FeO-poor chondrules which can deviate by more than a factor of 30 , nor $K_{D}$ values higher than 0.3 that are seen in FeO-rich chondrules. Our isothermal oxidation experiments are an alternative for producing non-equilibrium olivine-liquid Fe/Mg partitioning. In this case the driving force is 
not a kinetic effect (rapid cooling) but rather the rapid changes in melt composition (from 0 up to almost $50 \mathrm{wt} \% \mathrm{FeO}$ content; see Tables 2, 3) before ferroan olivine crystallization due to the sudden oxidation of iron filings. Although cooling rates must certainly play a role, our data support the idea that chemical disequilibrium (here by the oxidation of Fe metal in chondrules) has also a prominent effect on the olivine-liquid Fe/Mg partitioning. The sudden FeO enrichment of the melt due to iron metal oxidation can indeed explain (i) $K_{D}$ 's in the range of $0.15-0.30$ (similar to those in type II chondrules) for olivine crystallizing from the melt by analogy with the olivine overgrowth of our experiments (Fig. 16b), as well as (ii) $\mathrm{K}_{\mathrm{D}}$ $<0.15$ (similar to those in Type I chondrules) by assuming that Mg-rich olivines did not crystallize in situ but are rather xenocrysts on a dissolution track in the mesostasis (Fig. 16a; Symes and Lofgren, 1999). It is of note that because $K_{D}$ is sensitive to the $X_{\mathrm{FeO}}$ of the melt, only slight enrichments in the FeO content of the melt in FeO-poor chondrules are necessary to drive $K_{D}$ towards extremely low values. Finally, such oxidation process may also explain $K_{D}$ $>0.3$ of type II chondrules either by increasing the $\mathrm{Fe}^{3+} / \mathrm{Fe}^{2+}$ ratio of the melt in response to an increase in the ambient oxygen fugacity or by precipitation of FeS blebs for appropriate oxygen and sulfide fugacities in the environment. Olivine-liquid $\mathrm{Fe} / \mathrm{Mg}$ partitioning in chondrules has undeniably a great potential for characterizing processes at work during chondrule formation.

\section{Chemical zoning at relict/overgrowth interface in type II chondrules}

That oxidation of Fe metal blebs causes a major chemical disequilibrium within chondrules is further strengthened by the detailed survey of the chemical zoning at relict/overgrowth interface in type II chondrules. As already pointed out, relict forsterite 
grains in type II chondrules are ubiquitous in most of the chondrite groups (Rambaldi, 1981; Miyamoto et al., 1986; Steele, 1986; Jones, 1990; Wasson and Rubin, 2003; Ruzicka et al., 2007 and 2008). Diffusive exchange profiles between relict olivine and surrounding meltgrown olivine have been extensively studied for their implications in determining the cooling rates of type IIA chondrules (Miyamoto et al., 1986, 2009; Greeney and Ruzicka, 2004; Bejina et al., 2009; Hewins et al., 2012; Hewins, 2009).

In Fig. 20, we show a typical example of a type IIA chondrule of Semarkona, which contains a relict forsterite grain $\left(\mathrm{Fa}_{<1}\right)$ surrounded by a more fayalitic overgrowth (up to $\left.\mathrm{Fa}_{25}\right)$. The corresponding phosphorus $(\mathrm{P})$, calcium (Ca), aluminium (Al), iron (Fe), chromium $(\mathrm{Cr})$ and cobalt (Co) X-ray Koelemental intensity maps are also shown. The BSE image clearly shows the forsterite relicts, though the boundary between core and relict is blurred due to diffusion. The boundary in the P map is much sharper and outlined by a P-rich boundary layer (0.3-0.4 wt\% $\mathrm{P}_{2} \mathrm{O}_{5}$ ) on the overgrowth side (see also Hewins, 2009). This layer also includes minute chromian-ferroan spinels, responsible for the hot spots of $\mathrm{Fe}, \mathrm{Cr}, \mathrm{Co}$, and $\mathrm{Ni}$ seen in the corresponding X-ray maps, and Ca-phosphate (maybe some whitlockite) (Fig. 20). The forsterite relict has high abundance of $\mathrm{CaO}(\approx 0.8 \mathrm{wt} \%)$ and $\mathrm{Al}_{2} \mathrm{O}_{3}(\approx 0.35 \mathrm{wt} \%)$ and is strongly depleted in $\mathrm{P}(<60 \mathrm{ppm}$, the detection limit) as well as siderophile elements. The fayalitic overgrowth is in contrast enriched in $\mathrm{Fe}(\approx 12-25 \mathrm{wt} \% \mathrm{FeO}), \mathrm{Mn}(\approx 0.4-0.5 \mathrm{wt} \%$ $\mathrm{MnO}), \mathrm{Cr}\left(\approx 0.4 \mathrm{wt} \% \mathrm{Cr}_{2} \mathrm{O}_{3}\right), \mathrm{P}\left(\approx 0.2-0.3 \mathrm{wt} \% \mathrm{P}_{2} \mathrm{O}_{5}\right)$, Ni $(\approx 0.04-0.05 \mathrm{wt} \% \mathrm{NiO})$ and Co (see $\mathrm{X}-$ ray maps).

Trace elements that diffuse more slowly than Fe and Mg, especially $\mathrm{P}$, have been shown to reveal details (e.g., overgrown relicts as phenocryst cores, skeletal cores, oscillatory zoning) that allow to distinguish the nature of growth or resorption history in igneous 
processes (Milman-Barris et al., 2008; McCanta et al., 2008; Hewins, 2009). Hewins (2009) in a study of minor element zoning of olivine in type IIA chondrules in Semarkona suggests that P-rich zones coating anhedral relict cores mark periods of rapid growth and also mark onset of growth on resorbed relict grains. Because the P-rich zones correspond to greater than equilibrium partitioning between olivine and melt and because he considered it implausible that the bulk liquid experienced fluctuations in $\mathrm{P}$ concentration, he inferred periods of rapid growth and fluctuations in liquid boundary layer composition (see also Milman-Barris et al., 2008).

A simultaneous enrichment of the major siderophile elements ( $\mathrm{Fe}, \mathrm{Cr}, \mathrm{Co}, \mathrm{Ni}, \mathrm{P}$ ) in P-rich zones coating anhedral relict cores cannot be coincidence. Our interpretation favours instead the rapid release of siderophile elements in the melt due to the sudden oxidation of Fe-Ni metal blebs. Elevated concentrations in all these siderophile elements, i.e., $0.05-55.2$ wt\% $\mathrm{Ni}, 0.04-2.1$ wt\% Co, 0.03-1.8 wt\% $\mathrm{P}$, and 0.02-1.2 wt\% $\mathrm{Cr}$ analysed in Fe-Ni metal in Semarkona chondrules (Kimura et al., 2008) seem indeed consistent with this interpretation. In addition, Zanda et al. (1994) and Kimura et al. (2008) amongst others have shown that FeNi metal spherules in several Semarkona chondrule interiors contain schreibersite grains of sub-micrometer size as well as tiny inclusions of chromite and Fe- or Ca-phosphate. Since dephosphorization of Fe-P alloys by reactions with molten silicate at $1550^{\circ} \mathrm{C}$ with high degree of oxidation (Gaye and Riboud, 1977) has been shown to be also a very fast process $\left(<60\right.$ s), it is very likely that the concentration of $\mathrm{P}_{2} \mathrm{O}_{5}$ rises rapidly in the melt as metal is oxidized. According to the proportion of Fe-Ni metal blebs involved in the dissolution, enrichment of $\mathrm{P}_{2} \mathrm{O}_{5}$ in the melt can be thus elevated since withlockite saturation is in the range of 1 to $5 \mathrm{wt} \% \mathrm{P}_{2} \mathrm{O}_{5}$ for typical type II mesostasis (55-65 w\% $\mathrm{SiO}_{2}$ ) or even higher, e.g., 2 and $8 \mathrm{wt} \% \mathrm{P}_{2} \mathrm{O}_{5}$ for type I chondrule mesostasis (Sha, 2000). With the olivine-melt $\mathrm{P}_{2} \mathrm{O}_{5}$ 
partition coefficient of $D \approx 0.09-0.1$ (Libourel et al., 1994; Brunet and Chazot, 2001), olivine precipitating from this high $\mathrm{P}$ melt must be enriched in phosphorus, as is observed (Jones, 1990). Finally, it is worth noticing that, in agreement with our oxidation model, McCanta et al. (2008) suggest, from dynamic crystallization experiments on chondrule-like samples, that crystal growth rate (rather than cooling rate) governs the development of $\mathrm{P}$ zonation in olivines.

To summarize the above experimental results and their similarities with meteoritic chondrules, we thus propose that chemical disequilibrium caused by the sudden oxidation of Fe metal blebs of type IA chondrule assemblages could be an important driving force for the formation of the ferroan olivine of type II chondrules. If so, the key parameters of the transformation of typical type IA chondrule assemblages into type IIA chondrules are the following:

(i) Chemical inheritance from type IA chondrules.

Depending on the initial modal abundance of Fe metal blebs, in a precursor equivalent to a type I chondrule, oxidized chondrules will or will not acquire textures of type IIA chondrules. In type IA chondrules that do not contain Fe metal, it is obvious that if magnesian olivines can be partially resorbed in response to a given chemical disequilibrium they will never evolved towards ferroan olivines, as is the case in experimental samples prepared with CO (Fig. 10). In contrast, if type IA chondrules do contain Fe metal blebs, ferroan olivines will form at the expense of magnesian olivines as seen in our experimental samples prepared with C1-C4 (Figs. 7, 10). This observation highlights the fact that Fe modal abundance, and by extension the oxidation of iron metal, could be a central parameter for the formation of type IIA chondrules. Fe-Mg zonation from core to rim observed in our 
experimental olivine samples, i.e., magnesian forsteritic core overlayed by a ferroan olivine overgrowth with an inward diffusion of iron (Fig. 15, 19), may, depending on the thin section cut, mimic a normal igneous zoning with an iron enrichment towards the rim, as it is observed in ferroan olivine of type IIA chondrules (Jones 1990).

(ii) Initial grain size of magnesian olivines.

Our experiments demonstrate that the final grain size of the ferroan olivine is strongly related to the initial forsterite grain size (Figs. 7, 8, 10). This relation holds also for chondrules: large relicts of magnesian olivines evolved into large ferroan olivines while small relicts evolved into small ferroan olivines. Furthermore, the survival of relict magnesian olivines strongly depends on the initial grain size of the forsterite, i.e. relicts survived in the core of larger ferroan olivine (Figs. 11, 19), as shown in our experiments.

\section{(iii) Coupling of duration of heating and temperature.}

Both the size of ferroan olivine overgrowths and the distance of FeO diffusion (or the survival of forsteritic relict) depend mainly on the paired parameters: duration of heating under oxidizing conditions and temperature. Due to the relationship between these two parameters, we used the term $\tau$ to define the degree of heating of the sample. Qualitatively, high values of $\tau$ indicate either a high temperature and/or a long heating in oxidizing conditions, while low values of $\tau$ correspond to low temperature and/or short heating in oxidizing conditions. For large forsterite grain size processed at low $\tau$ the contour of the ferroan olivine overgrowth outlines the contour of the forsterite relict (Figs. 7, 10), while for high $\tau$ and/or smaller forsterite grain size the ferroan olivine overgrowths acquire euhedral textures, both kind of textures being observed in chondrules (Figs. 7, 10, 19b-d). 


\subsubsection{Implications on conditions of chondrule formation}

We propose that most Type IIA chondrules could have been formed from Type IA chondrule assemblages. At odds with a classical cooling model (see reviews in Hewins et al., 2005; Desch et al., 2012), we suggest that the driving force for Type IIA chondrule formation could be due to a high temperature (nearly isothermal) chemical disequilibrium caused by the rapid oxidation of Fe metal blebs of Type IA chondrules. FeO dissolved in the melt will promote first the dissolution of magnesian olivines of the type I chondrules and then, when the new melt reaches ferroan olivine saturation, the crystallization of ferroan olivine either as new crystals in the mesostasis or as overgrowths on the remaining unresorbed forsterite grains (relicts). Interruption of this process at any time before its completion by rapid cooling allows to reproduce the whole range of textures observed in type $A$ chondrules, i.e., from Type I to Type IIA-like textures with various amount of preserved relict grains (Fig. 19); fine grained and coarser grained Type IA chondrules generating fine grained and coarser grained Type IIA chondrules, respectively. If this model is correct, it thus has important implications on the chondrule formation processes that are considered in the following.

\section{Type II A chondrule precursors}

Classical models envisage that porphyritic chondrules formed from partial melting of dustballs (consisting of both fine and large grains) of sub-chondritic composition (e.g. Jones et al., 2005). However, due to high formation temperature, chondrules never preserved evidence of low temperature minute phases representative of such dusty precursors. 
Agglomeratic olivine objects documented recently by Ruzicka et al. (2012) in ordinary chondrites, composed of fine-grained $(<5-10 \mu \mathrm{m})$ ferroan olivine, troilite, pyroxene and feldspathic materials and showing transitional variation in texture and chemistry with Type II chondrules were interpreted as type II proto-chondrules, and not as dust precursors. Relict grains in incompletely melted chondrules coming from AOA, or older generations of chondrules and the variability of chondrule compositions, emphasise the importance of coarse grains among chondrules precursors, as noted by Hewins and Zanda (2012). Even if open system behaviour, i.e., chemical and physical interaction between chondrules and ambient gas, may in part explain the variability of chondrule properties (Libourel et al., 2006; Alexander and Ebel, 2012; Hewins and Zanda, 2012), the nature of chondrule precursors remains still an unresolved issue.

Our study shows that type IA chondrules (or fragments of reduced chondrules) could well be the precursors of most type IIA chondrules. This assertion is supported by several observations. Relicts in type IIA chondrules are overwhelmingly dominated by forsteritic grains that are identical to magnesian olivines found in Type IA chondrules (Jones et al., 2005; Lauretta et al., 2006; Hewins and Zanda, 2012; Ruzicka et al., 2012). Type IIA chondrules very often contain several forsteritic relict grains, or, are composed of a single cluster of relicts that resembles texture of Type I chondrules, especially in carbonaceous chondrites (Fig. 19). Small type II chondrules formed around a single forsterite relict (i.e., chondrule fragment) also exist. The occurrence of rare Fe-Ni metal in type II chondrules (Jones, 1994; Schrader et al., 2008), together with the elevated $\mathrm{Fe}, \mathrm{Ni}, \mathrm{Co}, \mathrm{Cr}, \mathrm{P}$ siderophile element concentrations in the P-rich zones of the ferroan olivine coating anhedral relicts (Fig. 20) also suggest the presence of Fe-Ni metal in the precursor. In addition to these textural and petrological arguments, oxygen isotope measurements in chondrules provide 
complementary information giving support to the same idea. In CR chondrites, it has been shown that relict grains within type II chondrules have both Fa values and O-isotope ratios that are similar to those of type I chondrules (Connolly and Huss, 2010). Recent data on CV, CO and ordinary chondrites (Kita et al., 2010; Libourel and Chaussidon, 2011; Rudraswami et al., 2011; Tenner et al., 2012; Ushikubo et al., 2012 and 2013) confirmed this observation but also show that $\Delta^{17} \mathrm{O}$ of olivines from type II chondrules cluster at the same discrete values as those observed for type I chondrules (e.g., $\Delta^{17} \mathrm{O} \approx+0.5 \%$; $\Delta^{17} \mathrm{O} \approx-2 \%$; $\Delta^{17} \mathrm{O} \approx-5 \%$ ). At a minimum, such findings suggest that type I and type II chondrules may have formed in the same environment (whether this environment is of nebular or planetary origin or a mix), thus giving the possibility for type I to be indeed the precursors of type II. However, the occurrence of forsteritic relicts with different $\Delta^{17} \mathrm{O}$ than their host ferroan olivines in type IIA chondrules in carbonaceous chondrites (Jones et al., 2000; Kita et al., 2010; Ushibuko et al., 2012; Tenner et al. 2013, 2015) clearly suggests in some case a more complex history.

In ordinary chondrites the iron abundance (Fig. 2) is generally higher in type II chondrules than in type I chondrules (Jones et Scott, 1989; Jones 1990, 1994, 1996; Tachibana et al., 2003). For instance $\approx 70 \%$ of type I chondrules have less than 4 wt $\%$ Fe while $\approx 70 \%$ of type II chondrules have more than $10 \mathrm{wt} \% \mathrm{Fe}$ (Fig. 2). It is also the case in chondrules from carbonaceous chondrites. This feature indicates that the process we proposed is not the only one implicated into the formation of type IIA chondrules. Actually, it is possible to make type IIA chondrules from type IA chondrules if some part of the Fe content is not inherited from the precursors, i.e. Fe metal blebs from Type IA chondrule-like material, but is added in the form of FeO-rich silicate dusts (Nagashima et al., 2013), FeS, and/ or Fe oxides condensed from the gas phase according to the fact that Fe is a moderately volatile element. This scenario of an external seeding is supported by mineralogical evidences such as oxidized and 
ferroan igneous rims around type I chondrules in CR and CO chondrites and around type II chondrules in ordinary chondrites. Type II chondrules usually contain higher moderately volatile and volatile elements $(\mathrm{Na}, \mathrm{K}, \mathrm{Si}, \mathrm{Mn} . .$.$) than type I chondrules. As well as for \mathrm{Fe}$ enrichments, enrichments in moderately volatile and volatile elements may possibly come from interaction with the surrounding gas and/or dust suggesting that the chondritic signature observed in chondrules is not inherited from the chondrule precursors but is generated from interactions with the gaseous environments during chondrule formation (see Marrocchi and Libourel, 2013). In these circumstances and depending on the oxygen fugacity, relatively modest $P$ Fe in the chondrule forming region may explain the concomitant enrichment in iron as well as the lack of measurable iron mass fractionation in chondrules (Alexander and Wang, 2001). This is analogous to suggestions that high partial pressure of other volatile and moderately volatile elements $(\mathrm{K}, \mathrm{Si}, \mathrm{O})$ in the chondrule forming region can explain the very limited range of isotopic mass fractionation (Alexander et al., 2000; Georges et al., 2000; Kita et al., 2010; Hewins and Zanda, 2012; Fedkin et al., 2012). Finally, it is worth noting that if Fe enters the molten mesostasis from the gas phase (i.e., a solubility process) or from ferroan rims, this will dilute the other siderophile elements $\left(\mathrm{SE}_{\text {metal }}=\mathrm{Ni}, \mathrm{Co}\right.$, $\mathrm{Cr}, \mathrm{P}$ ) dissolved in the melt from the Fe-Ni metal blebs by disturbing the $\mathrm{Fe} / \mathrm{SE}_{\text {metal }}$ ratio. This dilution effect may explain in turn the lower $\mathrm{Ni}$ and $\mathrm{Co}$ contents measured in the bulk composition of type II chondrules compared with their type I equivalents while keeping the $\mathrm{Co} / \mathrm{Ni}$ ratio closed to chondritic (Grossman and Wasson, 1985; Ruzicka et al., 2008 and 2012).

The fact that some type II chondrules contain relict grains from multiple generations of type I chondrules and/or refractory inclusions (CAIs and AOAs; see for instance Yurimoto and Wasson, 2002; Ushibuko et al., 2012; Tenner et al. 2012) does not rule out our 
hypothesis of forming type IIA chondrules by the heating under oxidizing conditions of reduced precursors. Without excluding the possibility of rare oxidized materials, this suggests that precursors of type IIA chondrules are overwhelmingly dominated by reduced (or iron-poor) olivine and Fe-Ni metal rich materials, and that in some (rare) cases they may originate from multiples sources including previous generations of type I chondrules.

\section{Timing and cooling rate for chondrule formation}

Comparison of textures, Fe-Mg partitioning between olivine and melt $\left(\mathrm{K}_{\mathrm{D}}\right)$ and inward diffusion of iron in forsteritic relicts within type II chondrules (Jones, 1990, 1994; Wasson and Rubin, 2003, Ruzicka et al., 2012; Hewins and Zanda, 2012) and our experimental data point towards a relatively short duration, for the formation of type IIA chondrules. The heating time required to form ferroan olivines from magnesian ones by oxidation of Fe metal, and by extension to form type IIA chondrules from type IA chondrules or their fragments, can be quantified as follows. Ferroan olivines from type IIA chondrules from ordinary chondrites are in the range of $\approx \mathrm{Fa}_{10}$ to $\approx \mathrm{Fa}_{40}$ (e.g., Jones, 1990; Jones, 1996; Hewins and Zanda, 2012) and crystallize approximately in the range of $\approx 1800^{\circ} \mathrm{C}$ to $\approx 1500^{\circ} \mathrm{C}$ according to the Fo-Fa binary phase diagram (see also Hewins et al., 2012). Distances of FeMg interdiffusion (Fig. 21) can be thus calculated at any temperature using results obtained by Tachibana et al. (2013), the most relevant Fe-Mg diffusion data for chondrule applications.

Assuming an average size of magnesian olivines in type IA of $\approx 50 \mu \mathrm{m}$ diameter, one can see that during an isothermal oxidation event in the range of $\approx 1800-1500^{\circ} \mathrm{C}$, diffusion of FeO to the core would not exceed a few tens of minutes, i.e. $\approx 10-20 \mathrm{~min}$, to a few hours, 
i.e. $\approx 5 \mathrm{~h}$ (Fig. 21). Calculated distances of FeO diffusion in Figure 21 seem to be lower than those observed in our experiments (Figs. 12, 15, 17b) but the order of magnitude is the same. In the case of the Semarkona relict grain shown in Figure 20, the distance of Fe-Mg interdiffusion is of the order 5-10 $\mu \mathrm{m}$ suggesting a timing of less than three tens of minutes at these temperatures for its formation. Similar distances of Fe-Mg interdiffusion have also been documented in type II chondrules of different chondrite groups (Miyamoto et al., 1986; Wasson and Rubin, 2003; Greeney and Ruzicka, 2004; Bejina et al., 2009; Hewins et al., 2010; Hewins, 2010). These olivines being surrounded by a glassy mesostasis with or without dendritic crystals, we thus propose that type A chondrules could have formed accordingly with the following thermal pathway: after periods at high temperature as short as several tens of minutes and no longer than a few hundreds of minutes between $\approx 1500-1800^{\circ} \mathrm{C}$, they terminate their formation by a fast cooling $\left(>10^{3}-10^{4} \mathrm{~K} / \mathrm{h}\right)$ or a quench in order to prevent further crystallization of their mesostasis (Fig. 22).

This alternative to a continuous cooling provided by the above experimental work is at odds with thermal histories inferred from shock-wave models (e.g., Desch and Connolly, 2002; Desch et al., 2005; Morris and Desch, 2010; Desch et al., 2012 and refs therein), in which primordial dusty materials were flash heated from ambient temperatures $(<650 \mathrm{~K})$ to above liquidus temperature $(1700-2000 \mathrm{~K})$ and then cooled at a rate slow enough to allow crystals to form. In these models, e.g., bow shocks driven by planetesimals or embryos on eccentric orbits, or large-scale shocks driven by gravitational instabilities (Desch et al., 2012; Morris et al., 2012), it is generally assumed (Fig. 22) that, cooling rates from peak temperature are elevated, i.e., in the range $\approx 10^{3}-10^{4} \mathrm{~K} / \mathrm{h}$ and then slow down to $\approx 10-10^{3}$ $\mathrm{K} / \mathrm{h}$ in relation to the optical depth or the dust/gas ratio of the medium. For a given chondrule, heating duration from the peak temperature down to the closure of the system 
at the glass transition temperature $(\mathrm{Tg})$ must vary between several tens of hours to several days.

Comparison of chondrule petrologic textures and Fe-Mg profiles measured in type II chondrules with dynamic crystallization experiment analogues have shown that porphyritic textures and Fe-Mg igneous zonation could be duplicated by relatively slow cooling from their peak temperatures at rates $\approx 1-10^{2} \mathrm{~K} / \mathrm{h}$ in a matter of several tens of hours (Hewins and Radomsky, 1990; Jones and Lofgren, 1993; Lofgren, 1996; Desch and Connolly, 2002; Hewins et al., 2005; Lauretta et al., 2006; Wick and Jones, 2012). Despite the fact that shock models explain satisfactorily such slow cooling of chondrules over tens of hours (Desch et al., 2012), it is worth noticing here the important caveat that such chondrule thermal histories were deduced from closed system experiments in which only kinetic effects (cooling rate) governed the crystal growth rate and the corresponding texture of the chondrule analogues. However, we have shown by this set of isothermal open system experiments, i.e. oxidation process, that chemical disequilibrium reproduces not only the same porphyritic textures but also the chemical diversity of type IA and type IIA chondrules observed in chondrites. This finding clearly challenges both the common view that cooling rate is the only driving force during chondrule crystallization, and the reliability of cooling rate values for producing porphyritic textures inferred from dynamic crystallization experiments. That olivines in porphyritic type II chondrules show Fe-Mg normal igneous zoning consistent with dynamic crystallization experiments at slower cooling rates (1-100 K/h, e.g. Jones 1990 , Jones and Lofgren, 1993; or < $50 \mathrm{~K} / \mathrm{h}$ if we take the recent limit proposed by Welsch et al. (2012) to separate euhedral from dendritic growth for olivine crystallizing from a basaltic magma) is not inconsistent with results we obtain with isothermal experiments. A model that combines both ideas would also work, i.e. a non-linear slow cooling at high-temperature in oxidizing 
conditions followed by a rapid cooling or quench. Overgrowths on relicts could grow at the first stage, further zoned growth of the phenocrysts could occur during slow cooling, and a final rapid cooling ensuring to preserve these textures and their chemical zonations in a glassy or poorly crystallized mesostasis.

Several points support our challenge of the general consensus. Multi elemental diffusive exchange profiles ( $\mathrm{Fe}, \mathrm{Mg}, \mathrm{Ca}, \mathrm{Mn}, \mathrm{Cr}$ ) between relict olivine and surrounding melt-grown olivine calculated as resulting only from kinetic effects allow calculation of cooling rates of type IIA chondrules. Different authors have calculated cooling rates that scatter over several orders of magnitude between 1 and $10^{6} \mathrm{~K} / \mathrm{h}$ (Miyamoto et al. 1986 and 2009; Yurimoto and Wasson, 2002; Greeney and Ruzicka, 2004; Bejina et al., 2009; Hewins et al., 2009; Hewins, 2009), a majority are above the $10-10^{3} \mathrm{~K} / \mathrm{h}$ range inferred from furnace simulations of type II chondrule textures (Hewins et al., 2005). This mismatch is difficult to reconcile when such scattering is obtained in a single olivine grain, i.e., 340-18500 K/h (Greeney and Ruzicka, 2004) or $700-3600 \mathrm{~K} / \mathrm{h}$ (Bejina et al., 2009) in which theoretically the diffusion of each element must record the same thermal history. If cooling rates as low as few $\mathrm{K} / \mathrm{h}$ are invoked for making porphyritic textures, we note that they will be well below the critical cooling rate (Cabral et al., 2003) required to freeze a molten mesostasis into a glassy matrix with small amounts of dentritic crystals, as we observed it in natural type IIA chondrules. The same is also true for chondrule thermal histories inferred from shock models (Fig. 22) that show cooling rates of the order of $1-5 \mathrm{~K} / \mathrm{h}$ close to the glass transition temperature $(\mathrm{Tg} \approx 900-1000$ K).

Roughly speaking the above inconsistencies for cooling rate values between authors and within a single olivine between different elements, point towards a short lived-time at high 
temperature followed by faster cooling rates than those inferred from furnace simulations to match both textural and chemical constraints of type A chondrules. We thus propose that chondrule formation could be also the result of processes generating crystal growth by chemical disequilibrium at high temperature, i.e., $\mathrm{dC} / \mathrm{dt}$ (that characterizes the importance of the chemical disequilibrium with time, as in our isothermal open system behaviour experiments) rather than processes in which crystallization is controlled only by cooling rates, i.e., dT/dt (as in dynamical cooling rate experiments). To illustrate this, we use as an example the diffusive exchange profiles between relict olivine and surrounding melt-grown olivine in type IIA chondrules in the Semarkona chondrite, specifically for chondrule 13-36A from Hewins et al. (2009). Temperature - time profiles from $1900 \mathrm{~K}$ to $1073 \mathrm{~K}$, retrieved from modelling a Fe-Mg zoning profile and based on asymptotic and exponential cooling models, give initial cooling rates from 300 to $400 \mathrm{~K} / \mathrm{h}$ and a total time from 3 to 4 hours (Hewins et al., 2009). In contrast, if one assumes that the driving force responsible for the same Fe-Mg zoning profile is an isothermal chemical disequilibrium (dC/dt; T=1900 K and 0 $\mathrm{K} / \mathrm{h}$ ) followed by a rapid quench, the time needed is much shorter, i.e. $5 \mathrm{~min}$.

\section{Redox conditions during chondrule formation}

If this model of formation of type IIA chondrules from type IA chondrules by an oxidation event is correct, it means that the redox state recorded by type II chondrules results from interactions between the intrinsic redox conditions of the precursors and the extrinsic oxidizing conditions imposed by the gaseous environment in which chondrules formed. In a similar manner to our experiments, we propose that ferroan olivines in type II chondrules can form in a two-stage process in which a reduced (type I-like) precursor assemblage is partially melted and re-crystallized in a relatively oxidizing environment. 
This inference is endorsed by several observations, including the occurrence of Fe-Ni relicts in fayalitic olivine of type II chondrules (Schrader et al., 2008), the simultaneous enrichment of the major siderophile elements ( $\mathrm{Fe}, \mathrm{Cr}, \mathrm{Co}, \mathrm{Ni}, \mathrm{P}$ ) in P-rich zones coating anhedral relict cores (see $\S 4.2 .1$ ), as well as the coexistence of $\mathrm{Ti}^{3+}$ and $\mathrm{Fe}^{2+}$ in both type I and type II chondrule olivines (Simon et al. 2007, 2008, 2011). In an effort to determine if type I chondrules were more reduced than those of type II chondrules, Simon and collaborators (Simon et al. 2007, 2008, 2011) used X-ray absorption near-edge spectroscopy to determine the oxidation state of $\mathrm{Ti}$ in both chondrule types in Semarkona. They have found $\mathrm{Ti}^{3+}$ in both chondrule types and that Ti valence is not correlated with fayalite content. In olivines from type I chondrules, the $\mathrm{Ti}^{3+} / \mathrm{Ti}^{4+}$ ratio decreases from cores to rims of olivine crystals while the fayalite content is constant. In olivines from type II chondrules, the $\mathrm{Ti}$ valence is uniform while fayalite content increases from crystal cores to rims. Because the $\mathrm{Ti}_{2} \mathrm{O}_{3} / \mathrm{TiO}_{2}$ buffer curve is $\approx 5$ log units below (more reducing than) that for $\mathrm{Fe} / \mathrm{FeO}$ (IW), none to only minor $\mathrm{Ti}^{3+}$ content should be found in a phase with measurable amounts of FeO. At this point, the best explanation of Simon and co-workers for the coexistence of $\mathrm{Ti}^{3+}$ and $\mathrm{Fe}^{2+}$, is that both chondrule types started with reduced precursors and were then exposed to relatively oxidizing conditions, the Fe redox state being equilibrated more rapidly than that of $\mathrm{Ti}$, in full agreement with our proposed model.

Assuming equilibrium between olivine and Fe-Ni metal in type I chondrules in the form of:

$$
\mathrm{FeSi}_{1 / 2} \mathrm{O}_{2 \text { (olivine) }}=\mathrm{Fe}_{(\text {metal) }}+1 / 2 \mathrm{SiO}_{2 \text { (melt) }}+1 / 2 \mathrm{O}_{2 \text { (gas) }}
$$

thermodynamic calculations relating the $\mathrm{FeO}$ content of the magnesian olivine to the oxygen fugacity (Nitsan, 1974; Matas et al., 2000) suggest that type I in Semarkona (Jones 
and Scott, 1989; Libourel et al., 2006) formed in redox conditions in the range of 2 to 4 log units below the IW buffer curve (Fig. 3). These calculated oxygen fugacities are also consistent with the low Si concentration ( $<<1 \mathrm{wt} \% \mathrm{Si}$ ) measured in the vast majority of Fe-Ni metals blebs of ordinary and carbonaceous chondrites (Matas et al., 2000). As noted by several studies (Johnson, 1986; Zanda, 1994; Sears et al., 1996; Lauretta et al., 2001; Cohen and Hewins, 2004) and more recently by Grossman et al. (2008, 2012), type IA chondrules and necessarily type IIA chondrules as well could not have been formed directly in a gas of solar composition that was lying between 3 to 5 log units of oxygen fugacity below IW (Fig. 3; Allende Prieto et al., 2002). Calculated $\mathrm{fO}_{2}$ for type II chondrules of Semarkona using the same olivine-iron metal-silicate melt (OSI) oxybarometer gives values in the range of 1 to 1.5 log units below the IW buffer curve (Yu and Hewins, 1998). Similarly, chromium solubility at chromite saturation (Roeder and Reynolds, 1991; Murck and Campbell, 1986; Ariskin and Nikolaev, 1996) together with sulfur solubility at sulfide saturation (Haughton et al., 1974; O'Neil and Mavrogenes, 2002) which are both dependent on oxygen fugacity, hint at redox conditions up to IW+1 for the formation of type IIA chondrules in ordinary chondrites.

In fair agreement with previous estimates (Yu and Hewins, 1998; Grossman et al., 2008; Grossman et al., 2012; Fedkin et al., 2012; Ruzicka et al., 2012), these inferred redox conditions suggest that (i) there is little overlap in redox conditions between type I ( $\approx$ IW-4 IW-1) and type IIA chondrules ( $\approx$ IW-1 - IW+1?), (ii) type IIA chondrules formed in more oxidized environments, i.e., very likely close to IW buffer, than their type I equivalents, and (iii) both chondrule types formed in redox environments far more oxidized than canonical conditions imposed by a gas of solar composition with high abundances of hydrogen and carbon relative to oxygen (Fig. 3; Allende Prieto et al. 2002). In nebular models type I and type II chondrules are necessarily formed in sub-regions with different (redox) conditions 
before being brought together in chondrite parent bodies (Cuzzi and Alexander, 2006). How to make enough oxidized systems to produce the different compositions of the two types of chondrules still remains an open question. This is the reason why so much water (Grossman et al., 2012; Fedkin et al., 2012) has to be added to solar gas or such high dust/gas ratios are needed in models (Alexander et al., 2008; Alexander and Ebel, 2012; Ruzicka et al., 2012; Fedkin and Grossman, 2013) to make up the huge difference in oxygen fugacity between the solar gas curve and chondrule formation conditions in particular the most oxidizing conditions of type IIA chondrules. If both approaches succeed more or less to match the required ranges of oxygen fugacity (see above), they have however some problems to deal with the great diversity of chondrule compositions (chemistry and oxygen isotopes) and textures. In nebular models, this diversity depends upon the composition and grain size of chondrule precursors, the formation conditions (temperature, opacity), the duration of the thermal events and/or the size of the formation region (Grossman et al., 2012; Alexander and Ebel, 2012). This may require too many specific conditions to satisfy and to tune at the right values in order to match the observed chondrule compositions and textures.

Recently, it has been noticed that there is no simple way to concentrate water by a factor $>10$ or dust by a factor $>125$ in large regions of the solar nebula (Grossman et al., 2008; Alexander and Ebel, 2012; Grossman et al., 2012; Fedkin et al., 2012; Hewins and Zanda, 2012; Ruzicka, 2012), nor any proof of the shock wave efficiency to heat dense particle clumps in the protoplanetary disk (Alexander and Ebel, 2012). As an alternative, a model of impacts on planetesimals causing rapid melting and vaporization is gaining ground since this provides the very high density and highly volatile-enriched environments required to form chondrules (Asphaug et al., 2011; Alexander and Ebel, 2012; Sanders and Scott, 2012; Fedkin et al., 2012; Morris et al., 2012; Fedkin and Grossman, 2013; Johnson et al., 
2015).

In the light of petrographic and isotopic studies arguing in favor of the inheritance of magnesian olivine of type IA chondrules from a planetary setting (Libourel and Krot, 2007; Chaussidon et al., 2008; Libourel and Chaussidon, 2011; Villeneuve et al., 2011) and the present model suggesting that type IIA chondrules formed by the oxidation of Type IA chondrule assemblages at high temperature, we thus propose as a testable working hypothesis that redox conditions around IW-4 to IW-3 recorded by type IA chondrules hosting the most Fe-poor olivines $\left(<\mathrm{Fa}_{1}\right)$ would be remnant of the conditions of their parental planetesimals from which they were ejected during the impact. In contrast, the range of redox conditions from IW-3 to IW+1 recorded by type IA chondrules hosting the more ferroan olivines ( $>\mathrm{Fa}_{1}$ ) and type IIA chondrules would be interpreted as resulting from various degree of (re-)heating of the ejected fragments during their ballistic trajectory through the impact vapor plume. Thus the most oxidizing conditions observed in type II chondrules would very likely be the closest to oxidation conditions of the impact vapor plume (Visscher and Fegley, 2013). These authors have shown indeed that during collisions the saturated silicate vapour is highly oxidizing with oxygen fugacity $(\approx \mathrm{IW})$ values several orders of magnitude higher than those in a solar composition gas. In this hypothesis, quenching of chondrules would be due to the fact that as the plume continues to expand and cool, the vapor density becomes so low that collisions between vapor molecules and partially molten chondrules become rare (Johnson and Melosh, 2012). The chondrules are thus to a certain extent analogous to cosmic spherules that can record through their spinel composition the diverse redox conditions of the atmosphere crossed by an extraterrestrial object during its fall towards the Earth's surface (Toppani et al., 2003). In this scenario dusty olivines or complete reduction of type II chondrules are expected in response to eddies in 
the plume that may drive grains, fragments and newly formed type II chondrules to different conditions.

\section{CONCLUSIONS}

Owing to a set of high temperature experiments, we have shown that (sub-isothermal) oxidation of type IA chondrules-like assemblages is a very efficient and rapid process to form textures similar to type IIA chondrules, with timescales of a few tens of minutes to few hundreds of minutes. Due to the rapid dissolution of Fe metal blebs, FeO dissolved in the melt promotes the dissolution of magnesian olivines and then, when the melt reaches the ferroan olivine saturation, the crystallization of ferroan olivine either as new crystals in the mesostasis or as overgrowths on the remaining unresorbed forsterite grains (relicts). Interruption of this process at any time before its completion by rapid cooling allows to reproduce the whole range of textures and chemical diversity observed in type $A$ chondrules, i.e., from type I to type II.

These results may have implications for chondrule formation processes. First, type IA chondrules or fragments of reduced chondrules may very likely be the main precursor material involved in the formation of type IIA chondrules. Second, type IIA chondrule formation may be the result of processes generating crystal growth by chemical disequilibrium at high temperature, i.e., $\mathrm{dC} / \mathrm{dt}$ as in our isothermal open system behaviour experiments, rather than processes generating crystallization only by cooling rates as it is assumed now in the literature, i.e., $\mathrm{dT} / \mathrm{dt}$ as in dynamical cooling rate experiments. This 
questions the reliability of cooling rate values hitherto inferred for producing porphyritic textures. Third, type A chondrule formation is a very fast process. After high temperature events of almost isothermal heating at slow cooling $(>50 \mathrm{~K} / \mathrm{h})$ as short as several tens of minutes and no longer than few hundreds of minutes (at $1500-1800^{\circ} \mathrm{C}$ ), type $\mathrm{A}$ chondrule

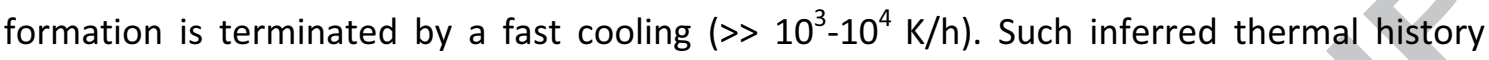
being at odds with nebular shock models, we thus advocate that impacts on planetesimals causing rapid melting and vaporization may provide the very high density and highly volatileenriched environments required to form chondrules.

In the frame of this model, the most reducing conditions recorded by type IA chondrules are interpreted as remnant of the conditions of their parental planetesimals from which they were ejected during the impact. In contrast, the oxidizing conditions recorded both by type IA chondrules and type IIA chondrules are the results of various degrees of interaction of the ejected fragments with the impact vapor plume; the most oxidizing conditions recorded in type IIA chondrules being very likely the closest to those imposed by the impact vapor plume.

\section{Acknowledgments}

The authors are grateful to Marc Chaussidon, Laurent Tissandier, and Jeff Grosmann for helpful discussions. We would like also to thank S. Tachibana, M. Petaev and the AE A. Krot for their helpful and constructive reviews, and more specifically R. Jones for her substantial work reviewing our manuscript. This study was supported by grants from the European Research Council (ERC grant FP7/2007-2013 Grant agreement 226846, Cosmochemical Exploration of the first two Years of the Solar System - CEMYSS), ANR-08-BLAN- ${ }^{\circ} 260-C S D 6$, 
the Programme National de Planétologie (INSU-CNRS) and by the French National Research Agency, contract ANRBS56-008, project Shocks. GL is indebted to the INSU-CNRS since part of his work was done at the HIGP (Honolulu, USA) as CNRS delegate. This is CRPG-CNRS contribution \#2125.

\section{References}

Alexander, C. M. O. D., Grossman, J. N., Ebel, D. S., and Ciesla, F. J. (2008). The formation conditions of chondrules and chondrites. Science 320, 1617-1619.

Alexander, C. M. O. D., Grossman, J. N., Wang, J., Zanda, B., Bourot-Denise, M., and Hewins, R. H. (2000). The lack of potassium-isotopic fractionation in Bishunpur chondrules. Meteoritics and Planetary Science 35, 859-868.

Alexander, C. M. O. D. and Ebel, D. S. (2012). Questions, questions: Can the contradictions between the petrologic, isotopic, thermodynamic and astrophysical constraints on chondrule formation be resolved? Meteoritics and Planetary Science 47, 1157-1175.

Alexander, C. M. O. D. and Wang, J. (2001). Iron isotopes in chondrules: Implications for the role of evaporation during chondrule formation. Meteoritics and Planetary Science 36, 419-428.

Allende Prieto, C., Lambert, D. L., and Asplund, M. (2002). A reappraisal of the solar photospheric C/O ratio. Astrophysical Journal 573, 137.

Amelin, Y., Krot, A. N., Hutcheon, I. D., Ulyanov, A. A. (2002). Lead isotopic ages of chondrules and calcium-aluminum-rich inclusions, Science $297,1678-1683$.

Ariskin, A. A., and Nikolaev, G. S. (1996). An empirical model for the calculation of spinelmelt equilibria in mafic igneous systems at atmospheric pressure: 1 . Chromian spinels. Contribution to Mineralogy and Petrology 123, 282-292.

Asphaug, E., Jutzi, M., and Movshovitz, N. (2011). Chondrule formation during planetesimal accretion. Earth and Planetary Science Letters 308, 369-379.

Bejina, F., Sautter, V., and Jaoul, O. (2009). Cooling rate of chondrules in ordinary chondrites revisited by a new geospeedometer based on the compensation rule. Physics of the Earth and Planetary Interiors 172, 5-12.

Boesenberg, J. S., Cosarinsky, M., McKeegan, K. D., Chaussidon, M., Hewins, R. H. (2007). An 
experimental study of Fe-Mg and oxygen isotope exchange between relict olivine and chondrule melt. Lunar Planet. Sci. XXXVIII. Lunar Planet. Inst. \# 1621 (abstr.).

Bowen, N. L. and Schairer, J. F. (1932) The system FeO-SiO 2 . Am. J. Sci. 5th ser 24, 177-213.

Brunet, F. and Chazot, G. (2001). Partitioning of phosphorus between olivine, clinopyroxene and silicate glass in a spinel Iherzolite xenolith from Yemen. Chemical Geology 176, 51-72.

Cabral, A. A., Cardoso, A. A. D., and Zanotto, E. D. (2003). Glass-forming ability versus stability of silicate glasses. I. Experimental test. Journal of Non-Crystalline Solids, 320, 1-8.

Chakraborty, S., Farver, J. R., Yund, R. A., and Rubie, D. C. (1994). Mg tracer diffusion in synthetic forsterite and San Carlos olivine as a function of $\mathrm{P}, \mathrm{T}$ and fO2. Phys. Chem. Minerals 21, 489-500.

Chaussidon, M., Libourel, G., and Krot, A. N. (2008). Oxygen isotopic constraints on the origin of magnesian chondrules and on the gaseous reservoirs in the early solar system. Geochimica Et Cosmochimica Acta 72, 1924-1938.

Ciesla, F. J. (2005). Chondrule-forming processes - An overview. In Chondrites and the protoplanetary disk, ASP conference series (eds. A. N. Krot, E. R. D. Scott, and B. Reipurth). Sheridan Books, Ann Arbor, Michigan. pp 811-819.

Ciesla, F. J. and Cuzzi, J. N. (2006). The evolution of the water distribution in a viscous protoplanetary disk. Icarus 181, 178-204.

Clayton, R. N. (2004). The origin of oxygen isotope variations in the early solar system. Lunar Planet. Sci. XXXV. Lunar Planet. Inst. (abstr.).

Cohen, B. A., and Hewins, R. H. (2004). An experimental study of the formation of metallic iron in chondrules. Geochimica Et Cosmochimica Acta 68, 1677-1689.

Connelly, J., Amelin, Y., Krot, A. N., Bizzarro, M. (2008). Chronology of the solar system's oldest solids, Astrophysical Journal 675, 121-124.

Connelly, J. N., Bizzarro, M., Krot, A. N., Nordlund, Å., Wielandt, D., and Ivanova, M. A. (2012) The absolute chronology and thermal processing of solids in the solar protoplanetary disk, Science 338, 651-655.

Connolly, H. C., Hewins, R. H., Ash, R. D., Zanda, B., Lofgren, G. E., and Bourot-Denise, M. (1994). Carbon and the formation of chondrules. Nature 371, 136-139.

Connolly, H. C. and Huss, G. R. (2010). Compositional evolution of the protoplanetary disk: Oxygen isotopes of type II chondrules from CR2 chondrites. Geochimica Et 
Cosmochimica Acta 74, 2473-2483.

Connolly, H. C., Huss, G. R., Nagashima, K., Weisberg, M. K., Ash, R. D., Ebel, D. S., Schrader, D. L., and Lauretta, D. S. (2008). Oxygen isotopes and the nature and origins of type-II chondrules in CR2 chondrites. Lunar Planet. Sci. XXXIX. Lunar Planet. Inst. \# 1675 (abstr.).

Cuzzi, J. N., and Alexander, C. M. O'D. (2006). Chondrule formation in particle-rich nebular regions at least hundreds of kilometers across. Nature 441, 483-485.

Desch, S. J., Ciesla, F. J., Hood, L. L., and Nakamoto, T. (2005). Heating of chondritic materials in solar nebula shocks. In Chondrites and the protoplanetary disk, ASP conference series (eds. A. N. Krot, E. R. D. Scott, and B. Reipurth). Sheridan Books, Ann Arbor, Michigan. pp 849-872.

Desch, S. J. and Connolly, H. C. (2002). A model of the thermal processing of particles in solar nebula shocks: Application to the cooling rates of chondrules. Meteoritics and Planetary Science 37, 183-207.

Desch, S. J., Morris, M. A., Connolly, H. C., Boss, A. P. (2012). The importance of experiments: Constraints on chondrule formation models. Meteoritics \& Planetary Science 47, 1139-1156.

Dohmen, R., Chakraborty, S. (2007). Fe-Mg diffusion in olivine II: point defect chemistry, change of diffusion mechanisms and a model for calculation of diffusion coefficient in natural olivine, Phys. Chem. Miner. 34, 409-430.

Fedkin, A. V., Grossman, L., Ciesla, F. J., Simon, S. B. (2012). Mineralogical and isotopic constraints on chondrule formation from shock wave thermal histories. Geochimica et Cosmochimica Acta, 87, 81-116.

Fedkin, A. V., Grossman, L. (2013). Vapor saturation of sodium: Key to unlocking the origin of chondrules. Geochimica et Cosmochimica Acta, (in press).

Gaye, H. and Riboud, P. V. (1977). Oxidation kinetics of iron alloy drops in oxidizing slags. Metallurgical transactions B 8B, 409-415.

Georges, P., Libourel, G., and Deloule, E. (2000). Experimental constraints on alkali condensation in chondrule formation. Meteoritics and Planetary Sciences 35, 11831188.

Greeney, S. and Ruzicka, A. (2004). Relict forsterite in chondrules: Implications for cooling rates. Lunar Planet. Sci. XXXV. Lunar Planet. Inst., Houston. (abstr.).

Grossman, J. N., and Wasson, J. T. (1985). The origin and history of the metal and sulfide components of chondrules. Geochimica Et Cosmochimica Acta 49, 925-939. 
Grossman, L. (2010). Vapor-condensed phase processes in the early solar system. Meteoritics and Planetary Sciences 45, 7-20.

Grossman, L., Beckett, J. R., Fedkin, A. V., Simon, S. B., and Ciesla, F. J. (2008). Redox conditions in the solar nebula: Observational, experimental, and theoretical constraints. In Oxygen in the solar system, reviews in mineralogy and geochemistry vol. 68 (eds. G. J. MacPherson, D. W. Mittlefehldt, J. H. Jones, S. B. Simon, J. J. Papike, and S. Mackwell). Mineralogical Society of America, Geochimical Society. pp 93-140.

Grossman L, Fedkin A.V., Simon S.B. (2012) Formation of the first oxidized iron in the solar system. Meteoritics and Planetary Sciences. 1-10.

Haughton D. R., Roeder P. L., Skinner B. J. (1974). Solubility of sulfur in mafic magmas. Economic Geology. 69, 451-467.

Hewins, R. H. (2009). Minor element zoning of olivine in type IIA chondrules in Semarkona, Lunar Planet. Sci. XXXX. Lunar Planet. Inst., Houston. \# 1669. (abstr.).

Hewins, R.H., and Radomsky, P.M. (1990) Temperature conditions for chondrule formation. Meteoritics 25, 309-318.

Hewins, R. H., Connolly, H. C., Lofgren, G. E., and Libourel, G. (2005). Experimental constraints on chondrules formation. In Chondrites and the protoplanetary disk, asp conference series (eds. A. N. Krot, E. R. D. Scott, and B. Reipurth). Sheridan Books, Ann Arbor, Michigan. pp 286-316.

Hewins, R. H., Ganguly, J., and Mariani, E. (2009). Diffusion modeling of cooling rates of relict olivine in semarkona chondrules. Lunar Planet. Sci. XXXX. Lunar Planet. Inst., Houston. (abstr.).

Hewins, R. H., and Zanda, B. (2012). Chondrules: Precursors and interactions with the nebular gas. Meteoritics \& Planetary Science 47, 1120-1138.

Hewins, R. H., Zanda, B. ; and Bendersky, C. (2012). Evaporation and recondensation of sodium in Semarkona type II chondrules. Geochimica Et Cosmochimica Acta 78, 1-17.

Johnson, B. C., and Melosh, H. J. (2012). Distal impact ejecta: Melt droplets, impact lapilli and tektites. Lunar Planet. Sci. XXXXIII. Lunar Planet. Inst., Houston. \#1456 (abstr.).

Johnson, B. C., Minton, D. A., Melosh, H. J., and Zuber, M. T. (2015). Impact jetting as the origin of chondrules. Nature 517, 339-341.

Johnson, M. C. (1985). The solar nebula redox state as recorded by the most reduced chondrules of five primitive chondrites. Geochimica Et Cosmochimica Acta 50, 14971502. 
Jones, R. H. (1990). Petrology and mineralogy of type-II, FeO-rich chondrules in Semarkona (LL3.0) - origin by closed-system fractional crystallization, with evidence for supercooling. Geochimica Et Cosmochimica Acta 54, 1785-1802.

Jones, R. H. (1994). Petrology of FeO-poor, porphyritic pyroxene chondrules in the Semarkona chondrite. Geochimica Et Cosmochimica Acta 58, 5325-5340.

Jones, R. H. (1996). FeO-rich, porphyritic pyroxene chondrules in unequilibrated ordinary chondrites. Geochimica Et Cosmochimica Acta 60, 3115-3138.

Jones, R. H. (2012). Petrographic constraints on the diversity of chondrule reservoirs in the protoplanetary disk. Meteoritics and Planetary Science 47, 1176-1190.

Jones, R. H. and Carey, E. R. (2006). Identification of relict forsterite grains in forsterite-rich chondrules from the Mokoia CV3 carbonaceous chondrite. American Mineralogist 91, 1664-1674.

Jones, R. H. and Danielson, L. R. (1997). A chondrules origin for dusty relict olivine in unequilibrated chondrites. Meteoritics and Planetary Science 32, 753-760.

Jones, R. H., Grossman, J. N., and Rubin, A. E. (2005). Chemical, mineralogical and isotopic properties of chondrules: Clues to their origin. In Chondrites and the protoplanetary disk, asp conference series (eds. A. N. Krot, E. R. D. Scott, and B. Reipurth). Sheridan Books, Ann Arbor, Michigan. pp 251-285.

Jones, R. H. and Lofgren, G. E. (1993). A comparison of FeO-rich, porphyritic olivine chondrules in unequilibrated chondrites and experimental analogues. Meteoritics and Planetary Science 28, 213-221.

Jones, R. H. and Scott, E. R. D. (1989). Petrology and thermal history of type IA chondrules in Semarkona (LL3.0) chondrite. Proceedings of the 19th Lunar and Planetary Science Conference, 523-536.

Jurewicz, A. J. G. and Watson, E. B. (1988). Cations in olivine, part 2: Diffusion in olivine xenocrysts, with applications to petrology and mineral physics. Contributions to Mineralogy and Petrology 99, 186-201.

Kennedy, A. K., Lofgren, G. E., and Wasserburg, G. J. (1993). An experimental study of trace element partitioning between olivine, orthopyroxene and melt in chondrules: Equilibrium values and kinetic effects. Earth and Planetary Science Letters 115, 177195.

Kilinc, A., Carmichael, I. S. E., Rivers, M. L., and Sack, R. O. (1983). The ferric-ferrous ratio of natural silicate liquids equilibrated in air. Contributions to Mineralogy and Petrology 83, 136-140. 
Kimura, M., Grossman, J. N., Weisberg, M. K. (2008). Fe-Ni metal in primitive chondrites: indicators of classification and metamorphic conditions for ordinary and CO chondrites. Meteoritics and Planetary Science 43, 1161-1177.

Kita, N. T., Huss, G. R., Tachibana, S., Amelin, Y., Nyquist, L. E. (2005). Constraints on the Origin of Chondrules and CAls from Short-lived and Long-lived Radionuclides, in: A.N. Krot, E.R.D. Scott, B. Reipurth (Eds.), Chondrites and the Protoplanetary Disk, ASP Conference Series, pp. 558-587

Kita, N. T., Nagahara, H., Tachibana, S., Tomomura, S., Spicuzza, J., Fournelle, J. H., and Valley, J. W. (2010). High precision SIMS oxygen three isotope study of chondrules in LL3 chondrites: Role of ambient gas during chondrule formation. Geochimica Et Cosmochimica Acta 74, 6610-6635.

Krot, A. N., Libourel, G., Goodrich, C. A., and Petaev, M. I. (2004). Silica-rich igneous rims around magnesian chondrules in CR carbonaceous chondrites: Evidence for condensation origin from fractionated nebular gas. Meteoritics and Planetary Science 39, 1931-1955.

Kuo, L.-C., Kirkpatrick, J. (1985). Kinetics of crystal dissolution in the system diopsideforsterite-silica. American Journal of Science 285, 51-90.

Kurahashi, E., Kita, N. T., Nagahara, H. and Morishita, Y. (2008). Al-26-Mg-26 systematics of chondrules in a primitive CO chondrite, Geochimica Et Cosmochimica Acta 72, 38653882.

Lauretta, D. S., Buseck, P. R., and Zega, T. J. (2001). Opaque minerals in the matrix of the Bishunpur (LL3.1) chondrite: Contraints on the chondrule formation environment. Geochimica Et Cosmochimica Acta 65, 1337-1353.

Lauretta, D. S., Nagahara, H., and Alexander, C. M. O. D. (2006). Petrology and origin of ferromagnesian silicate chondrules. In Meteorites and the Early Solar System II (eds. D. S. Lauretta and H. Y. McSween). The University of Arizona Press. pp 431-459.

Lemelle, L., Guyot, F., Leroux, H., and Libourel, G. (2001). An experimental study of external reduction of olivine single crystals. American Mineralogist 86, 47-54.

Leroux, H., Libourel, G., Lemelle, L., and Guyot, F. (2003). Experimental study and tem characterization of dusty olivines in chondrites: Evidence for formation by in situ reduction. Meteoritics and Planetary Science 38, 81-94.

Libourel, G. (1999). Systematics of calcium partitioning between olivine and silicate melt: implications for melt structure and calcium content of magmatic olivines. Contribution to Mineralogy and Petrology 136, 63-80.

Libourel, G. and Chaussidon, M. (1995). Experimental constraints on chondrule reduction. 
Meteoritics. (abstr.).

Libourel, G. and Chaussidon, M. (2011). Oxygen isotopic constraints on the origin of Mg-rich olivines from chondritic meteorites. Earth and Planetary Science Letters 301, 9-21.

Libourel, G. and Krot, A. N. (2007). Evidence for the presence of planetesimal material among the precursors of magnesian chondrules of nebular origin. Earth and Planetary Science Letters 254, 1-8.

Libourel, G., Krot, A. N., and Tissandier, L. (2003). Evidence for high temperature condensation of moderately-volatile elements during chondrule formation. Lunar Planet. Sci. XXXIV. Lunar Planet. Inst., Houston. (abstr.).

Libourel, G., Krot, A. N., and Tissandier, L. (2006). Role of gas-melt interaction during chondrule formation. Earth and Planetary Science Letters 251, 232-240.

Libourel, G., Deloule, E., and Toplis, M.J. (1994). Phosphorus partitioning in basalts: an experimental and ion probe study. Mineralogical Magazine 58A, 527-528.

Lofgren, G. E. (1996). A Dynamic Crystallization Model for Chondrule Melts. In R.H. Hewins, R.H. Jones, E.R.D. Scott (Eds.), International conference: Chondrules and the protoplanetary disk, Cambridge University Press, pp. 187-196.

Lofgren, G. E. and Le, L. (1998). Partial melting of type I chondrule precursor aggregates: An experimental and petrographic study. Lunar Planet. Sci. XXIX. Lunar Planet. Inst., Houston. (abstr.).

Marrocchi, Y. and Libourel, G. (2013). Sulfur and sulfides in chondrules. Geochimica et Cosmochimica Acta, 119, 117-136.

Matas, J., Ricard, Y., Lemelle, L., and Guyot, F. (2000). An improved thermodynamic model of metal-olivine-pyroxene stability domains. Contributions to Mineralogy and Petrology $140,73-83$.

Matsunami, S., Ninagawa, K., Nishimura, S., Kubono, N., Yamamoto, I., Kohata, M., Wada, T., Yamashita, Y., Lu, J., Sears, D. W., and Nishimura, H. (1993). Thermoluminescence and compositional zoning in the mesostasis of a Semarkona group IA chondrule and new insights into chondrule-forming process. Geochimica Et Cosmochimica Acta 57, 2101-2110.

McCanta, M. C., Beckett, J. R., Stolper, E. M. (2008). Zonation of phosphorus in olivine: Dynamic crystallization experiments and a study of chondrule olivine in unequilibrated ordinary chondrites. Lunar Planet. Sci. XXXIX. Lunar Planet. Inst., Houston. \#1807 (abstr.).

Milman-Barris, M. S., Beckett, J. R., Baker, M. B., Hofmann, A. E., Morgan, Z., Crowley, M. R., 
Vielzeuf, D. and Stolper, E. (2008). Zoning of phosphorus in igneous olivine. Contrib. Mineral. Petrol. 155, 739-765.

Morris, M. A., Boley, A. C., Desch, S. J., and Athanassiadou, T. (2012). Chondrule formation in bow shocks around eccentric planetary embryos. The Astrophysical Journal 752, 27.

Morris, M. A. and Desch, S. J. (2010). Thermal histories of chondrules in solar nebula shocks. The Astrophysical Journal 722, 1474-1494.

Miyamoto, M., McKay, D. S., McKay, G. A., Duke, M. B. (1986). Chemical zoning and homogenization of olivines in ordinary chondrites and implications for thermal histories of chondrules. Journal of Geophysical Research, 91, 12804-12816.

Miyamoto, M., Mikouchi, T., and Jones, R. H. (2009). Cooling rates of porphyritic olivine chondrules in the Semarkona (LL3.00) ordinary chondrite: A model for diffusional equilibration of olivine during fractional crystallization. Meteoritics and Planetary Science 44, 521-530.

Murck B. W., and Campbell, I. H. (1986). The effects of temperature, oxygen fugacity and melt composition on the behavior of chromium in basic and ultrabasic melts. Geochimica Et Cosmochimica Acta 50, 1871-1887.

Nagahara, H., Kita, N. T., Ozawa, K., and Morishita, Y. (1999). Condensation during chondrule formation: Elemental and $\mathrm{mg}$ isotopic evidence. Lunar Planet. Sci. XXXI. Lunar Planet. Inst., Houston. (abstr.).

Nagashima, K., Krot, A. N., Libourel, G., and Huss, G. R. (2013). Magnesian porphyritic chondrules surrounded by ferroan igneous rims from CR chondrite GRA 95229. Lunar Planet. Sci. XXXXIV. Lunar Planet. Inst., Houston. \#1780 (abstr.).

Nettles, J. W., Lofgren, G. E., Carlson, W. D. and McSween, H. Y. (2006). Extent of chondrule melting : Evaluation of experimental textures, nominal grain size, and convolution index. Meteoritics and Planetary Science 41, 1059-1071.

Nitsan, U. (1974). Stability field of olivine with respect to oxidation and reduction. Journal of Geophysical Research 79, 706-711.

O'Neill, H. S. C. and Mavrogenes, J. A. (2002). The sulfide Capacity and the Sulfur Content at Sulfide Saturation of Sllicates Melts at $1400^{\circ} \mathrm{C}$ and 1 bar. Journal of Petrology 43, 1049-1087.

Petry, C., Chakraborty, S., and Palme, H. (2004). Experimental determination of Ni diffusion coefficients in olivine and their dependence on the temperature, composition, oxygen fugacity and crystallographic orientation. Geochimica Et Cosmochimica Acta 68, 4179-4188. 
Radomsky, P. M. and Hewins, R. H. (1990). Formation conditions of pyroxene-olivine and magnesian olivine chondrules. Geochimica Et Cosmochimica Acta 54, 3475-3490.

Rambaldi, E. R. (1981). Relict grains in chondrules. Nature 293, 558-561.

Roeder, P. L. and Emslie, R. F. (1970). Olivine-liquid equilibrium. Contributions to Mineralogy and Petrology 29, 275-289.

Roeder, P .L., and Reynolds, I. (1991). Crystallization of chromite and chromium solubility in basaltic melts. Journal of petrology 32, 909-934.

Rudraswami, N. G., Ushikubo, T., Nakashima, D. and Kita, N. T. (2011). Oxygen isotope systematics of chondrules in the Allende CV3 chondrite: high precision ion microprobe studies. Geochimica Et Cosmochimica Acta 75, 7596-7611.

Russell, S. S., Hartmann, L., Cuzzi, J., Krot, A. N., Gounelle, M., Weidenschilling, S. (2006). Timescales of the solar protoplanetary disk. In Meteorites and the early solar system II (eds. D. S. Lauretta and H. Y. McSween). The University of Arizona Press. pp 233251.

Ruzicka, A., Floss, C., and Hutson, M. (2008). Relict olivine grains, chondrules recycling, and implications for the chemical, thermal, and mechanical processing of nebular materials. Geochimica Et Cosmochimica Acta 72, 5530-5557.

Ruzicka, A., Hiyagon, H., Hutson, M., and Floss, C. (2007). Relict olivine, chondrule recycling, and the evolution of nebular oxygen reservoirs. Earth and Planetary Science Letters 257, 274-289.

Ruzicka A., Floss C., and Hutson M. (2012). Agglomeratic olivine (AO) objects in ordinary chondrites: Accretion and melting of dust to form ferroan chondrules. Geochimica et Cosmochimica Acta 76, 103-124.

Ruzicka A. (2012). Chondrule formation by repeated evaporative melting and condensation in collisional debris clouds around planetesimals. Meteoritics and Planetary Science 47, 2218-2236.

Sanders, I. S., and Scott, E. R. D. (2012). Origin of chondrules, chondrites and cores. Meteoritics and Planetary Science Suppl., \# 5177 (abstr.).

Schrader, D. L., Connolly, H. C., and Lauretta, D. S. (2008). Opaque phases in type-II chondrules from CR2 chondrites: Implications for CR parent body formation. Geochimica Et Cosmochimica Acta 72, 6124-6140.

Scott, E. R. D. and Krot, A. N. (2003). Chondrites and their components. In Treatise on geochemistry, vol. 1, meteorites, comets, and planets, A.M. Davis (ed.) (eds. H. D. Holland and K. K. Turekian). Elsevier. pp 143-200. 
Sears, D. W., Huang, S., and Benoit, P. H. (1996). Open-system behaviour during chondrule formation. In International conference: Chondrules and the protoplanetary disk (eds. R. H. Hewins, R. H. Jones, and E. R. D. Scott). Cambridge University Press. pp 221-231.

Simon, S. B., Beckett, J. R., Vaughan, W. M., Sutton, S. R., and Grossman, L. (2011). Chondrule-composition melts: Response of $\mathrm{Fe}$ and $\mathrm{Ti}$ valence to changing redox conditions. Lunar Planet. Sci. XXXXII. Lunar Planet. Inst., Houston. \# 1271 (abstr.).

Simon, S. B., Sutton, S. R., and Grossman, L. (2008). Constraints on the oxidation state of chondrule precursors from titanium XANES analysis of Semarkona chondrules. Lunar Planet. Sci. XXXIX. Lunar Planet. Inst., Houston. \# 1352 (abstr.).

Simon, S. B., Sutton, S., Newville, M., and Grossman, L. (2007). The valence of titanium in refractory forsterite. Lunar Planet. Sci. XXXVIII. Lunar Planet. Inst., Houston. \# 1892 (abstr.).

Soulié, C., Libourel, G., Tissandier, L. and Hiver, J.-M. (2012). Kinetics of olivine dissolution in chondrule melts: An experimental study. Lunar Planet. Sci. XXXXIII. Lunar Planet. Inst., Houston. \# 1840 (abstr.).

Steele, I. M. (1986). Compositions and textures of relict forsterite in carbonaceous and unequilibrated ordinary chondrites. Geochimica Et Cosmochimica Acta 50, 13791395.

Symes, S. J. and Lofgren, G. E. (1999). Distribution of FeO and MgO between olivine and melt in natural and experimental chondrules. Lunar Planet. Sci. XXX. Lunar Planet. Inst., Houston. \# 1869 (abstr.).

Tachibana, S., Nagahara, H., Mostefaoui, S., and Kita, N. T. (2003). Correlation between relative ages inferred from ${ }^{26} \mathrm{Al}$ and bulk compositions of ferromagnesian chondrules in least equilibrated ordinary chondrites. Meteoritics and Planetary Science 38, 939962.

Tachibana, S., Tamada, S., Kawasaki, H., Ozawa, K., and Nagahara, H. (2013). Interdiffusion of $\mathrm{Mg}-\mathrm{Fe}$ in olivine at $1,400-1,600{ }^{\circ} \mathrm{C}$ and $1 \mathrm{~atm}$ total pressure. Phys. Chem. Minerals 40, 511-519.

Taylor, L. A. and Cirlin, E. H. (1986). Olivine/melt Fe/Mg K 's <0.3: Rapid cooling of olivinerich chondrules. Lunar Planet. Sci. XVII. Lunar Planet. Inst., Houston. 19-38 (abstr.).

Tenner, T. J., Ushikubo, T., Kurahashi, E., Kita, N. T., and Nagahara, H. (2013). Oxygen isotope systematics of chondrule phenocrysts from the CO3.0 chondrite Yamato 81020: Evidence for two distinct oxygen isotope reservoirs. Geochimica Et Cosmochimica Acta 102, 226-245.

Tenner, T. J., Nakashima, D., Ushikubo, T., Kita, N. T., Weisberg, M. K. (2015). Oxygen isotope 
ratios of FeO-poor chondrules in CR3 chondrites: Influences of dust enrichment and $\mathrm{H}_{2} \mathrm{O}$ during chondrule formation. Geochimica Et Cosmochimica Acta 148, 228-250.

Thiemens, M. H. (1996). Mass-independant isotopic efffects in chondrites: The role of chemical processes. In International conference: Chondrules and the protoplanetary disk (eds. R. H. Hewins, R. H. Jones, and E. R. D. Scott). Cambridge University Press. pp 107-118.

Tissandier, L., Libourel, G., and Robert, F. (2002) Gas-melt interactions and their bearing on chondrule formation. Meteoritics \& Planetary Science 37, 1377-1389.

Toppani, A., and Libourel, G. (2003). Factors controlling compositions of cosmic spinels: application to atmospheric entry conditions of meteoritic materials. Geochimica Et Cosmochimica Acta 67, 4621-4638.

Ushikubo, T., Kimura, M., Kita, N. T. and Valley, J. W. (2012). Primordial oxygen isotope reservoirs of the solar nebula recorded in chondrules in Acfer 094 carbonaceous chondrite. Geochimica Et Cosmochimica Acta 76, 242-263.

Ushikubo, T., Nagashima, D., Kimura, M., Tenner, T. J., and Kita, N. T. (2013). Contemporary formation of chondrules in distinct oxygen isotope reservoirs. Geochimica Et Cosmochimica Acta 109, 280-295.

Villeneuve, J., Chaussidon, M. and Libourel, G. (2009). Homogeneous Distribution of ${ }^{26} \mathrm{Al}$ in the Solar System from the Mg Isotopic Composition of Chondrules, Science 325, 985988.

Villeneuve, J., Chaussidon, M. and Libourel, G. (2011). Magnesium isotopes constraints on the origin of Mg-rich olivines from the Allende chondrite: Nebular versus planetary? Earth and Planetary Science Letters 301, 107-116.

Villeneuve, J., Chaussidon, M. and Libourel, G. (2012). Lack of relationship between ${ }^{26} \mathrm{Al}$ ages of chondrules and their mineralogical and chemical compositions. Comptes rendus Geoscience 344, 423-431.

Visscher, C. and Fegley, B. (2013). Chemistry of impact-generated silicate melt-vapor debris disks. The Astrophysical Journal 767, L12.

Wasson, J. T., and Rubin, A. E. (2003). Ubiquitous low-FeO relict grains in type II chondrules and limited overgrowths on phenocrysts following the final melting event. Geochimica Et Cosmochimica Acta 67, 2239-2250.

Wadhwa, M., Amelin, Y., Davis, A. M., Lugmair, G. W., Meyer, B., Gounelle, M., Desch, S. J. (2007). From dust to planetesimals : Implications for the solar protoplanetary disk from short-lived radionuclides. In Protostars and Planets $V$, University of Arizona Press, pp. 835-848. 
Welsch, B., Faure, F., Famin, V., Baronnet, A., and Bachèlery, P. (2013). Dentritic crystallization: A single process for all the textures of olivine in basalts? Journal of Petrology, 54(3), 539-574.

Wick M. J., and Jones, R. H. (2012). Formation conditions of plagioclase-bearing type I chondrules in $\mathrm{CO}$ chondrites: A study of natural samples and experimental analogs. Geochimica Et Cosmochimica Acta 76, 140-159.

Wood, J. A. (1996). Unresolved issues in the formation of chondrules and chondrites. In International conference: Chondrules and the protoplanetary disk (eds. R. H. Hewins, R. H. Jones, and E. R. D. Scott). Cambridge University Press. pp 55-70.

Yu, Y. and Hewins, R. H. (1998). Transient heating and chondrule formation: Evidence from sodium loss in flash heating simulation experiments. Geochimica Et Cosmochimica Acta 62, 159-172.

Yu, Y., Hewins, R. H., Alexander, C. M. O. D., and Wang, J. (2003). Experimental study of evaporation and isotopic mass fractionation of potassium in silicate melts. Geochimica Et Cosmochimica Acta 67, 773-786.

Yurimoto, H., and Wasson, J. T. (2002). Extremely rapid cooling of a carbonaceous-chondrite chondrule containing very O-16-rich olivine and a Mg-26-excess, Geochimica Et Cosmochimica Acta 66, 4355-4363.

Zanda, B. (2004). Chondrules. Earth and Planetary Science Letters 224, 1-17.

Zanda, B., Bourot-Denise, M., Perron, C., and Hewins, R. H. (1994). Origin and metamorphic redistribution of silicon, chromium, and chromium, and phosphorus in the metal of chondrites. Science 265, 1846-1849. 


\section{FIGURE CAPTIONS}

Fig. 1: $\mathrm{CaO}$ concentrations in olivines versus the Fo content $[\mathrm{Mg} /(\mathrm{Mg}+\mathrm{Fe})$ in atomic \%] for porphyritic chondrules from Semarkona LL3.0 chondrite. The vertical dashed line indicates the theoretical limit between type I chondrules and type II chondrules. Data are from Libourel (1989), Jones and Scott (1989), Jones (1990, 1994 and 1996) and personal data.

Fig. 2: Fe abundances (in wt\%) estimated in porphyritic type I $(n=26)$ and type II $(n=42)$ chondrules from Semarkona and Bishunpur ordinary chondrites (Jones and Scott, 1989; Jones, 1990, Jones, 1994, Jones, 1996; Tachibana et al., 2003; and personal data).

Fig. 3: $\log \mathrm{fO}_{2}$ versus temperature for terrestrial air, NNO buffer, IW buffer and the canonical nebula (Allende Prieto et al., 2002). The grey field shows possible type IA chondrules redox conditions (Grosmann et al. 2008). Black stars indicate the selected conditions for this set of experiments. Area delimited by the question marks corresponds to the putative redox conditions inferred in this study for the formation of type IIA chondrules (see § 4.2.2).

Fig. 4: Schematic figure of the vertical furnace and of the alumina rods used in the experiments.

Fig. 5: Starting material composition from the series A (black diamond) and the series B (black circles) in a $\mathrm{SiO}_{2}-\mathrm{MgO}+\mathrm{FeO}-\mathrm{Al}_{2} \mathrm{O}_{3}+\mathrm{CaO}$ ternary diagram. Compositions of type IA chondrules (open squares) and type IIA chondrules (open triangles) from Semarkona are also shown (Jones and Scott, 1989, Jones, 1990). 
Fig. 6: Flow sheet diagram outlining the experimental procedure (see also Table 1).

Fig. 7: Representative BSE images of details of experimental samples from the series A heated at $1450^{\circ} \mathrm{C}$ and IW+1 after $15 \mathrm{~min}, 480 \mathrm{~min}$ and $1320 \mathrm{~min}$. The abundance of relict magnesian olivines decreases from the left to the right. FO = ferroan olivines (formed by crystallization and $\mathrm{FeO}$ diffusion), $\mathrm{FO}^{*}=$ dendritic ferroan olivines, rel. = relict magnesian olivines and mes. = mesostasis.

Fig. 8: Size distribution of olivine grains as a function of the heating duration at $1500^{\circ} \mathrm{C}$ and $\mathrm{IW}+1, \mathrm{a}$ ) in samples from the series $\mathrm{A}$ and $\mathrm{b}$ ) in samples from $\mathrm{C3}^{\prime}$ (see text for details).

Fig. 9: Representative BSE images of details of experimental samples from the series B ran at $1500^{\circ} \mathrm{C}$ at NNO buffer, after $15 \mathrm{~min}, 90 \mathrm{~min}$ and $180 \mathrm{~min}$ for $\mathrm{CO}, \mathrm{C} 2$ and $\mathrm{C} 4$. FO = ferroan olivines (formed by crystallization and FeO diffusion), FO* = dendritic ferroan olivines, rel. = relict magnesian olivines, $\mathrm{sp} .=$ ferroan spinels and mes. $=$ mesostasis .

Fig. 10: Representative BSE images of details of experimental samples from the series B run at $1500^{\circ} \mathrm{C}$ and IW+1 after $1 \mathrm{~min} 30$ (15 min for C3'), $360 \mathrm{~min}$ and $1440 \mathrm{~min}$ for C0, C2, C4 and C3'. Except for CO, the modal abundance of relict magnesian olivines clearly decreases from the left to the right. FO = ferroan olivines (formed by overgrowth and FeO diffusion), FO* = dendritic ferroan olivines, rel. = relict magnesian olivines and mes. = mesostasis. 
Fig. 11: Modal abundances of relict magnesian olivines (Mg\# $>0.9$ ) remaining compared with the total amount of olivine versus the duration of heating in samples from series $A$ and $B$ (Table 2). Modal abundances correspond to areas of relict olivine and total olivine determined from grayscale processing on BSE images calibrated with EPMA analyses, by using the Image $J^{\odot}$ software. For each sample, \% relics remaining $=($ area of relics $/$ area of olivine) $\times 100$.

Fig. 12: a) Mesostasis composition $\left(\mathrm{SiO}_{2}, \mathrm{MgO}, \mathrm{Al}_{2} \mathrm{O}_{3}\right.$ and $\mathrm{CaO}$ in wt\%) as function of duration of heating for series $\mathrm{A}$ and $\mathrm{b}$ ) $\mathrm{FeO}$ (in wt \%) profile in olivines for samples from the series $\mathrm{A}$. Data for the mesostasis are recalculated from measured compositions (Table 3 ) without the $\mathrm{FeO}$ and renormalized to $100 \%$. Profiles shown in b) are average values of ten measured profiles for each sample. Dashed vertical line marks the interface between ferroan olivine overgrowths and forsteritic relict prior to the inward Fe-Mg diffusion in the relict.

Fig. 13: Mesostasis composition as function of duration of heating for series B: a) FeO wt\%, b) $\mathrm{MgO}$ wt\% and c) $\mathrm{CaO}$ wt\%.

Fig. 14: BSE image of an olivine showing an epitaxial ferroan olivine overgrowth on forsteritic relict from a run at $\mathrm{IW}+1$ with $\mathrm{C} 4$ starting material and a duration of $24 \mathrm{~h}$, and the corresponding FeO (wt\%) profile.

Fig. 15: $\mathrm{CaO}, \mathrm{Al}_{2} \mathrm{O}_{3}$ and $\mathrm{FeO}$ profile composition in olivines from the series $\mathrm{B}$. $\mathrm{a}-\mathrm{b}-\mathrm{c}$ ) are from C2, d-e-f) from C4 and g-h-i) from C3'. Profiles shown are average values of five measured 
profiles for each sample. Dashed vertical lines mark the interface between ferroan olivine overgrowths and the forsteritic relict prior to the inward Fe-Mg diffusion in the relict.

Fig. 16: a) Parameter to indicate the track toward equilibration with time which is a ratio of $\mathrm{FeO}$ and $\mathrm{MgO}$ between bulk olivine and mesostasis (PTE) versus the heating duration in experimental samples. PTE values were calculated from data in Table 3. The dashed line and the dark grey area corresponds to the $K_{D}$ at equilibrium $(0.3 \pm 0.03)$ proposed by Roeder and Emslie (1970). b) Partitioning coefficient of Fe-Mg between olivine rims and bulk mesostasis $\left(\mathrm{K}_{\mathrm{D}}=\mathrm{KD}_{\mathrm{ol-liq}}^{\mathrm{Fe}-\mathrm{Mg}}\right)$ versus the heating duration in experimental samples. Olivine rims approach thus near equilibrium $K_{D}$ values in all the runs at shorter durations between 200 and 400 minutes. The lighter grey field show the field encompassed by $K_{D}$ values form natural volcanic rocks; the lower $K_{D}$ limit is also indicated.

Fig. 17: a) Thickness of ferroan olivine overgrowths and b) distance of Fe-Mg interdiffusion in forsteritic relict as a function of the square root of the heating duration at $1500^{\circ} \mathrm{C}$. One sigma error bars are shown only for C4 series as indicative of the heterogeneity of the data. In a) straight solid lines are regressions through each series from C1 to C4 while the dotted line illustrates the slowering of ferroan olivine crystallization with time for $\mathrm{C3}^{\prime}$. In b), straight solid lines are diffusion coefficients: $D_{\min }=0.0127 \mu \mathrm{m}^{2} / \mathrm{s}, D_{\max }=0.0444 \mu \mathrm{m}^{2} / \mathrm{s}$ and $D_{a v}=$ $0.0338 \mu \mathrm{m}^{2} / \mathrm{s}$ (see captions of Tables 2 and 3 for details). The light grey field and the darker grey field show the range of distances of interdiffusion for $\mathrm{D}^{\mathrm{Fe}-\mathrm{Mg}}$ calculated at $1500^{\circ} \mathrm{C}$ and $\mathrm{fO}_{2}=10^{-8}$ respectively from data from Jurewicz and Watson (1988) and data from Tachibana et al. (2013). 
Fig. 18: Cartoon of the formation ferroan olivine at the expense of magnesian olivine during heating process under oxidizing conditions of type IA chondrules or fragments. Detailed explanations are given in the text

Fig. 19: BSE of a) type IA chondrule from Semarkona (LL3.0), b) type IIA chondrule from Isheyevo (CB3), c) type IIA chondrule from Yamato 81020 (СО3) and d) type IIA chondrule from Semarkona (LL3.0). Mes. = mesostasis, met. = Fe, Ni-metal, rel. = relict magnesian olivine, $\mathrm{Fo}=$ magnesian olivine and $\mathrm{Fa}=$ ferroan olivine. The amount of magnesian olivines decreases from type IA (a) to type IIA (d) chondrules.

Fig. 20: BSE image, phosphorus (P), calcium (Ca), aluminium (Al), iron (Fe), chromium ( $\mathrm{Cr}$ ) and cobalt (Co) X-ray Koelemental intensity maps of a relict forsterite grain $\left(\mathrm{Fa}_{<1}\right)$ surrounded by a more fayalitic overgrowth within a type IIA chondrule of Semarkona LL 3.0 ordinary chondrite.

Fig. 21: Distances of Fe-Mg interdiffusion in the olivine as function of the heating duration at different temperatures using equations (6) and (7) and data extrapolated from data obtained at $1500^{\circ} \mathrm{C}$ by Tachibana et al. (2013). The survival of magnesian olivines of $\approx 50 \mu \mathrm{m}$ diameter to a sub-isothermal oxidation event in the range of $\approx 1800-1500^{\circ} \mathrm{C}$ would not exceed a few tens of minutes, i.e. $\approx 10-20 \mathrm{~min}$, to a few hours, i.e. $\approx 5 \mathrm{~h}$ (dotted arrows).

Fig. 22: Thermal history model for the formation type A chondrules as a function of the heating duration in an oxidizing environment. We inferred that type A chondrules, after periods of heating as short as a few tens of minutes and no longer than a few hours between 
$\approx 1500-1800^{\circ} \mathrm{C}$, terminates their formation by a very fast cooling ( $s>10^{4} \mathrm{~K} / \mathrm{h}$ at $\mathrm{Tg}$ ) in order to prevent further crystallization of their mesostasis. Interruption of this process at anytime before its achievement by rapid cooling allows to reproduce for a given range of duration of heating (and according to the modal abundance of Fe-Ni metal in type I fragments and/or the amount of Fe condensation in the mesostasis from the gas phase) the whole range of textures and chemical diversity observed in type $A$ chondrules, i.e., from Type I to Type IIA-like textures with various amount of preserved relict grains. Tm: partial melting temperature, Tg: glass transition temperature. (See text for further discussion). Schematic comparison with shock wave thermal history (e.g., Desch and Connolly, 2002; Morris and Desch, 2010) is provided in the inset; a: shock wave model, b: impact planetesimal vapor plume model. Main differences in the two scenarios rest with the duration of heating and the cooling rate at the glass transition temperature. $\mathrm{Tg}$ is set at 1000 $\mathrm{K}$ as a representative value. 


\section{Table captions}

Table 1: Phases abundances and chemical compositions of the starting materials for our experiments.

\section{Table 1}

\begin{tabular}{|c|c|c|c|c|c|c|c|c|c|c|}
\hline \multicolumn{4}{|l|}{ Sample } & \multicolumn{7}{|c|}{ Chemical composition (wt\%) } \\
\hline & & & & component & MgO & $\mathrm{CaO}$ & $\mathrm{Al}_{2} \mathrm{O}_{3}$ & $\mathrm{SiO}_{2}$ & $\mathrm{FeO}$ & Total \\
\hline $\mathbf{G}_{\mathrm{A}}$ & & & & & 39.25 & 3.12 & 4.63 & 53.02 & - & 100.02 \\
\hline \multirow[t]{2}{*}{$\mathbf{G}_{\mathrm{B}}$} & & & & & 6.44 & 24.09 & 29.65 & 39.77 & - & 99.95 \\
\hline & & hase & s (\%) & & & & & & & \\
\hline \multirow[t]{2}{*}{ Series A } & Fo & & Glass & & & & & & & \\
\hline & & & & Glass* & 27.64 & 5.58 & 6.94 & 59.81 & & 99.97 \\
\hline \multirow[t]{2}{*}{$\mathrm{G}_{\mathrm{A}}$ cryst. } & \multicolumn{2}{|c|}{$\sim 40$} & $\sim 60$ & Fo* & 57.23 & 0.04 & 0.06 & 42.73 & - & 100.06 \\
\hline & & & & Bulk $^{\ddagger}$ & 39.48 & 3.36 & 4.19 & 52.98 & - & 100.01 \\
\hline Series B & Fo & $\mathrm{G}_{\mathrm{B}}$ & Fe metal & & & & & & & \\
\hline $\mathrm{CO}$ & 75 & 25 & 0 & & 44.61 & 6.00 & 7.40 & 41.99 & 0.00 & 100 \\
\hline $\mathrm{C} 1$ & 70 & 25 & 5 & & 41.15 & 5.92 & 7.29 & 39.29 & 6.35 & 100 \\
\hline $\mathrm{C} 2$ & 65 & 25 & 10 & Bulk $^{\ddagger}$ & 37.79 & 5.84 & 7.19 & 36.67 & 12.52 & 100 \\
\hline C3/C3' & 60 & 25 & 5 & & 34.52 & 5.76 & 7.09 & 34.11 & 18.52 & 100 \\
\hline $\mathrm{C} 4$ & 55 & 25 & & & 31.34 & 5.68 & 6.99 & 31.63 & 24.36 & 100 \\
\hline
\end{tabular}

Fo $=$ forsterite, $\mathrm{G}_{\mathrm{A}}$ cryst. = glass A crystallized. ${ }^{*}$ EPMA analyses. ${ }^{\ddagger}$ Recombination based on EPMA analyses and modal BSE abundances. 
Table 2: Chemical compositions, forsteritic relics abundances, $K_{D} S$, ranges of widths of fayalitic overgrowths and ranges of widths of Fe-Mg interdiffusions for samples from series $\mathrm{A}$ $\left(\mathrm{IW}+1,1450^{\circ} \mathrm{C}\right)$

\begin{tabular}{|c|c|c|c|c|c|c|c|c|c|c|c|}
\hline \multirow{2}{*}{$\begin{array}{l}\text { Duration } \\
\text { (min) }\end{array}$} & \multicolumn{6}{|c|}{ Chemical composition ( \pm 1 s.d., $n=10$ ) } & \multirow{2}{*}{$\begin{array}{c}\text { Relics }^{\ddagger} \\
\left(\%{ }^{8}\right)\end{array}$} & \multirow{2}{*}{ PTE } & \multirow{2}{*}{$\mathrm{K}_{\mathrm{D}}$} & \multirow{2}{*}{$\begin{array}{l}\text { Overgr. }^{*} \\
(\mu \mathrm{m})\end{array}$} & \multirow{2}{*}{$\begin{array}{l}\text { Diff. }^{\ddagger} \\
(\mu \mathrm{m})\end{array}$} \\
\hline & component & $\mathrm{SiO}_{2}$ & MgO & $\mathrm{Al}_{2} \mathrm{O}_{3}$ & $\mathrm{CaO}$ & $\mathrm{FeO}$ & & & & & \\
\hline \multirow{3}{*}{15} & b. mes.* & $30.00 \pm 0.97$ & $13.43 \pm 1.06$ & $4.66 \pm 0.58$ & $3.74 \pm 0.46$ & $46.72 \pm 3.24$ & \multirow{3}{*}{67} & & \multirow{3}{*}{0.22} & \multirow{3}{*}{$3-10$} & \multirow{3}{*}{$5-15$} \\
\hline & b. ol. " & 41 & 49 & - & - & 10 & & 0.06 & & & \\
\hline & r. ol.* & $37.23 \pm 0.42$ & $35.46 \pm 1.52$ & $0.09 \pm 0.01$ & $0.28 \pm 0.02$ & $26.82 \pm 0.8$ & & & & & \\
\hline \multirow{3}{*}{60} & b. mes.* & $31.68 \pm 0.47$ & $12.93 \pm 0.58$ & $4.94 \pm 0.27$ & $3.82 \pm 0.23$ & $43.17 \pm 1.14$ & \multirow{3}{*}{36} & \multirow{3}{*}{0.08} & \multirow{3}{*}{0.22} & \multirow{3}{*}{$10-25$} & \multirow{3}{*}{$15-25$} \\
\hline & b. ol. ${ }^{\#}$ & 41 & 46 & - & - & $13>$ & & & & & \\
\hline & r. ol.* & $37.05 \pm 0.56$ & $36.00 \pm 1.01$ & $0.07 \pm 0.01$ & $0.26 \pm 0.01$ & $26.40 \pm 0.65$ & & & & & \\
\hline \multirow{4}{*}{180} & b. mes.* & $37.96 \pm 0.39$ & $16.34 \pm 1.36$ & $5.64 \pm 0.36$ & $4.41 \pm 0.28$ & $33.17 \pm 0.31$ & \multirow{3}{*}{18} & \multirow{3}{*}{0.20} & \multirow{3}{*}{0.29} & \multirow{3}{*}{$10-35$} & \multirow{3}{*}{$35-45$} \\
\hline & b. ol. ${ }^{\#}$ & 42 & 42 & & & 16 & & & & & \\
\hline & r. ol.* & $37.68 \pm 0.37$ & $38.95 \pm 0.94$ & $0.08 \pm 0.01$ & $0.19 \pm 0.01$ & $23.10 \pm 0.47$ & & & & & \\
\hline & b. mes.* & $35.02 \pm 0.18$ & $14.51 \pm 0.59$ & $5.90 \pm 0.28$ & $4.49 \pm 0.11$ & $37.97 \pm 0.53$ & \multirow{3}{*}{4} & \multirow{3}{*}{0.16} & \multirow{3}{*}{0.24} & \multirow{3}{*}{$60-80$} & \multirow{3}{*}{$45-65$} \\
\hline \multirow[t]{3}{*}{480} & b. ol. " & 43 & & - & - & 17 & & & & & \\
\hline & r. ol.* & $37.10 \pm 0.29$ & $38.65 \pm 1.36$ & $0.08 \pm 0.01$ & $0.25 \pm 0.02$ & $23.82 \pm 0.21$ & & & & & \\
\hline & b. mes.* & $50.36 \pm 0.45$ & $23.07 \pm 0.55$ & $6.40 \pm 0.06$ & $5.13 \pm 0.11$ & $12.22 \pm 0.21$ & \multirow{3}{*}{0} & \multirow{3}{*}{0.30} & \multirow{3}{*}{0.35} & & \\
\hline \multirow[t]{2}{*}{1320} & b. ol. " & 41 & 51 & - & - & 8 & & & & $55-80$ & $70-80$ \\
\hline & r. ol.* & $40.01 \pm 0.33$ & $50.48 \pm 0.84$ & $0.04 \pm 0.00$ & $0.17 \pm 0.02$ & $9.24 \pm 0.24$ & & & & & \\
\hline $\begin{array}{l}\text { b. mes. = b } \\
\text { evolution } \mathrm{t} \\
{ }^{*} \text { EPMA ana } \\
\text { Estimation } \\
\text { each sampl } \\
\text { rich olivine }\end{array}$ & $\begin{array}{l}\text { oulk mesostasi } \\
\text { oward equilib } \\
\text { alyses. }{ }^{+} \text {Recom } \\
\text { of } \mathrm{FeO} \text { and } \mathrm{Mg} \\
\text { le, extremum }\end{array}$ & $\begin{array}{l}\text { is, b. ol. = bulk } \\
\text { ration, } K_{D}=\text { pa } \\
\text { bination based } \\
\text { gO abundances }\end{array}$ & $\begin{array}{l}\text { K olivine, r. ol. } \\
\text { artitioning coef } \\
\text { d on EPMA anal } \\
\text { s from EPMA an } \\
\text { rayscale for olis }\end{array}$ & $\begin{array}{l}=\text { olivine rim } \\
\text { fficient of Fe } \\
\text { lyses and moc } \\
\text { nalyses crosse } \\
\text { ivine were anc } \\
\text { es of Ol.bulk }\end{array}$ & $\begin{array}{l}\mathrm{n} \text {, Overgr. =o } \\
\text { and Mg betw } \\
\text { dal abundanc } \\
\text { ed with graysc } \\
\text { chored with } \mathrm{E}\end{array}$ & $\begin{array}{l}\text { vergrowth, Diff } \\
\text { veen olivine rin } \\
\text { es on BSE imag } \\
\text { cale analyses on } \\
\text { PMA analyses, } \\
\text { ed from the ave }\end{array}$ & 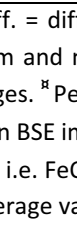 & $\begin{array}{l}\text { usion d } \\
\text { nesosta } \\
\text { rcentag } \\
\text { nages by } \\
\text {-rich ol }\end{array}$ & $\begin{array}{l}\text { stance, } \\
\text { is, } n= \\
\text { of olivi } \\
\text { using In }\end{array}$ & $\begin{array}{l}\mathrm{TE}=\text { para } \\
\text { Imber of } \\
\text { e with } \mathrm{Mg} \\
\text { ge } J^{\circ} \mathrm{Soft} \text {. }\end{array}$ & $\begin{array}{l}\text { neter of } \\
\text { nalyses. } \\
>0.9 \text {. } \\
\text { are. For } \\
\text { d MgO- }\end{array}$ \\
\hline
\end{tabular}


Table 3: Chemical compositions, forsteritic relics abundances, $K_{D} S$, ranges of widths of fayalitic overgrowths, ranges of widths of Fe-Mg interdiffusions and estimation of the iron loss for samples from series B.

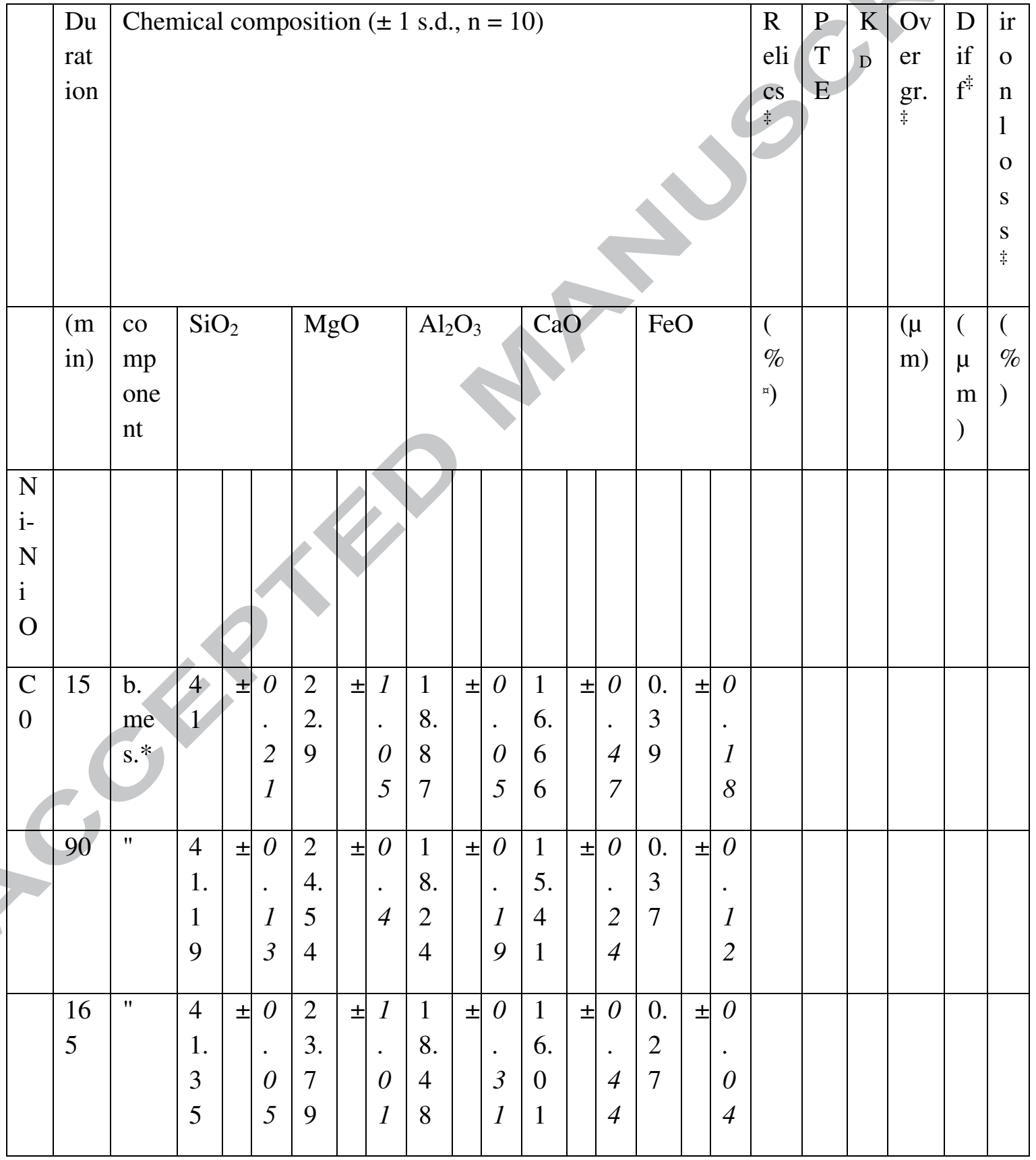




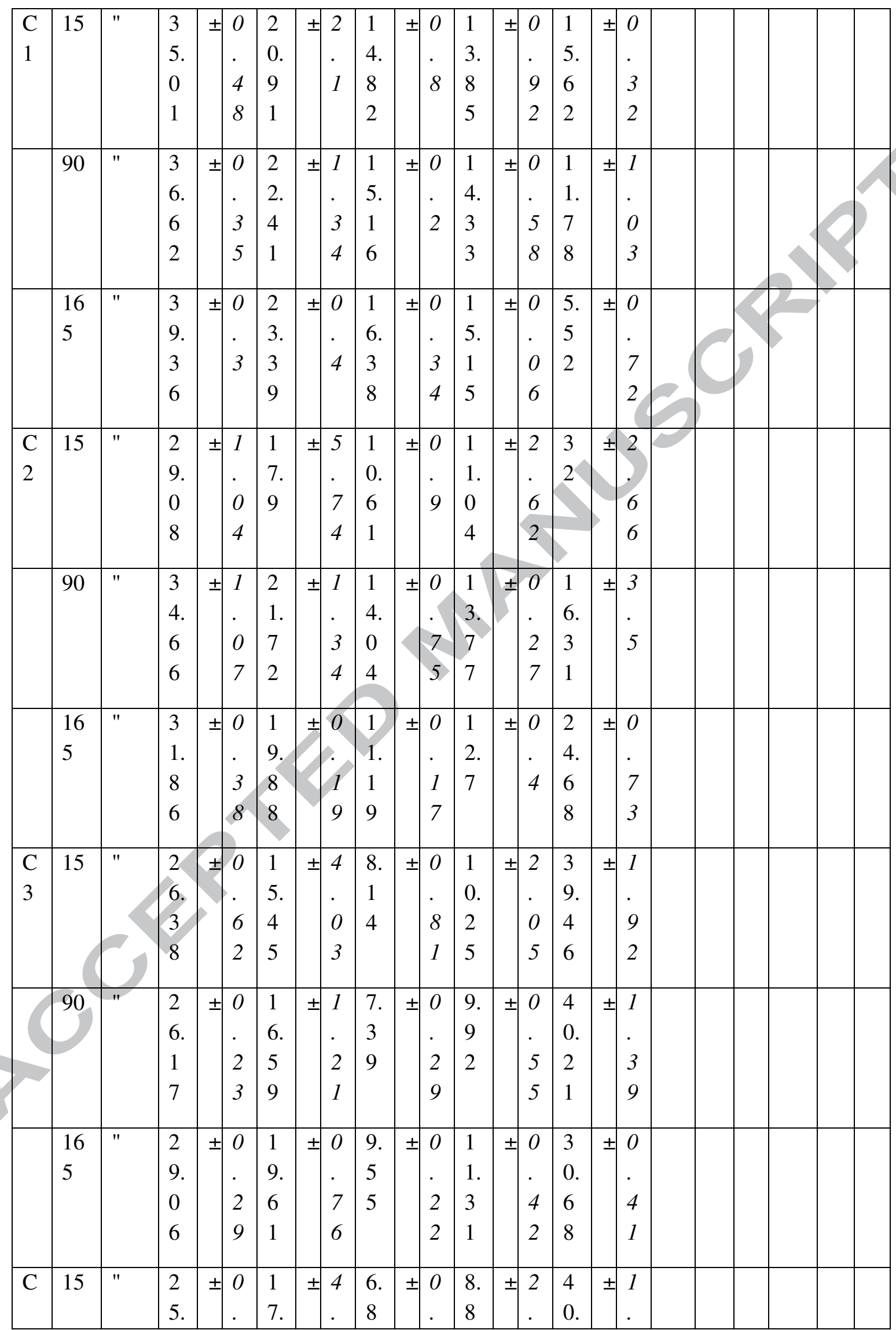




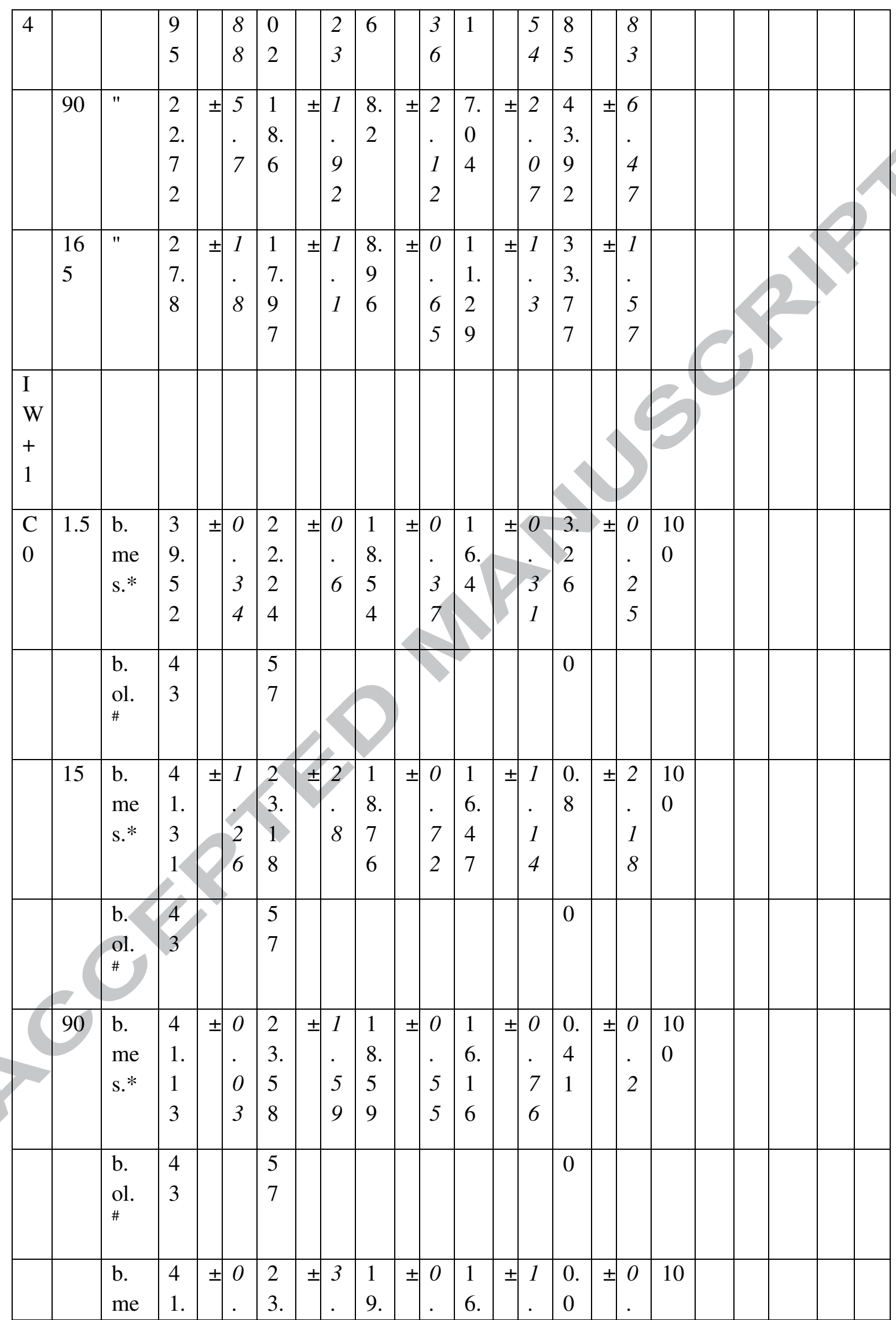




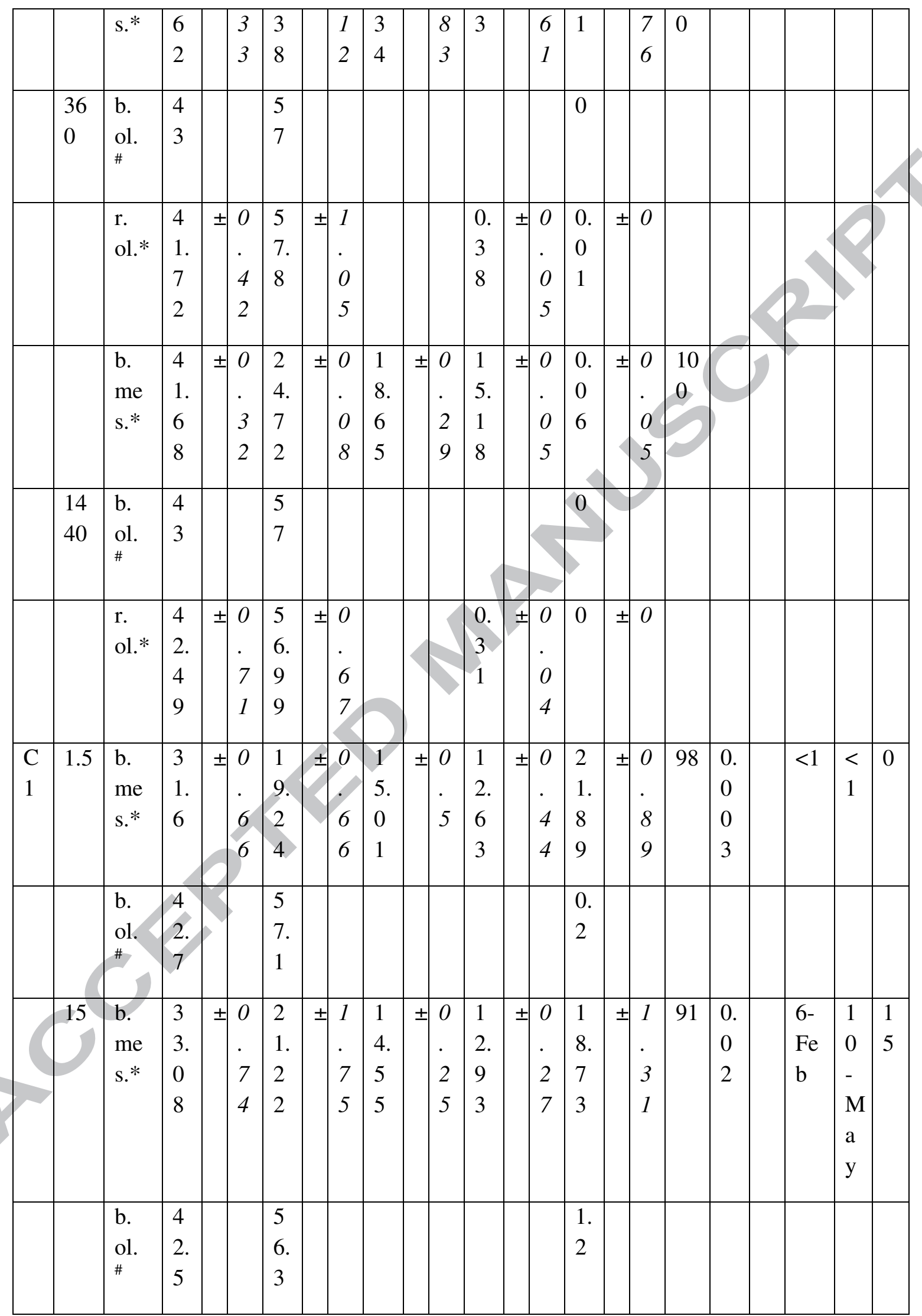




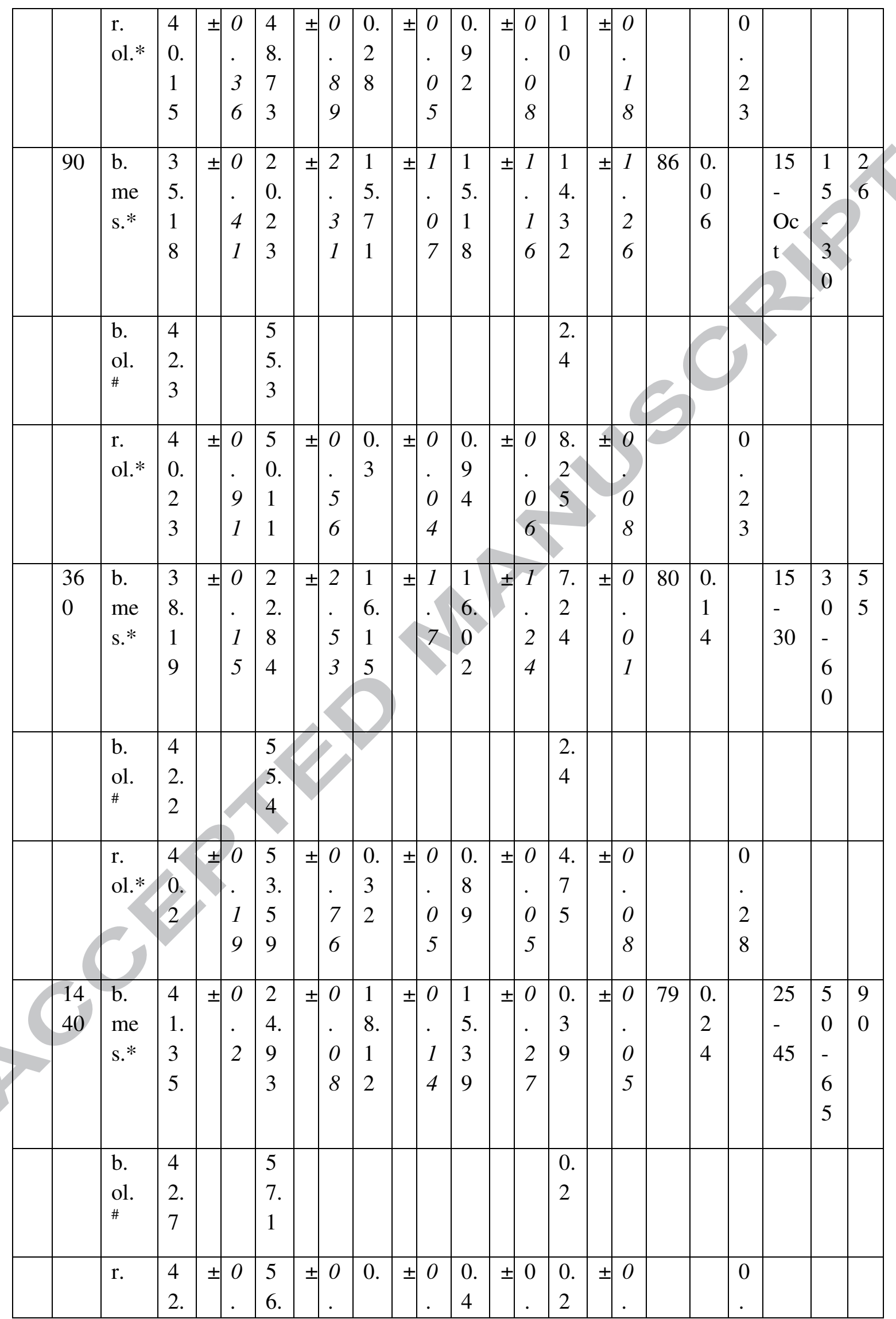




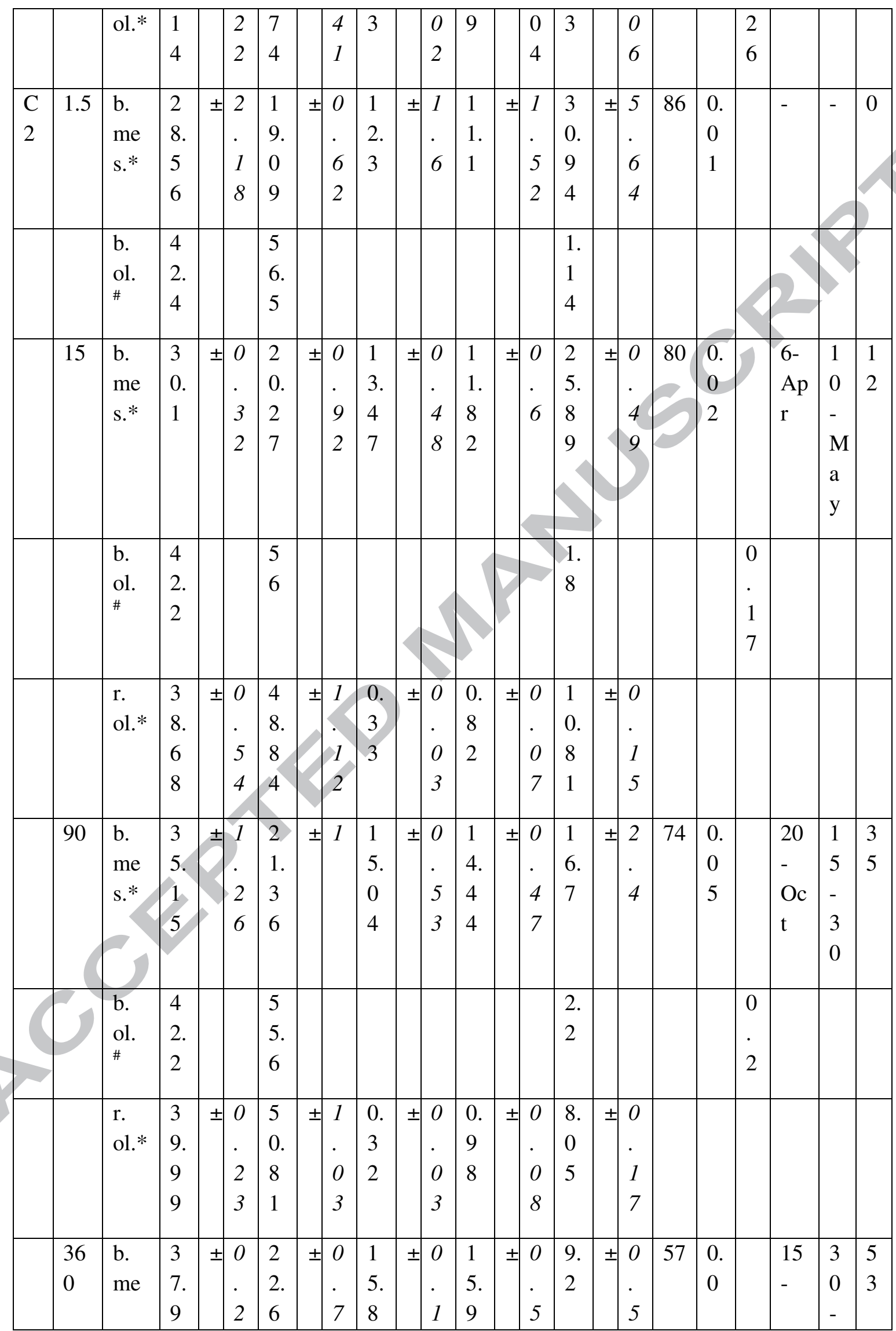




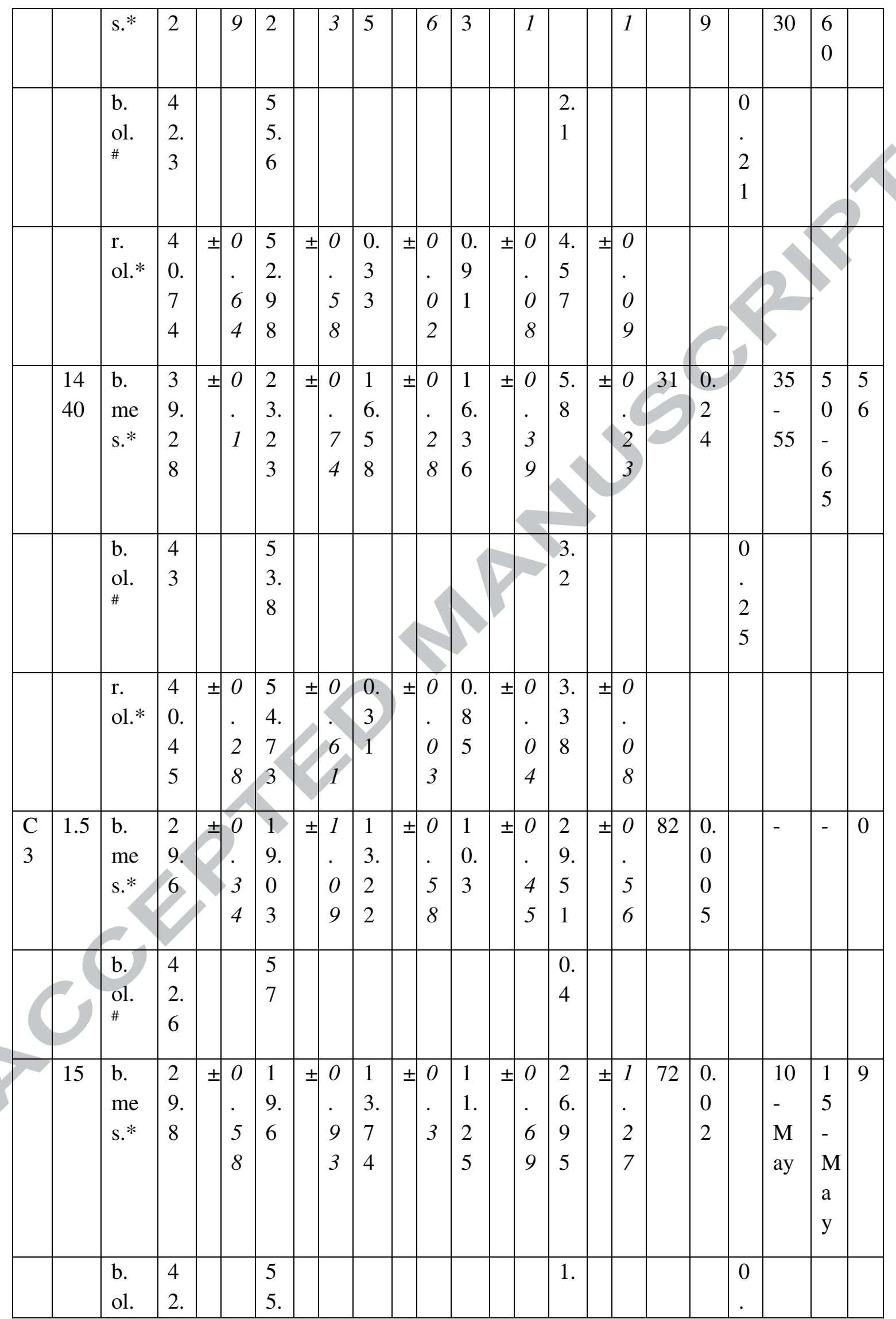




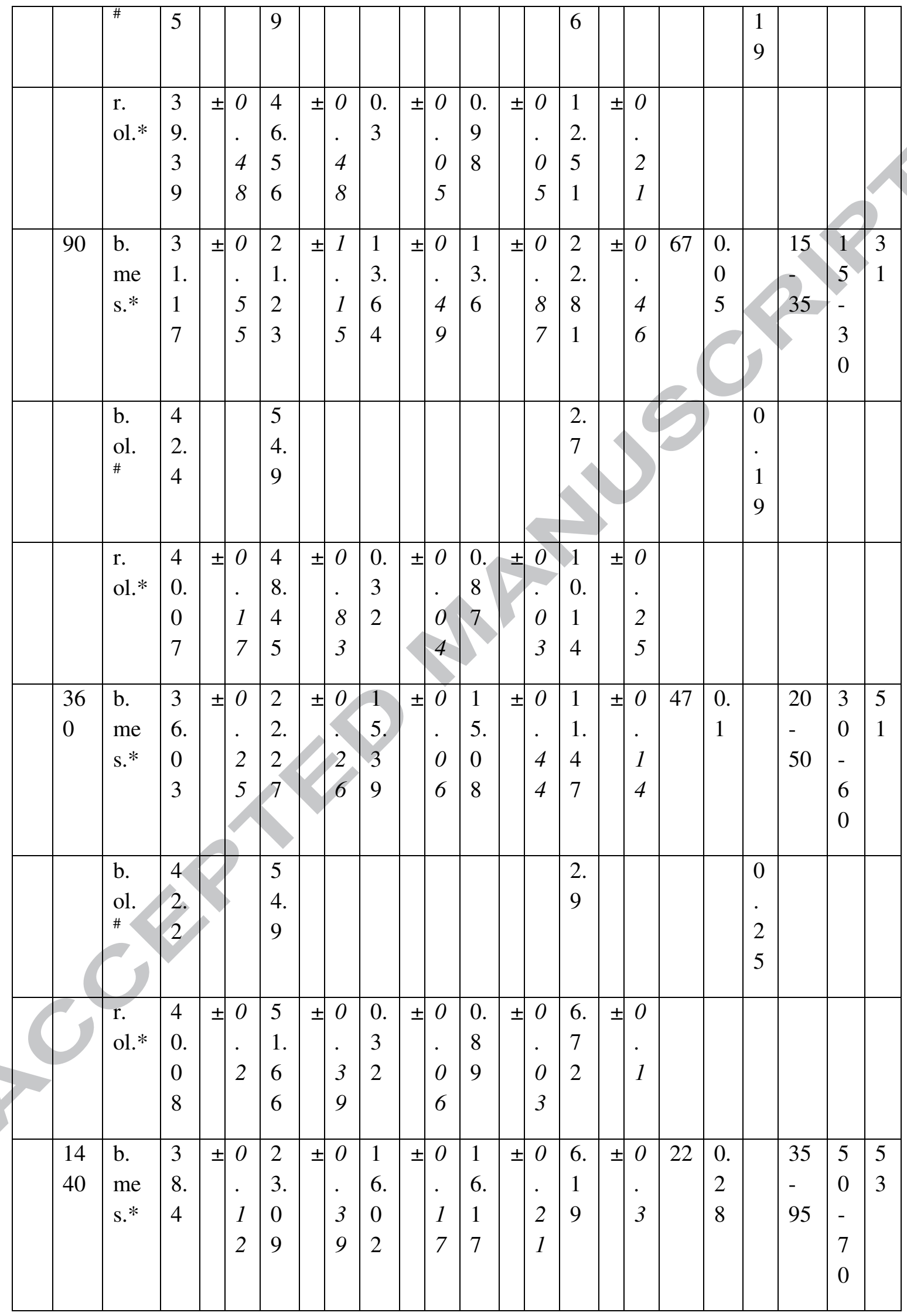




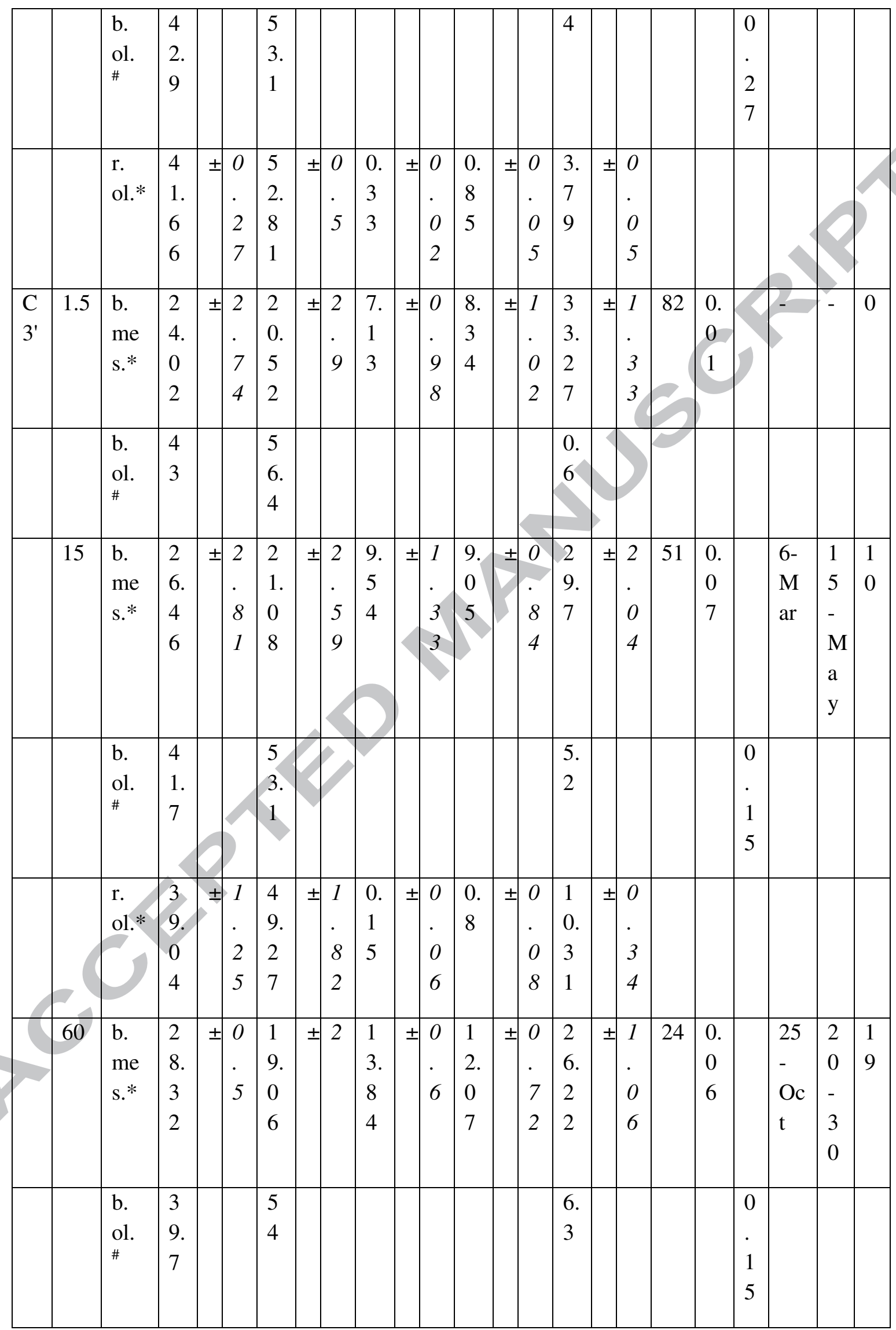




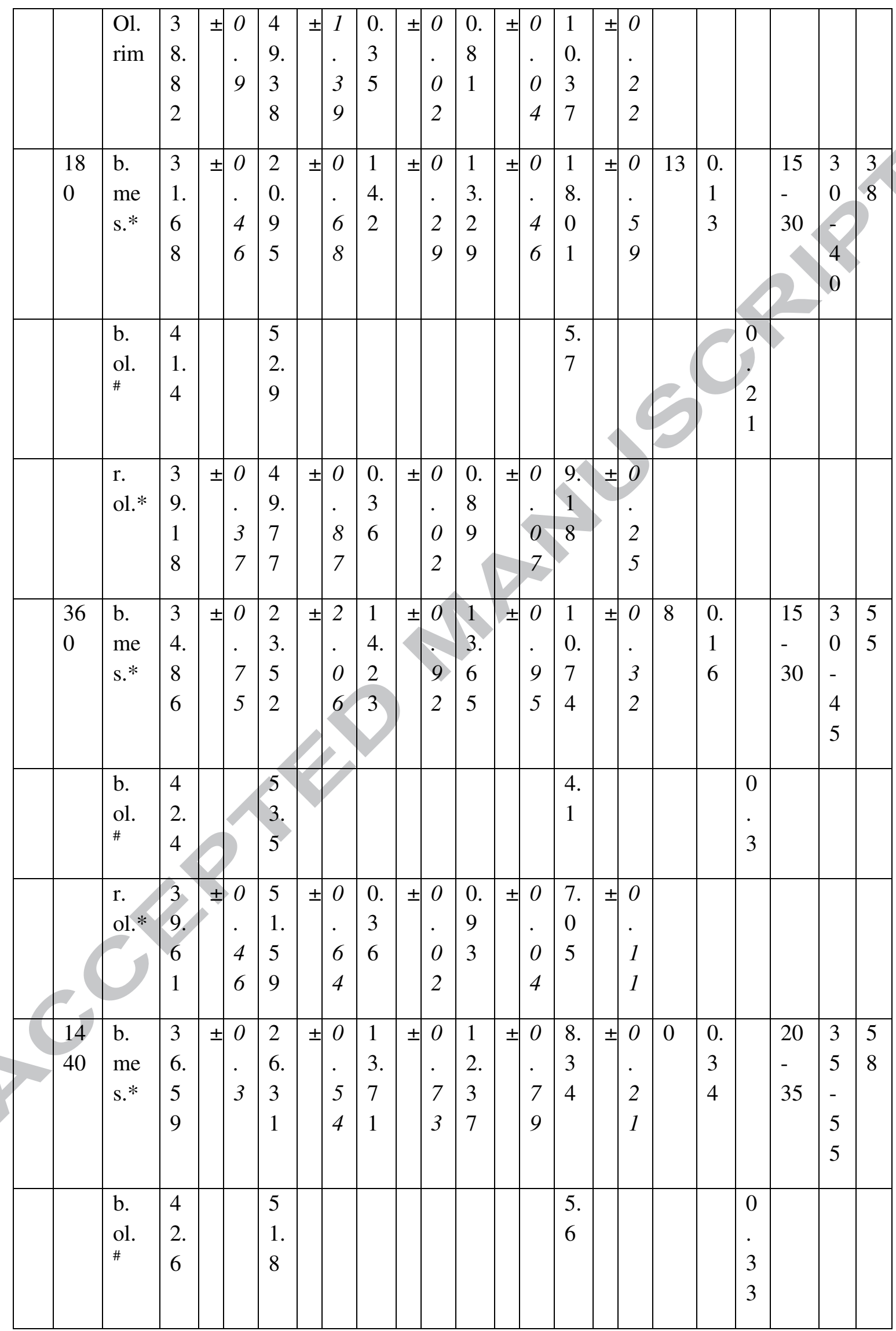




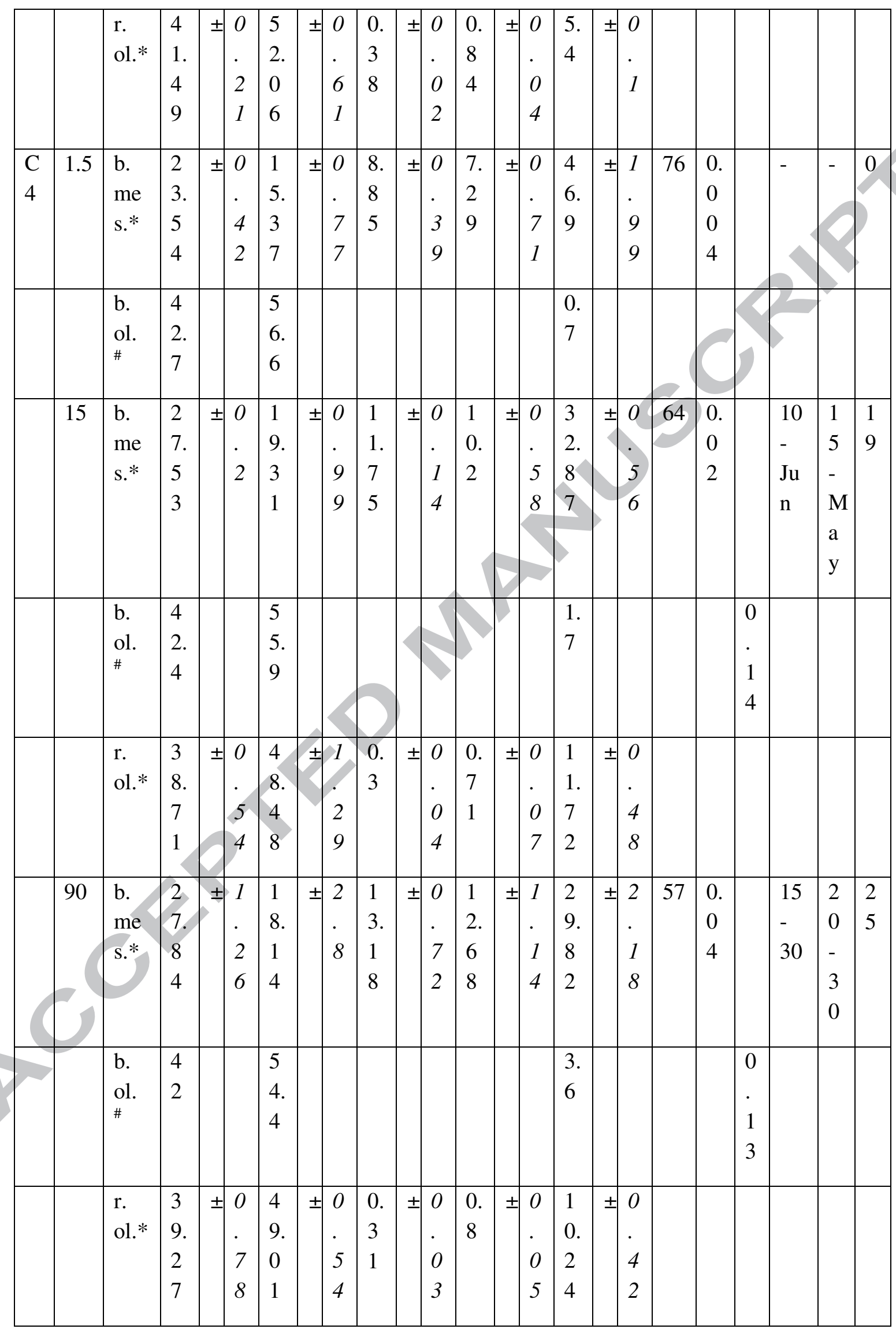




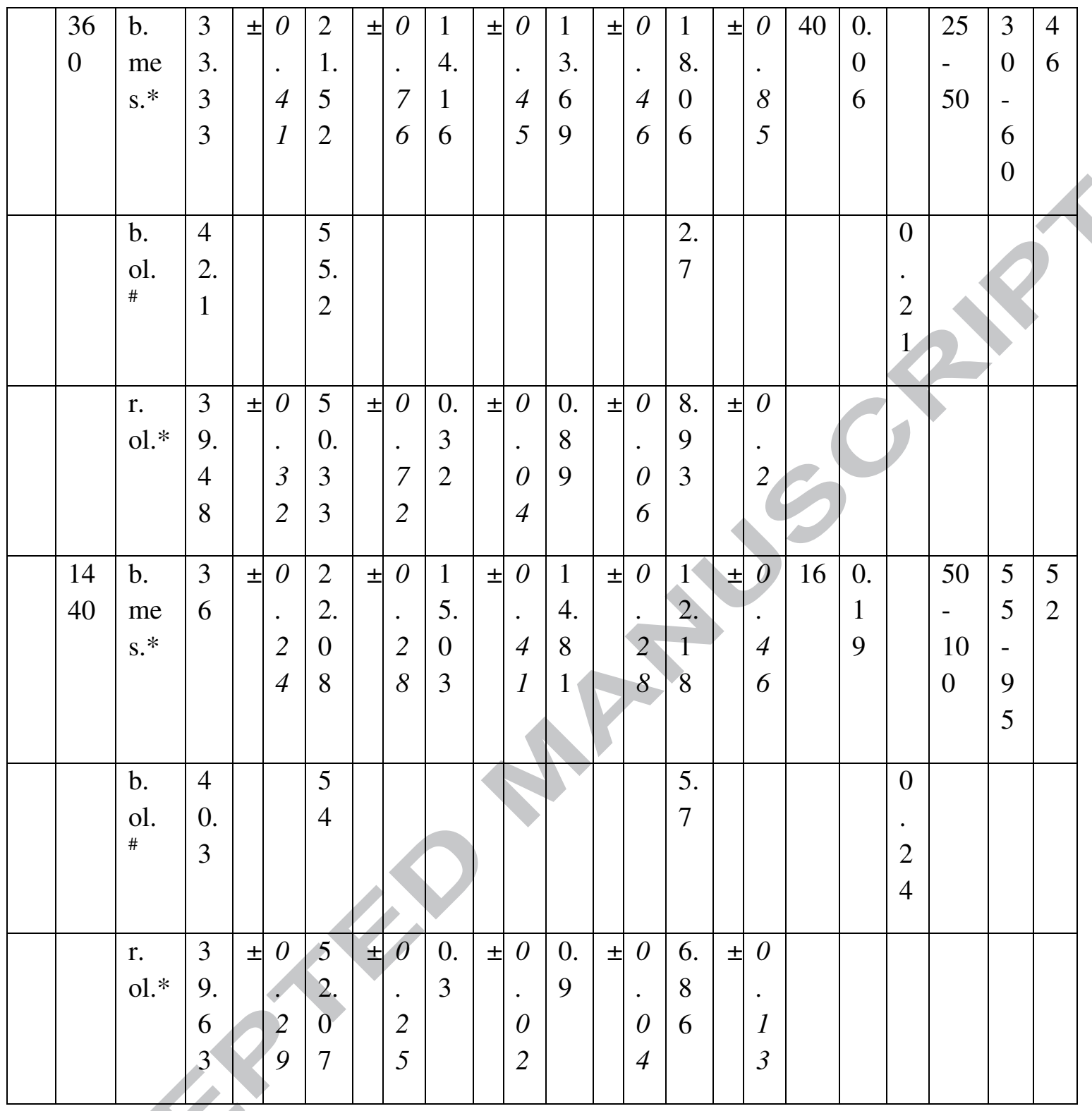

b. mes. = bulk mesostasis, b. ol. = bulk olivine, r. ol. = olivine rim, Overgr. = overgrowth, Diff. = diffusion distance, PTE = parameter of evolution toward equilibration, $\mathrm{K}_{\mathrm{D}}=$ partitioning coefficient of $\mathrm{Fe}$ and $\mathrm{Mg}$ between olivine rim and mesostasis, $\mathrm{n}=$ number of analyses. *EPMA analyses. "Recombination based on EPMA analyses and modal abundances on BSE images. "Percentage of olivine with Mg\# >0.9 \# Estimation of $\mathrm{FeO}$ and $\mathrm{MgO}$ abundances from EPMA analyses crossed with grayscale analyses on BSE images by using Image $\mathrm{J}^{\bullet}$ Software. For each sample, extremum values of the grayscale for olivine were anchored with EPMA analyses, i.e. FeO-rich olivine for light grey and MgOrich olivine for dark grey, and $\mathrm{FeO}$ and $\mathrm{MgO}$ abundances of Ol.bulk were estimated from the average value of the grayscale. 
ACCEPTED MANUSCRIPT

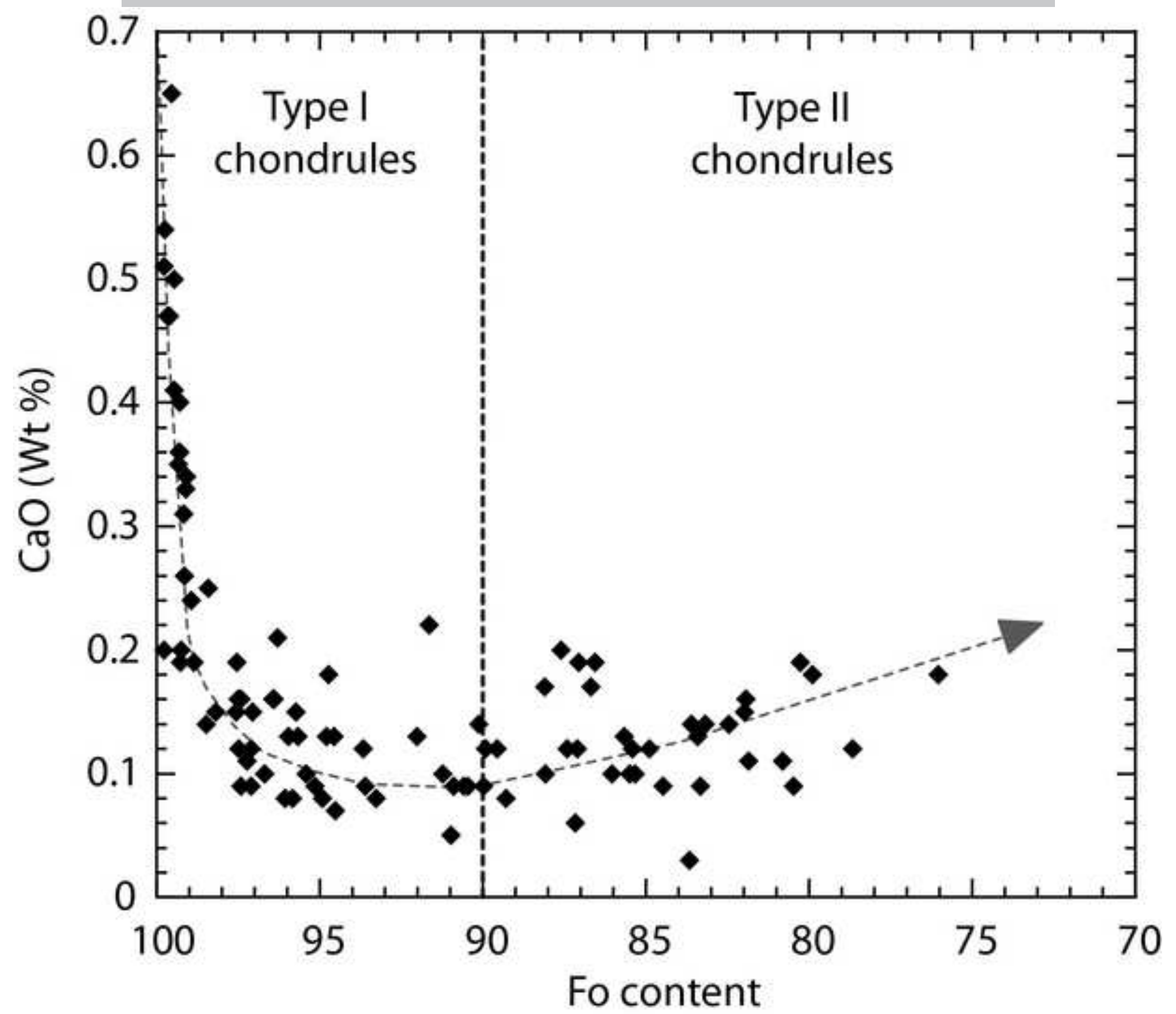




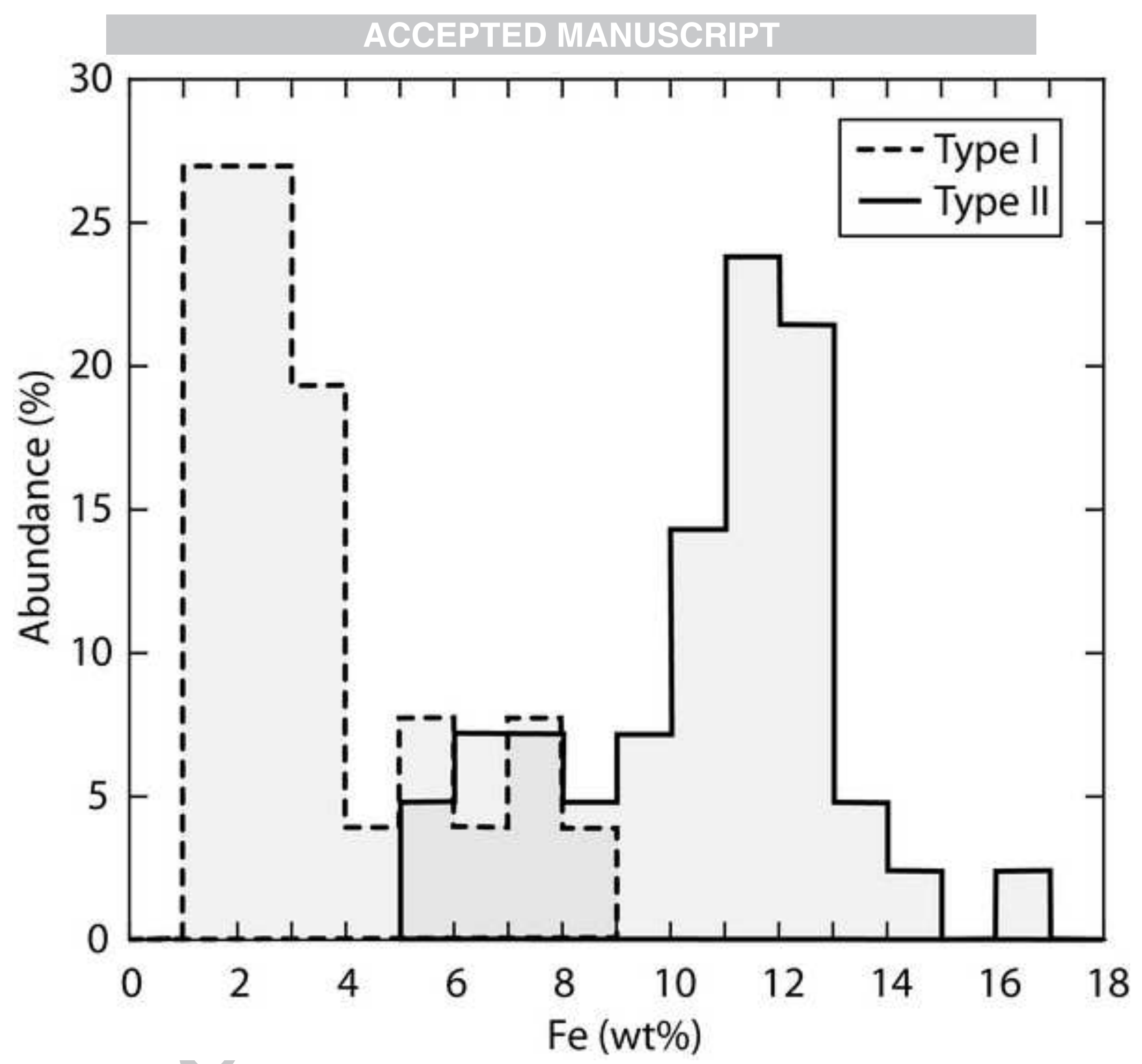




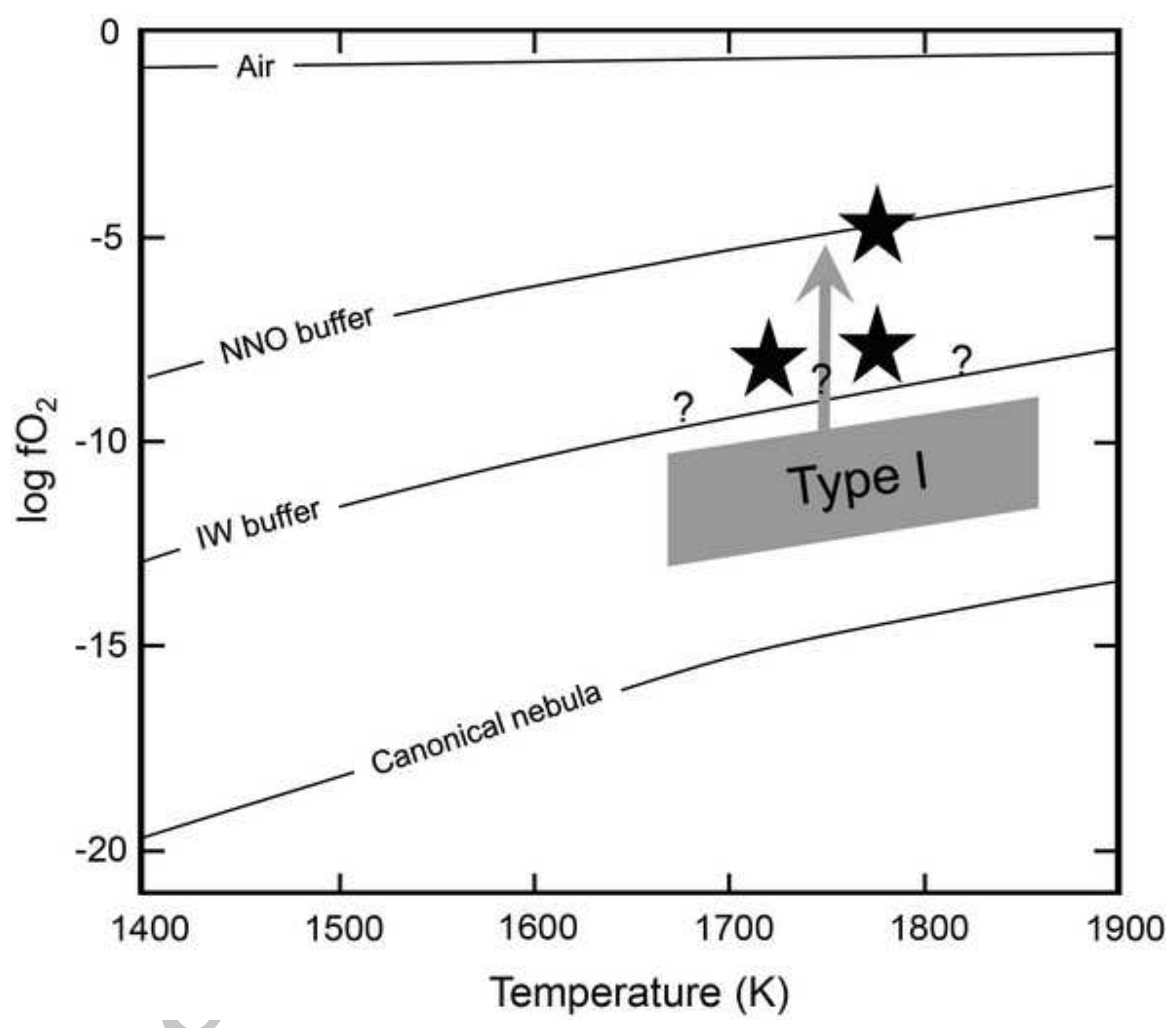




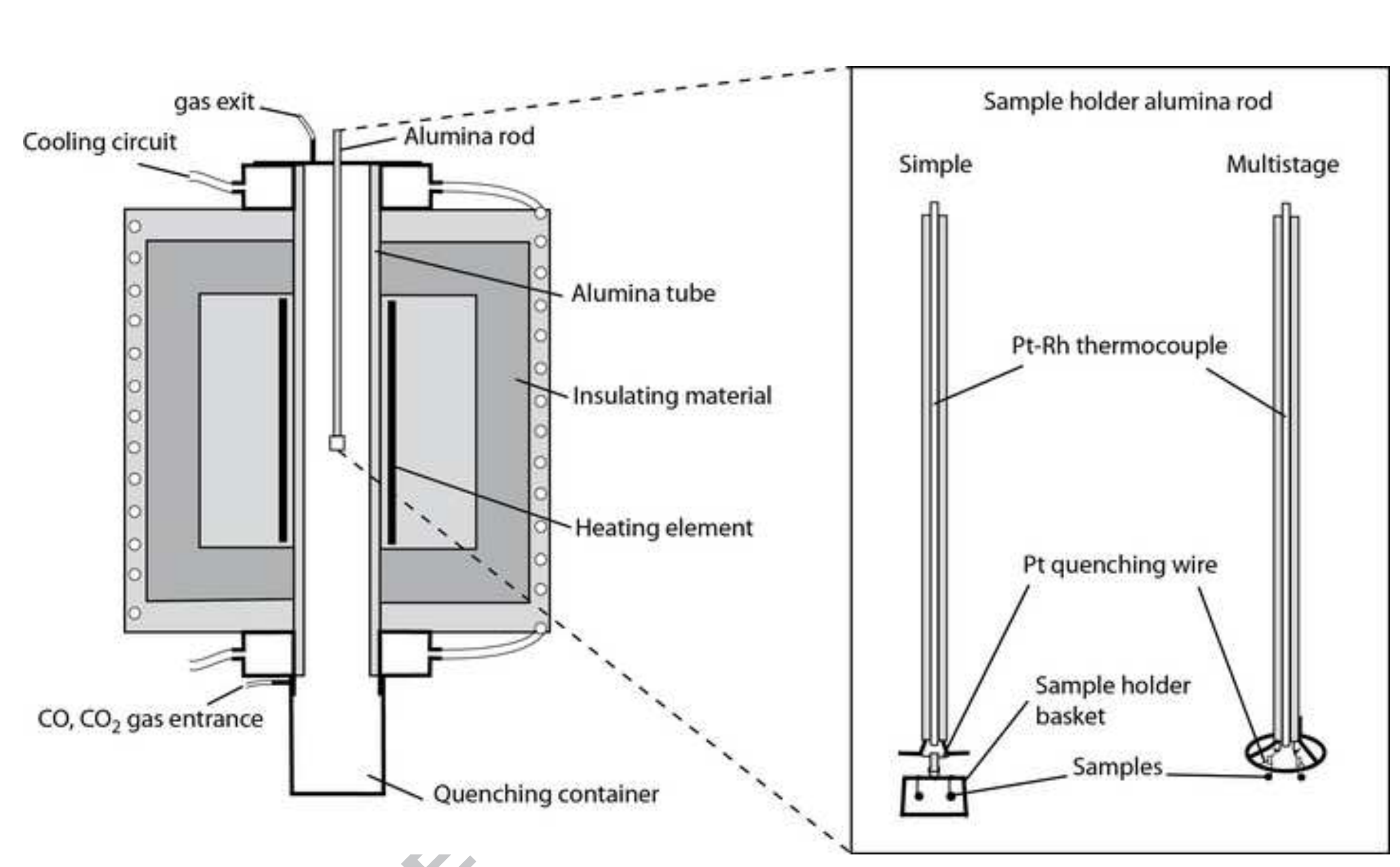

\section{MCCEPTED MANUSCAIPT}




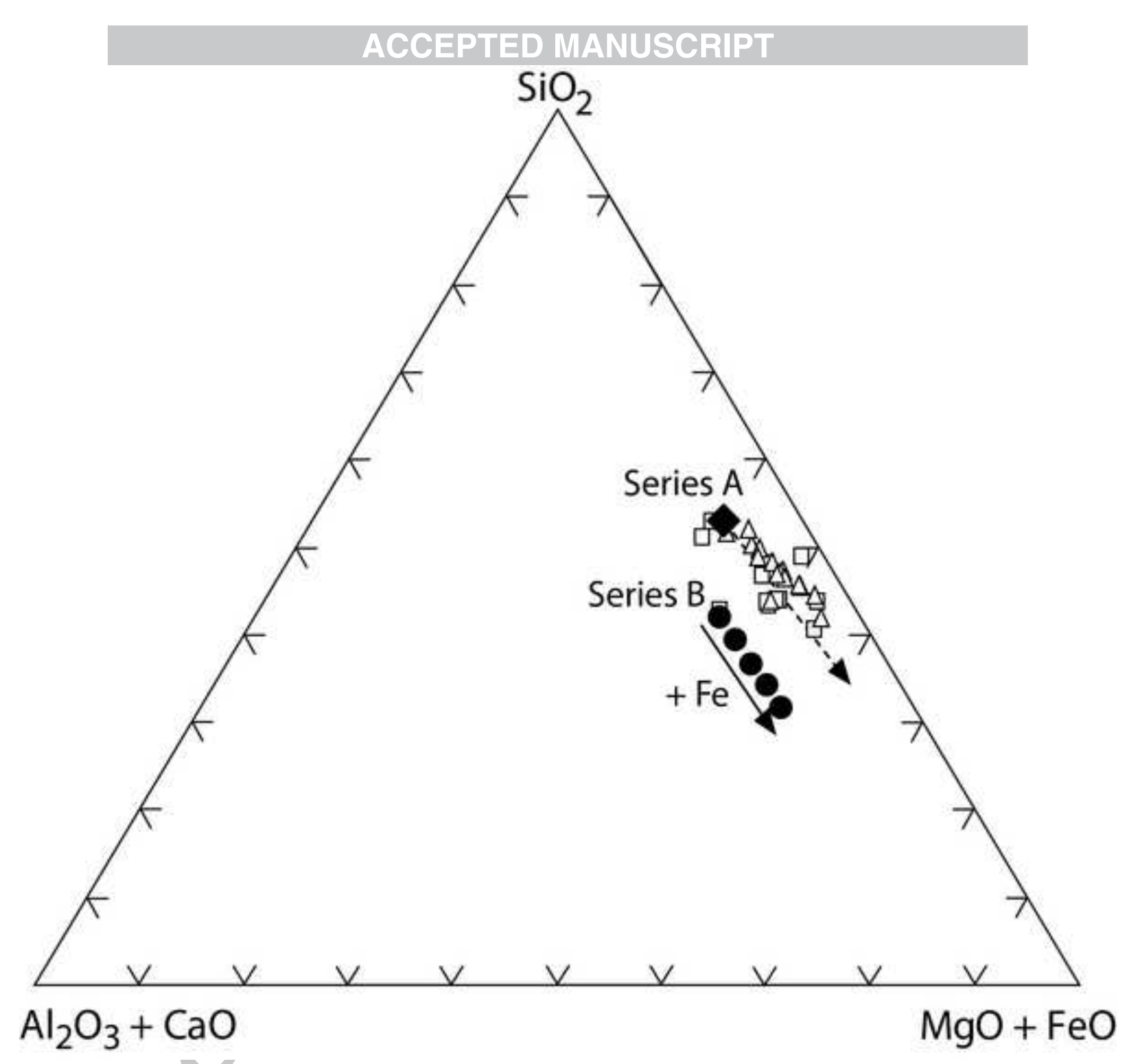


Starting Material

Series A

Forsterite $(\sim 40 w t \%)$
$+G_{A}$ cryst. glass $(\sim 60 w t \%)$
+ Fe metal $(? w t \%)$

Series B

Forsterite (55-75 wt\%)

$+G_{B}$ glass $(25 w t \%)$

+ Fe metal (0-20 wt\%)
Isothermal Oxidation

Quench

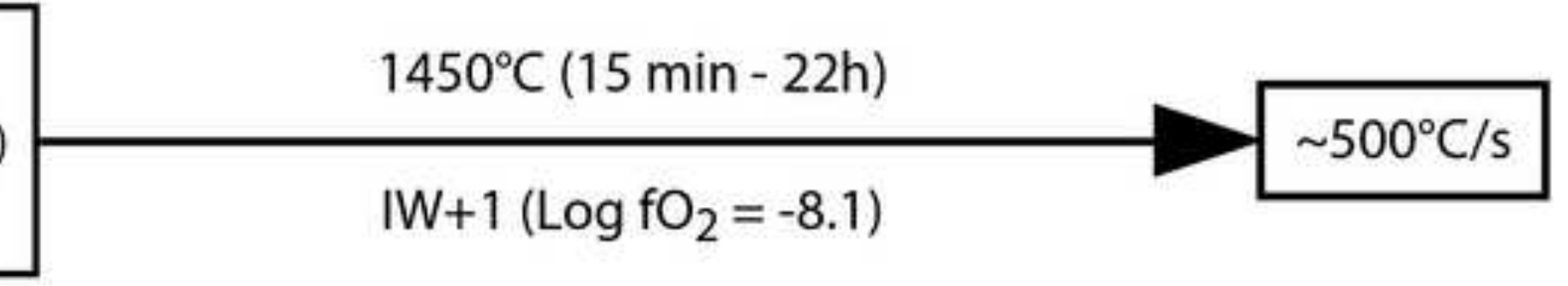

$\frac{1500^{\circ} \mathrm{C}(1 \mathrm{~min} 30-24 \mathrm{~h})}{\mathrm{IW}+1\left(\log \mathrm{fO}_{2}=-7.7\right) ; \mathrm{Ni}-\mathrm{NiO}\left(\log \mathrm{fO}_{2}=-4.7\right)} \sim 500^{\circ} \mathrm{C} / \mathrm{s}$ 

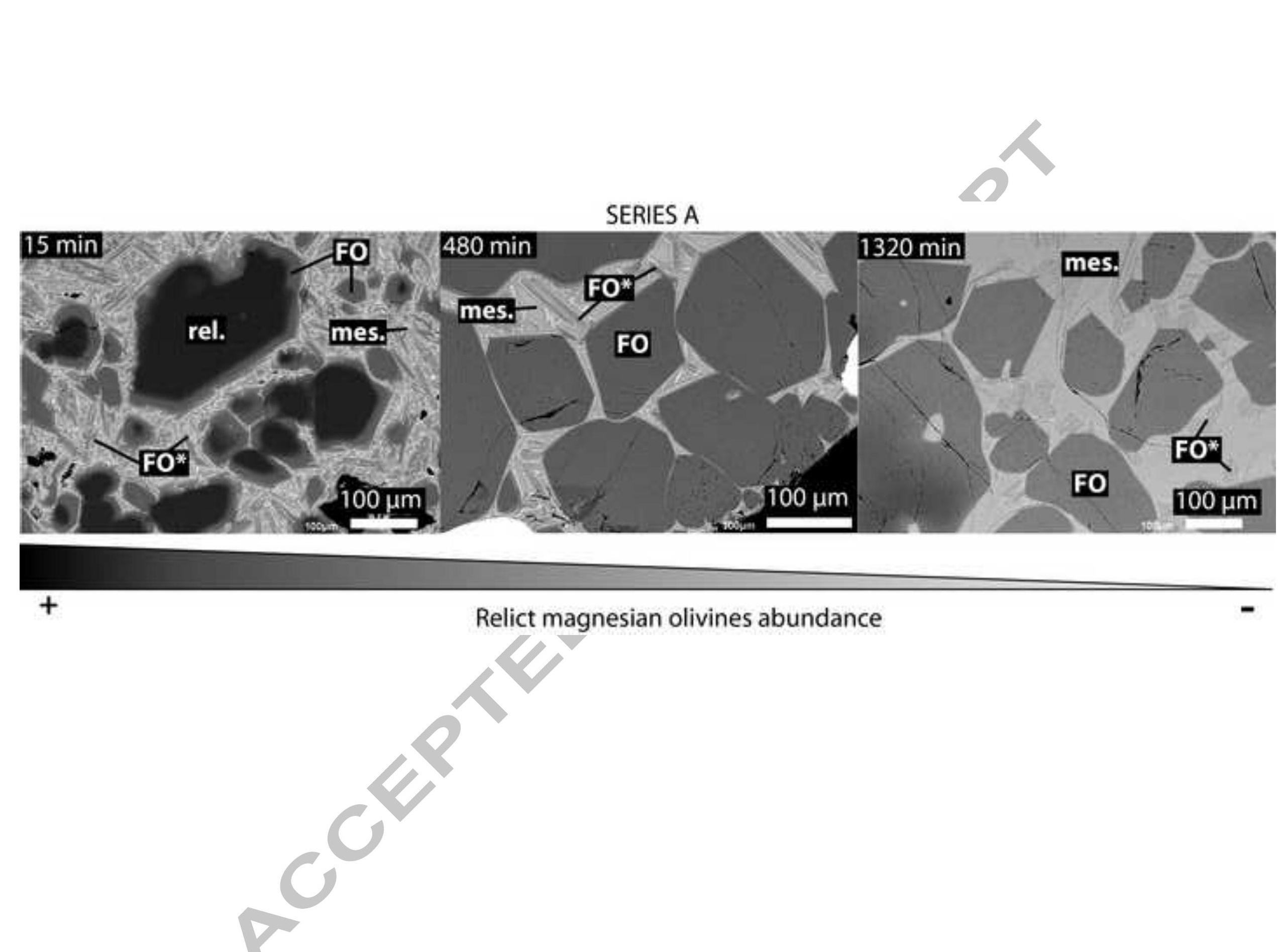

SERIES A
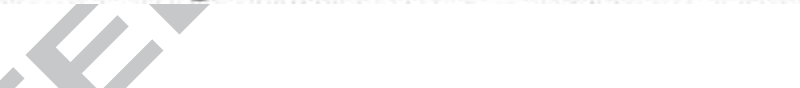

( 24 Y
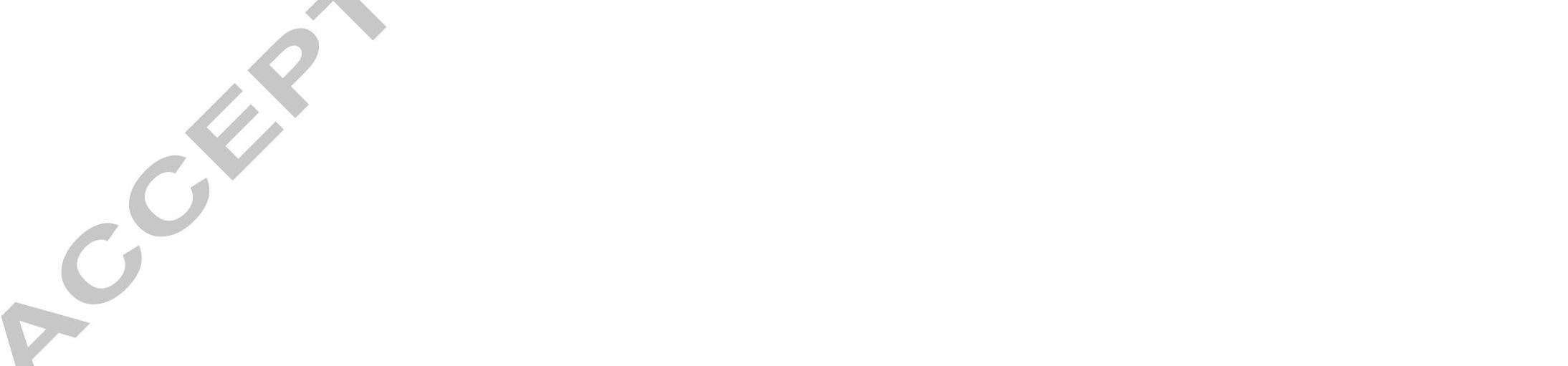

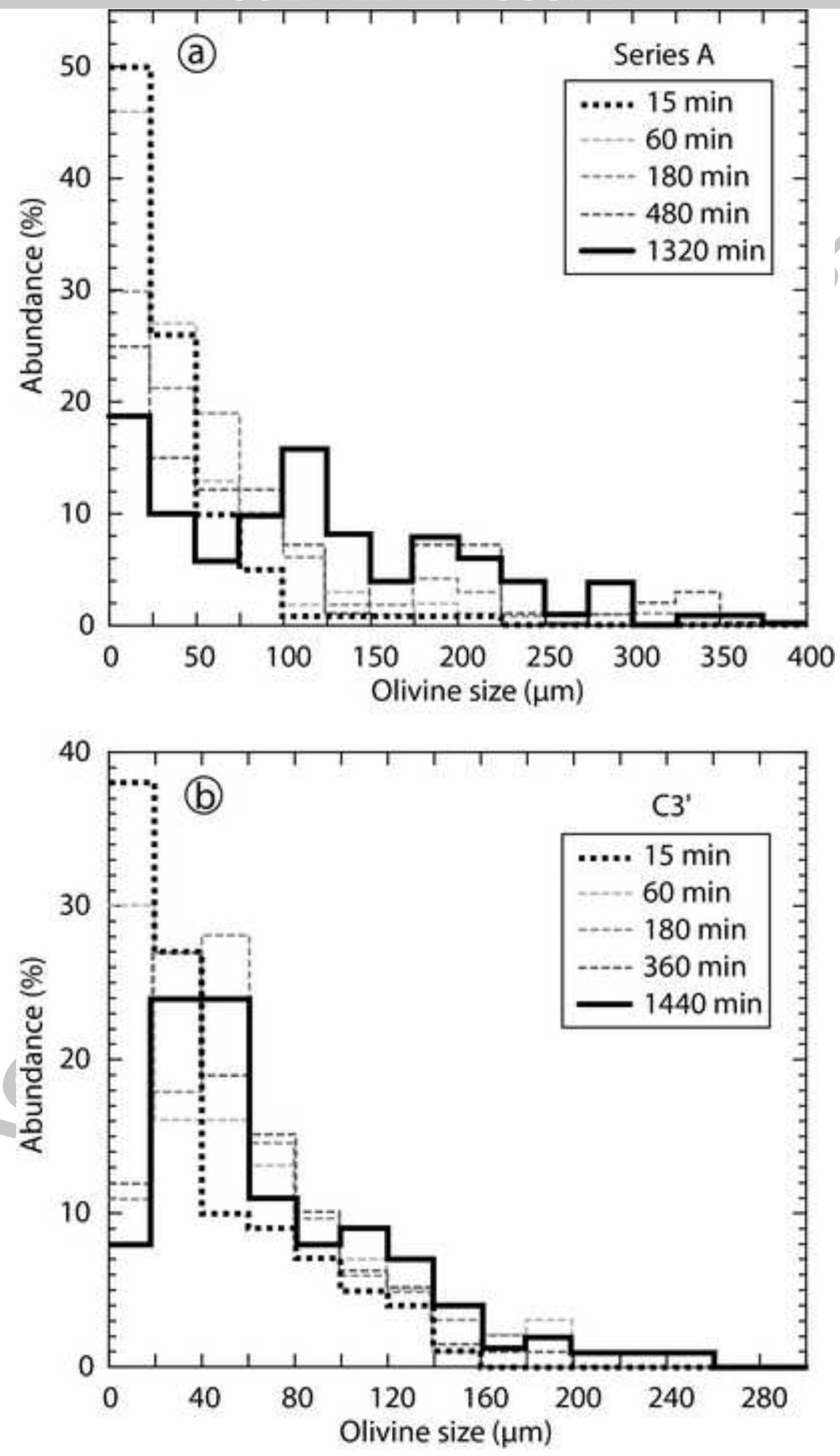


\section{ACCEPTED MANUSCRIPT SERIES B (Ni-NiO)}
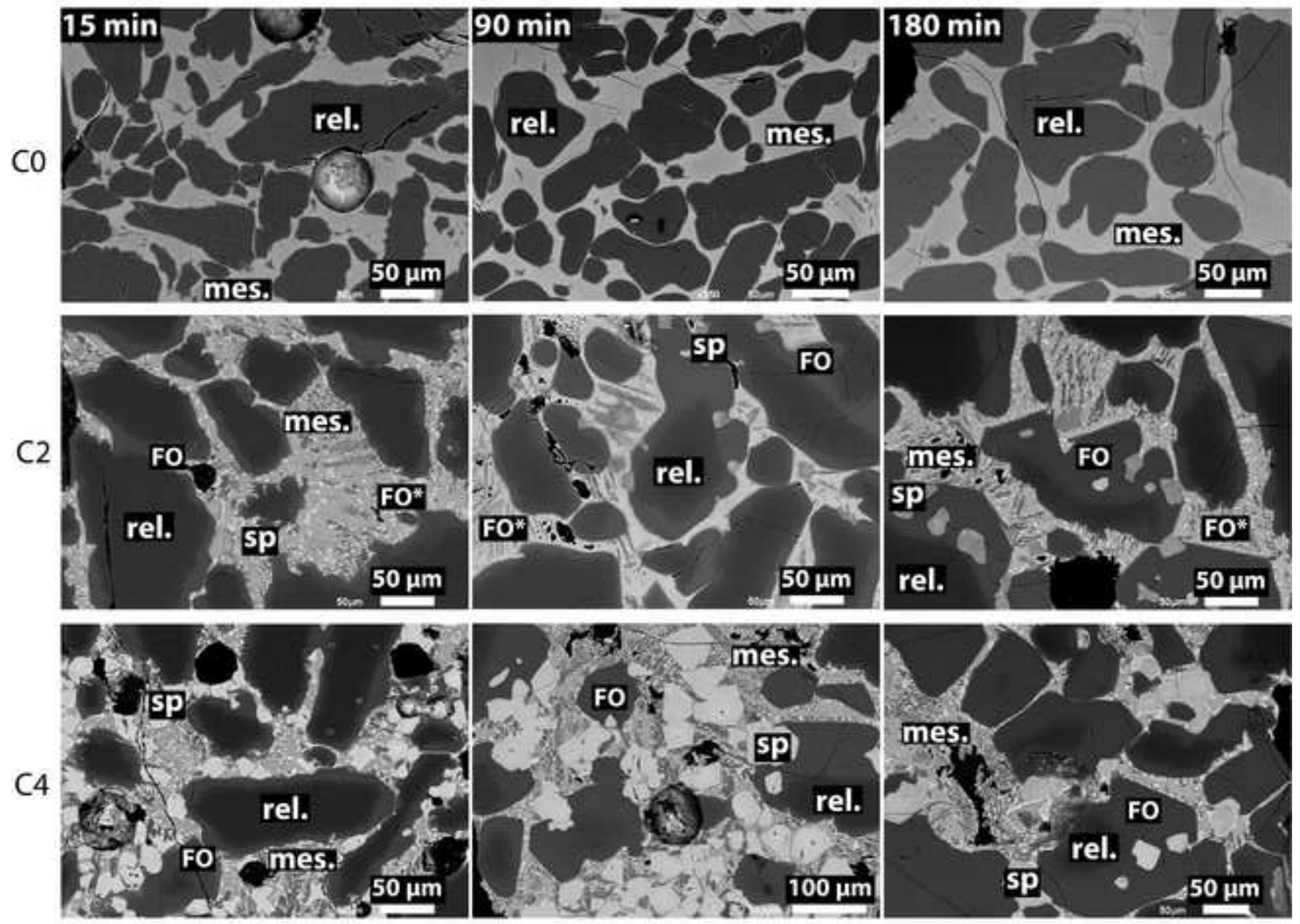

$+$

Relict magnesian olivine abundance 
SERIES B $(I W+1)$
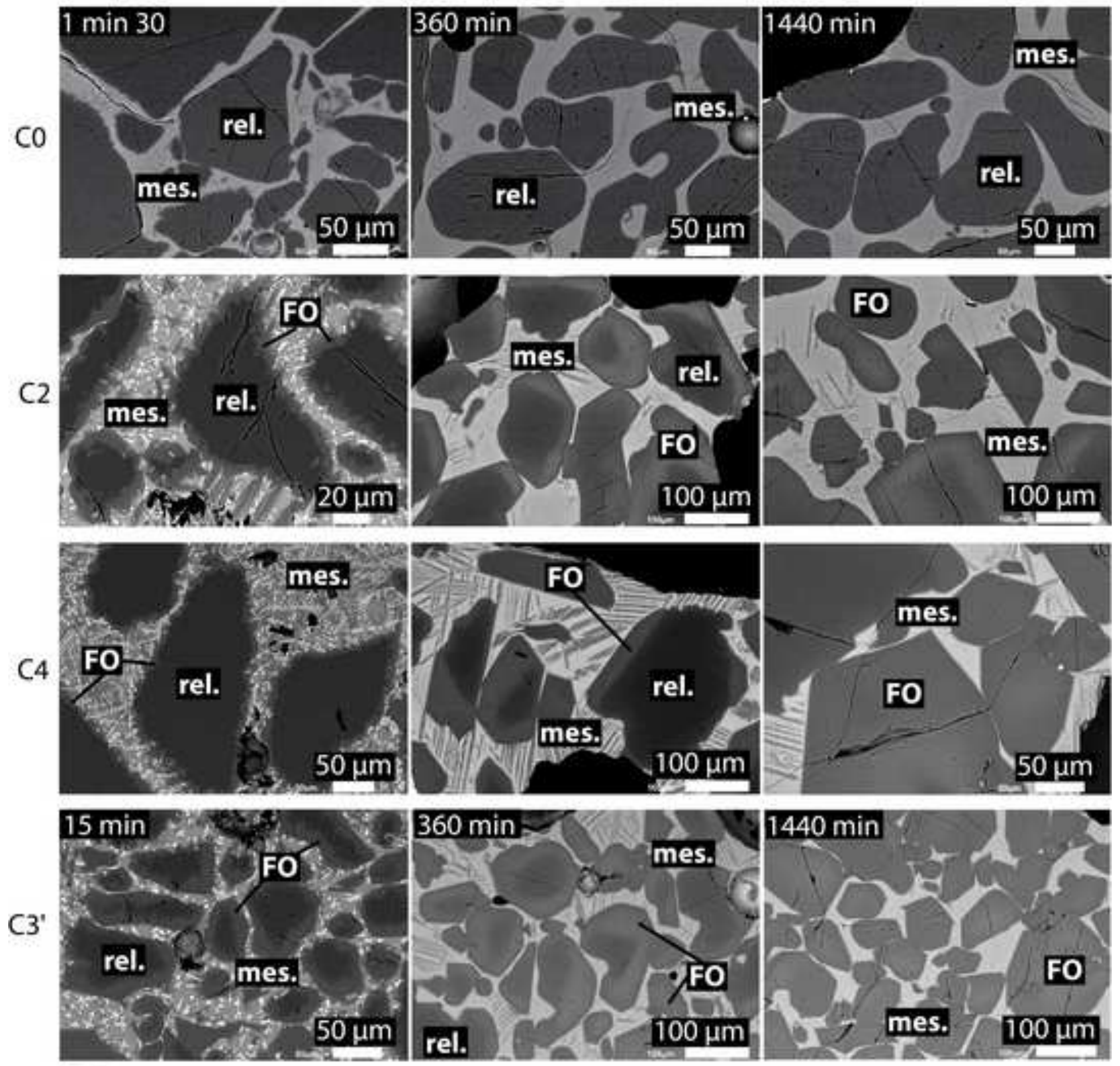


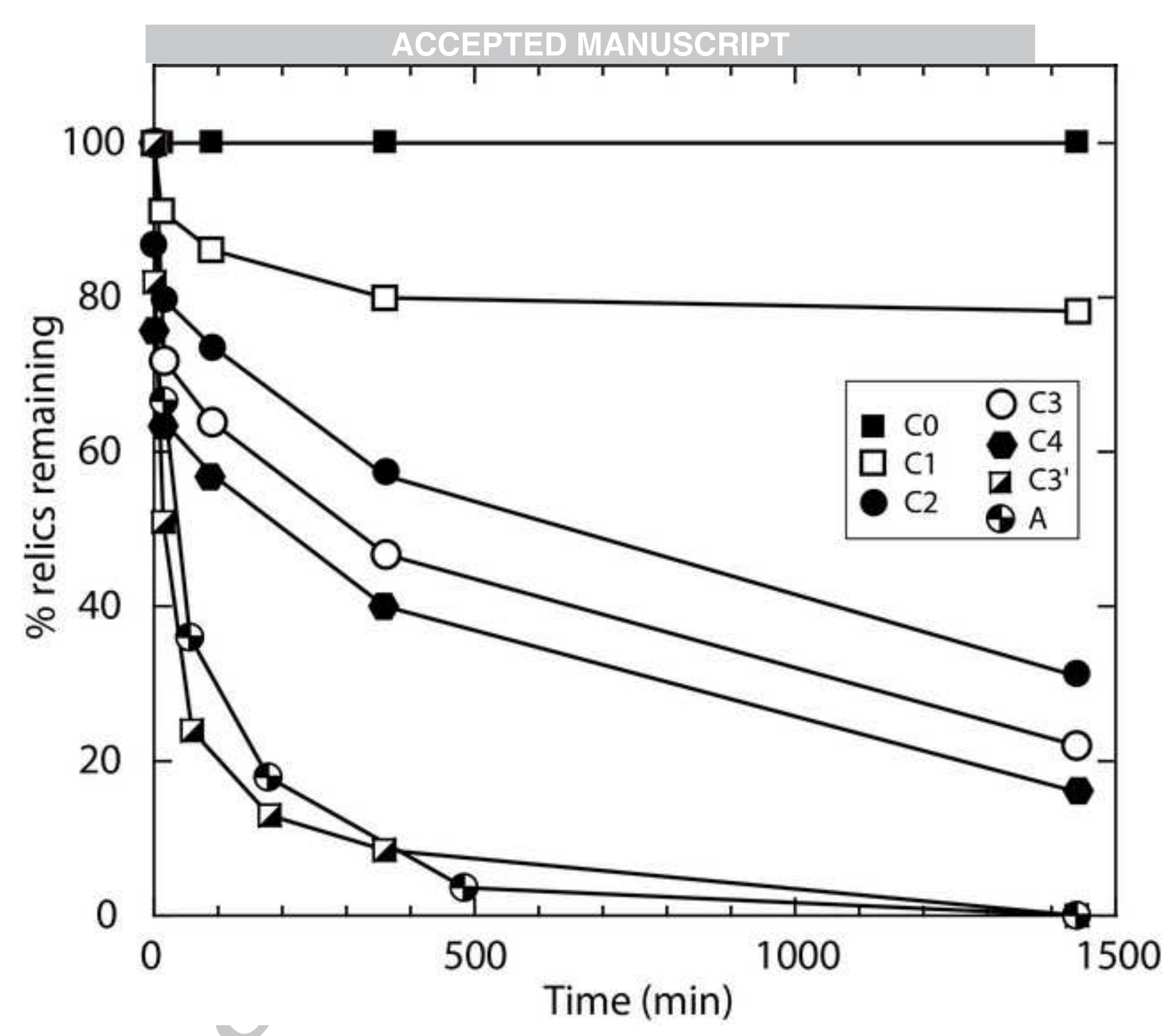


ACCEPTED MANUSCRIPT
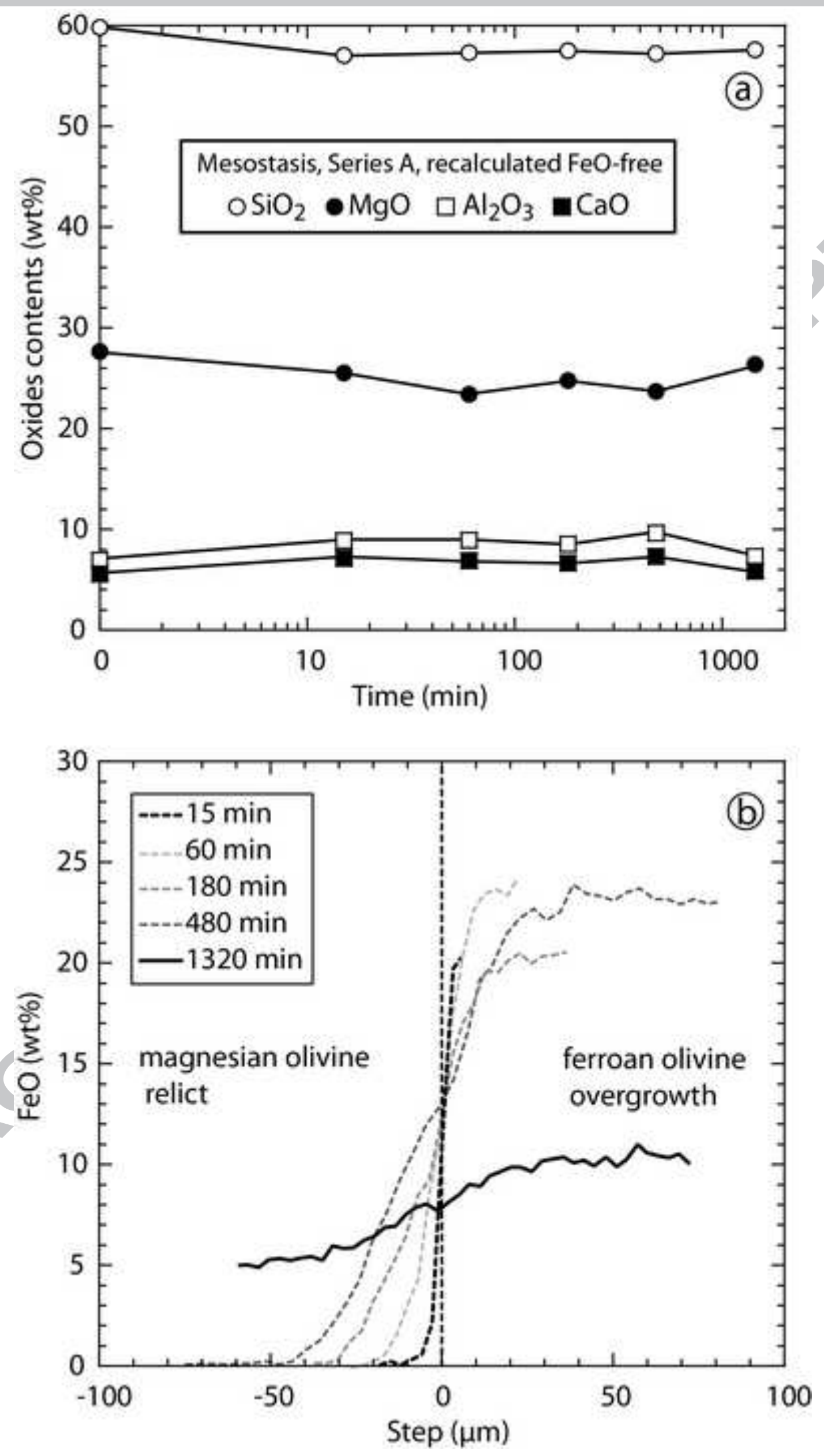


\section{ACCE PTED MANUSCRIPI}
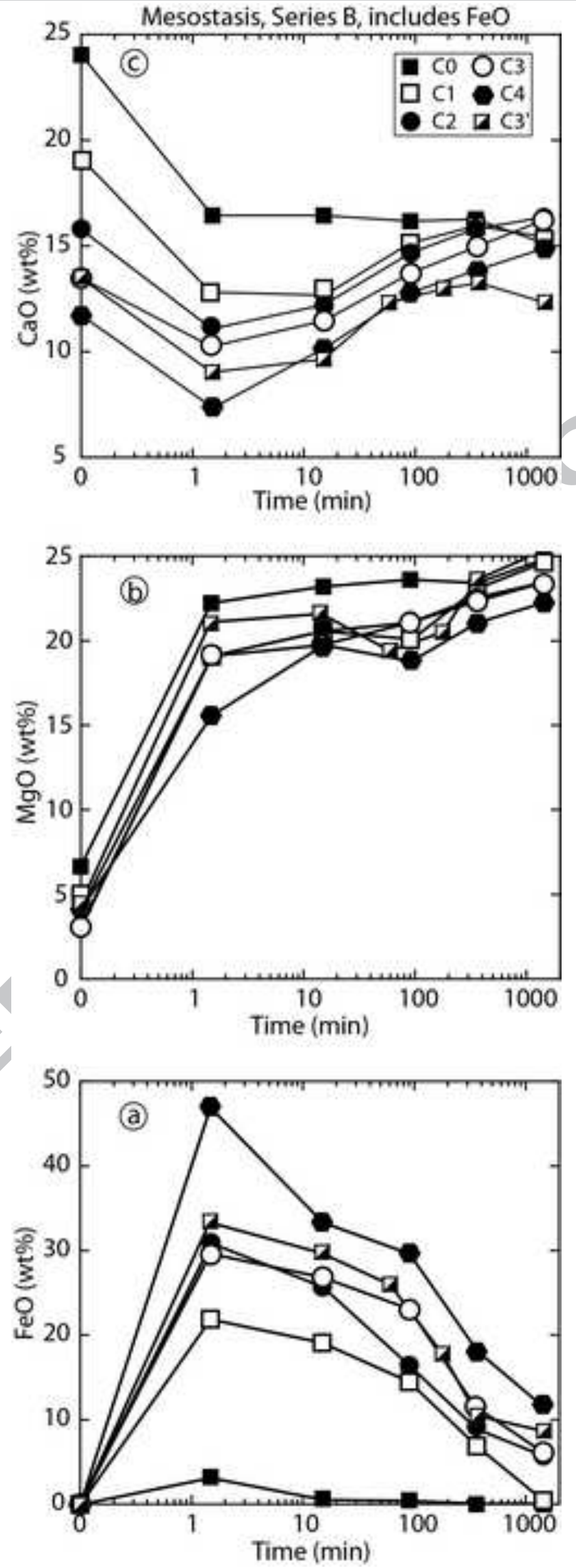

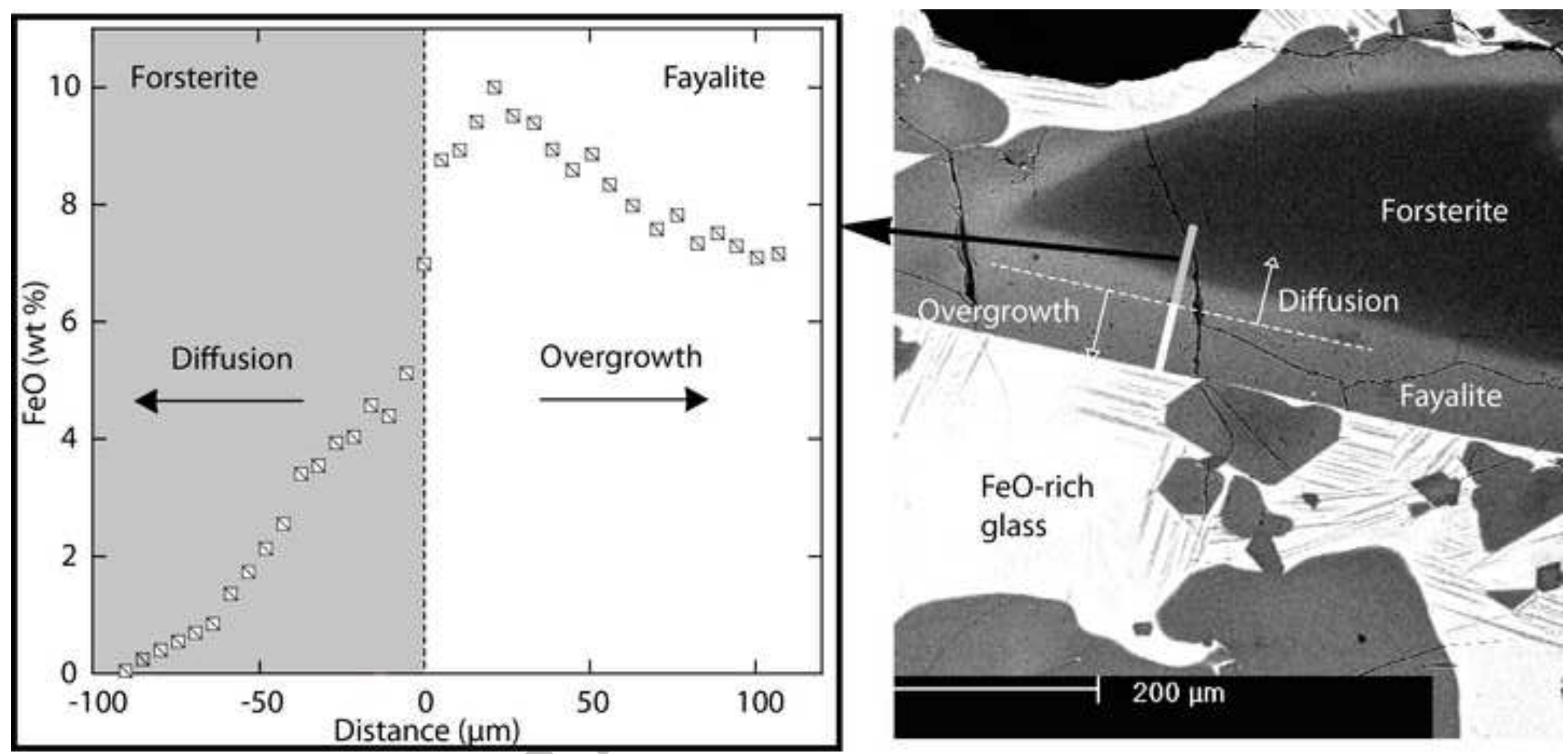
ACCEPTED MANUSCRIPT
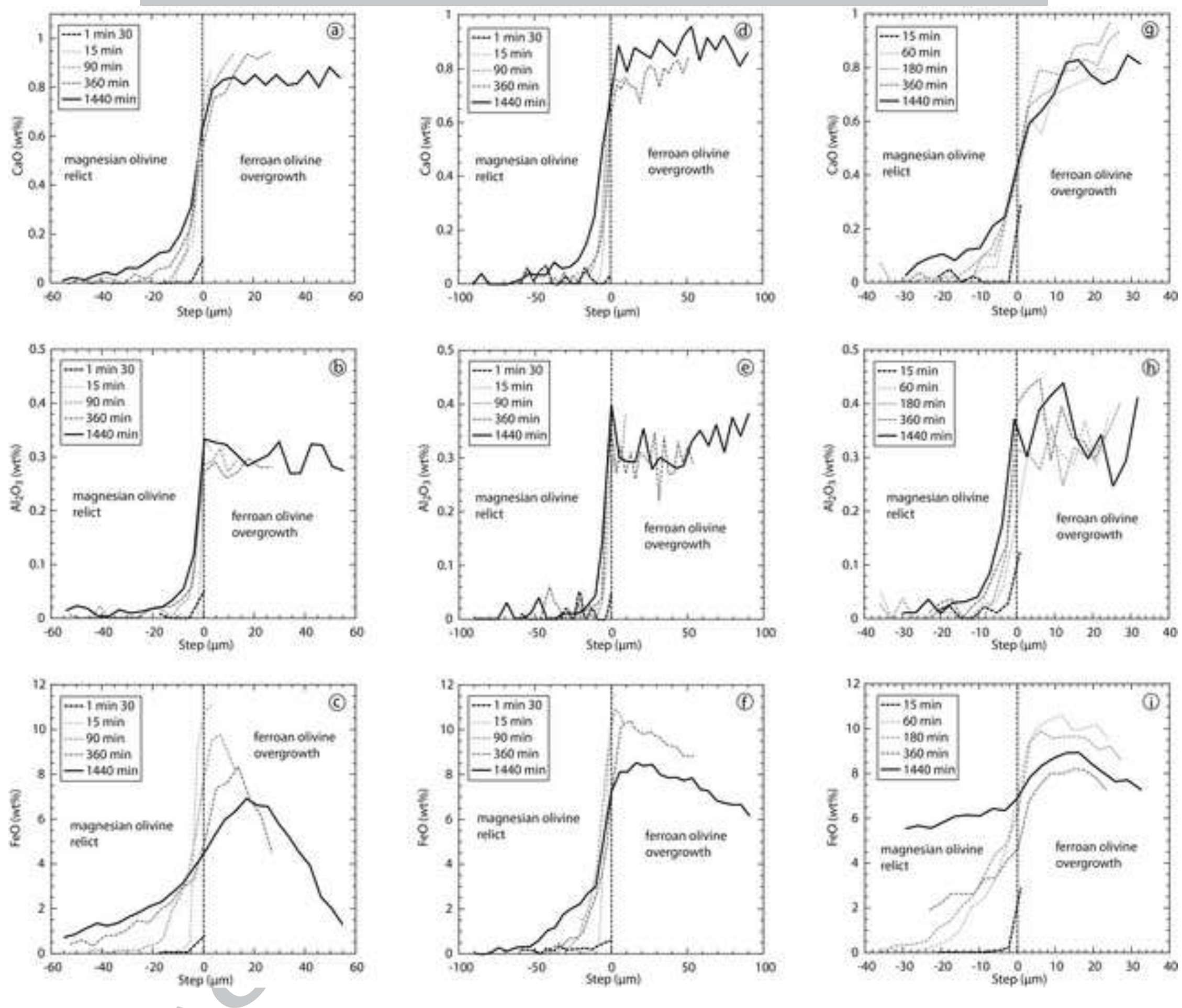

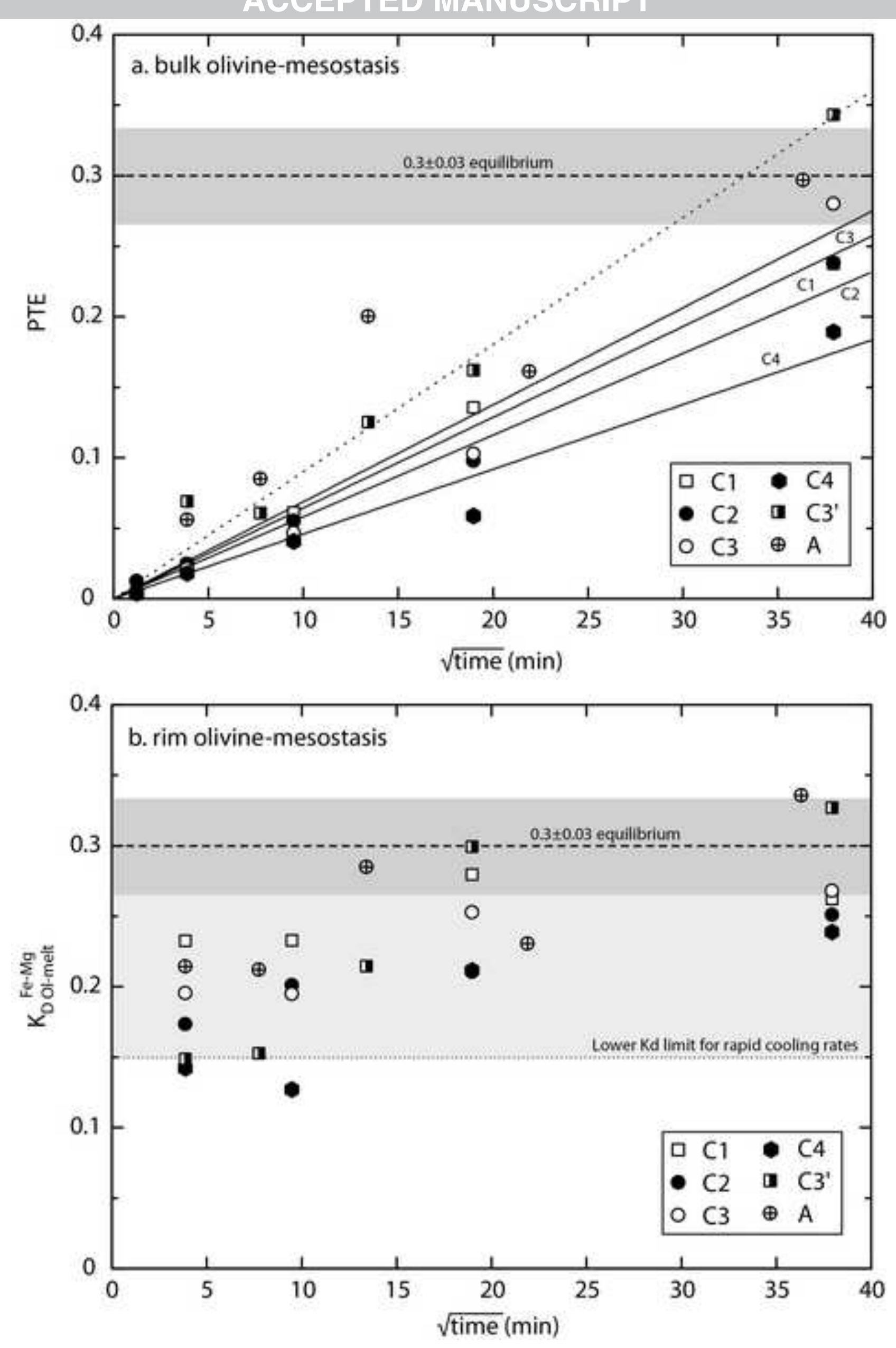

ACCEPTED MANUSCRIPT 
ACCEPTED MANUSCRIPT
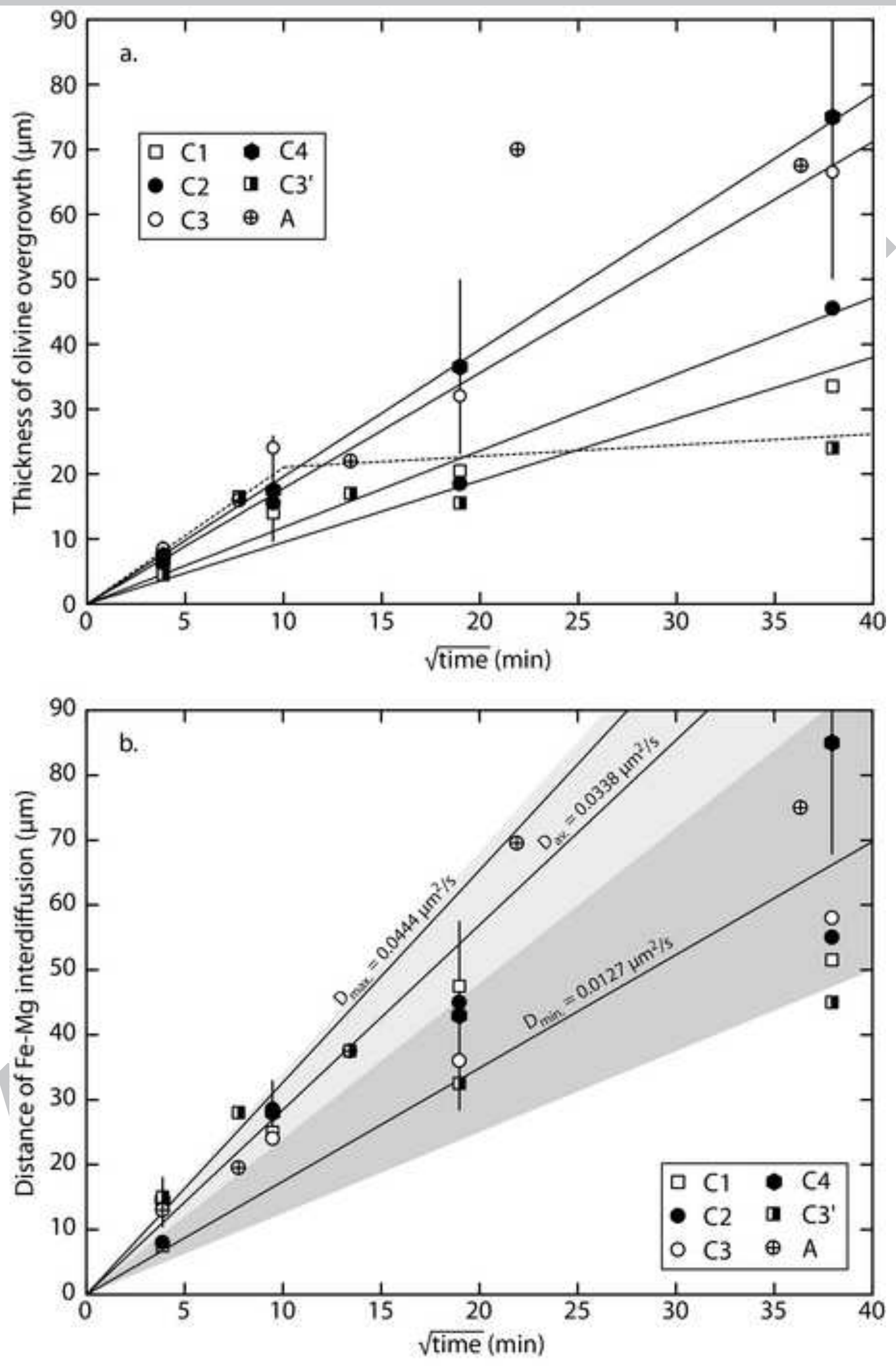


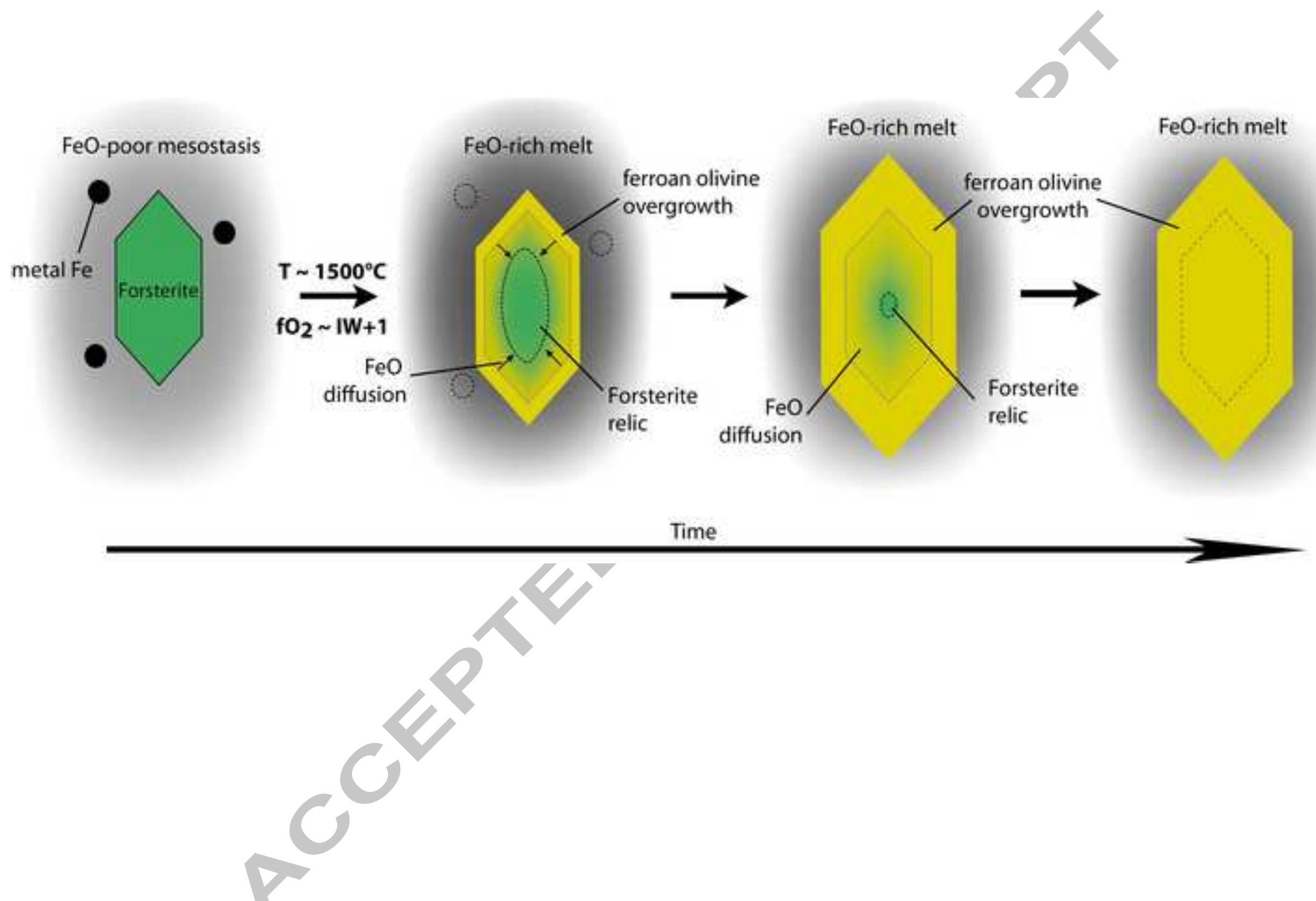




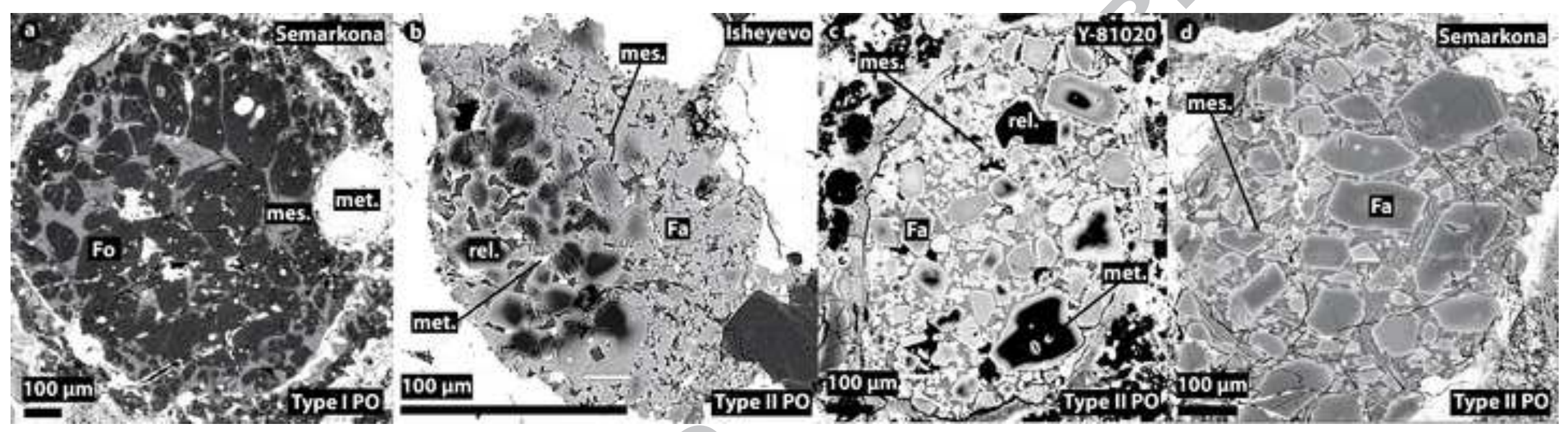




\section{ACCEPTED MANUSCRIPT}
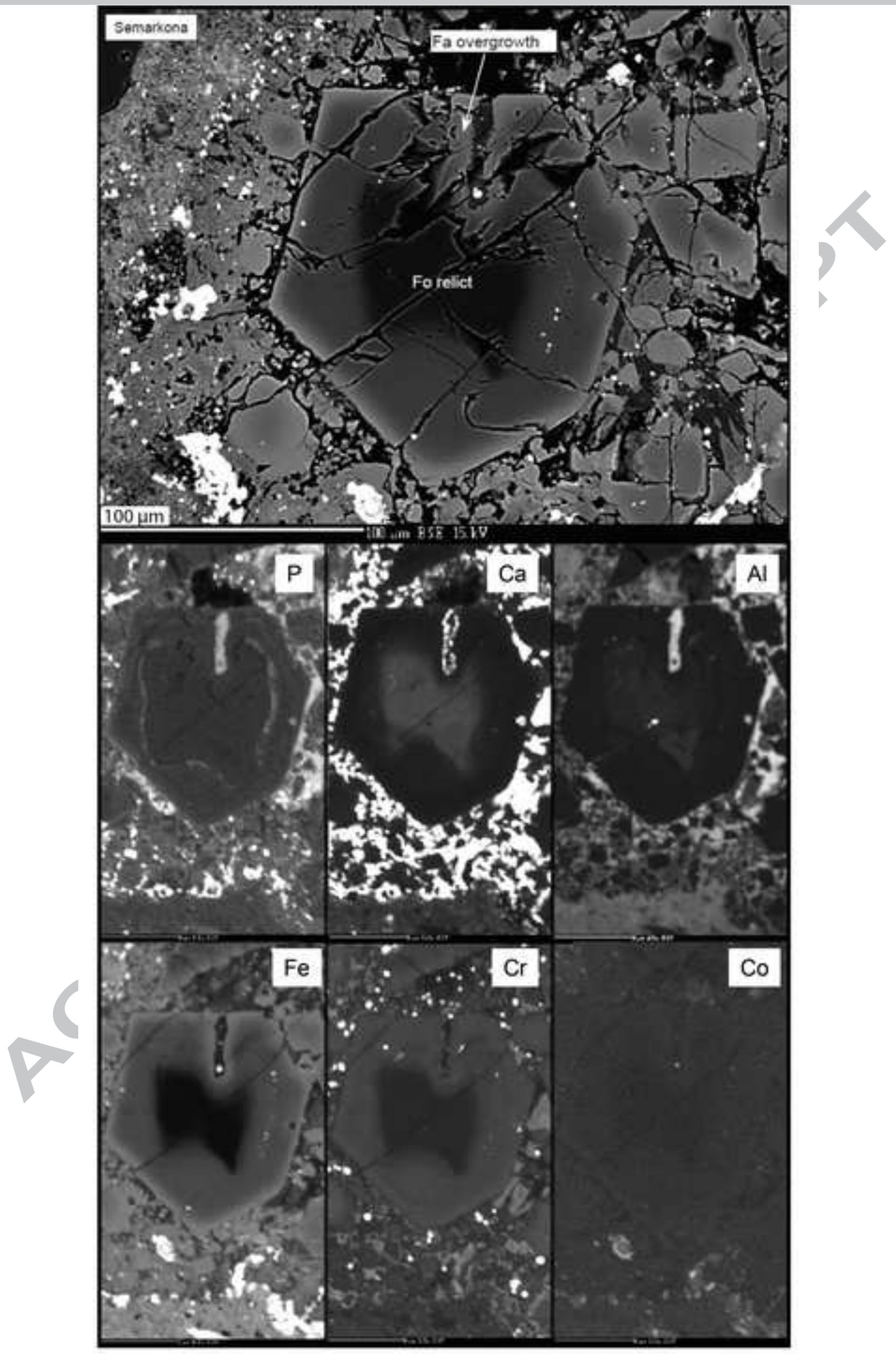


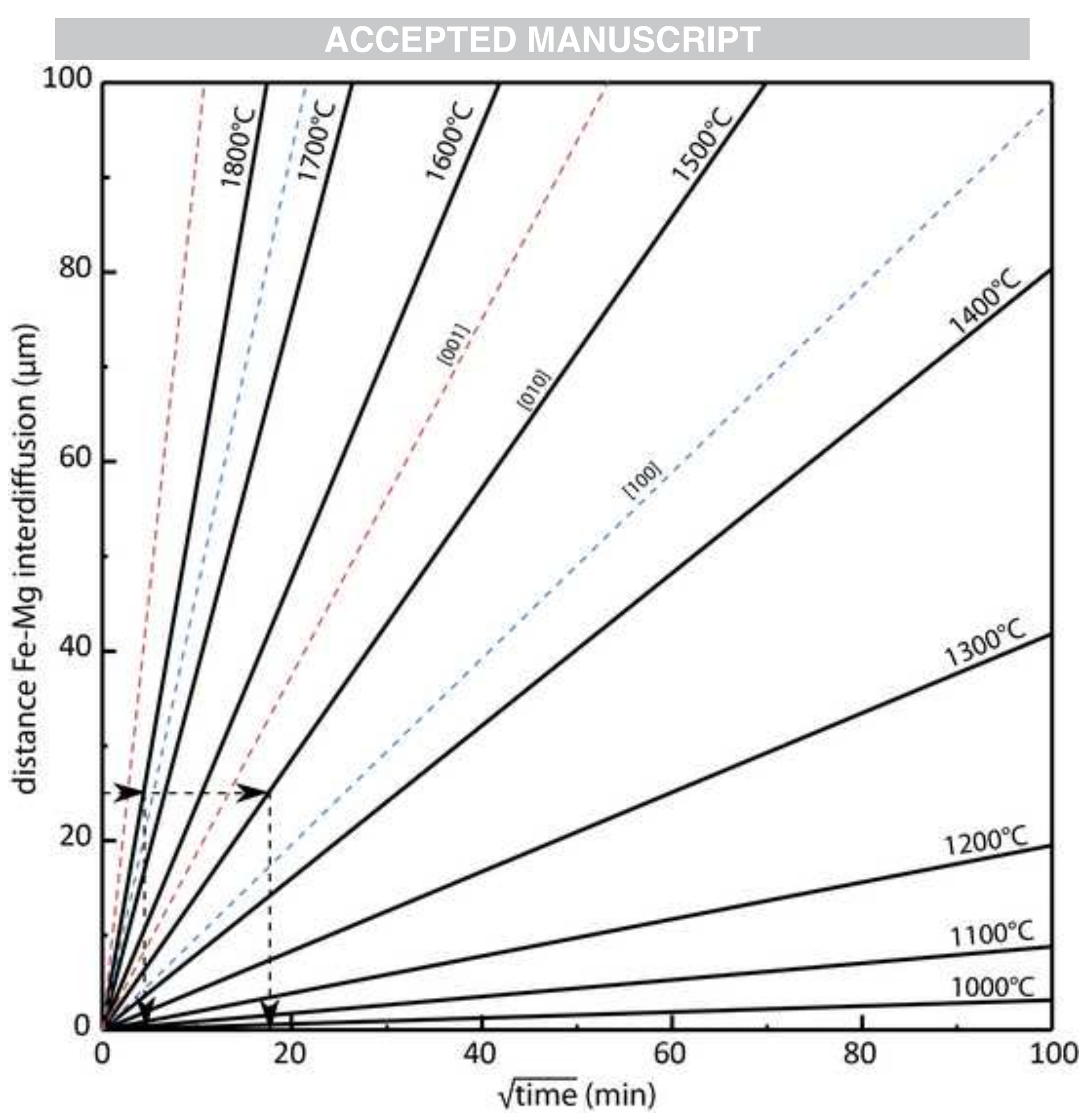




\section{ACCEPTED MANUSCRIPT}

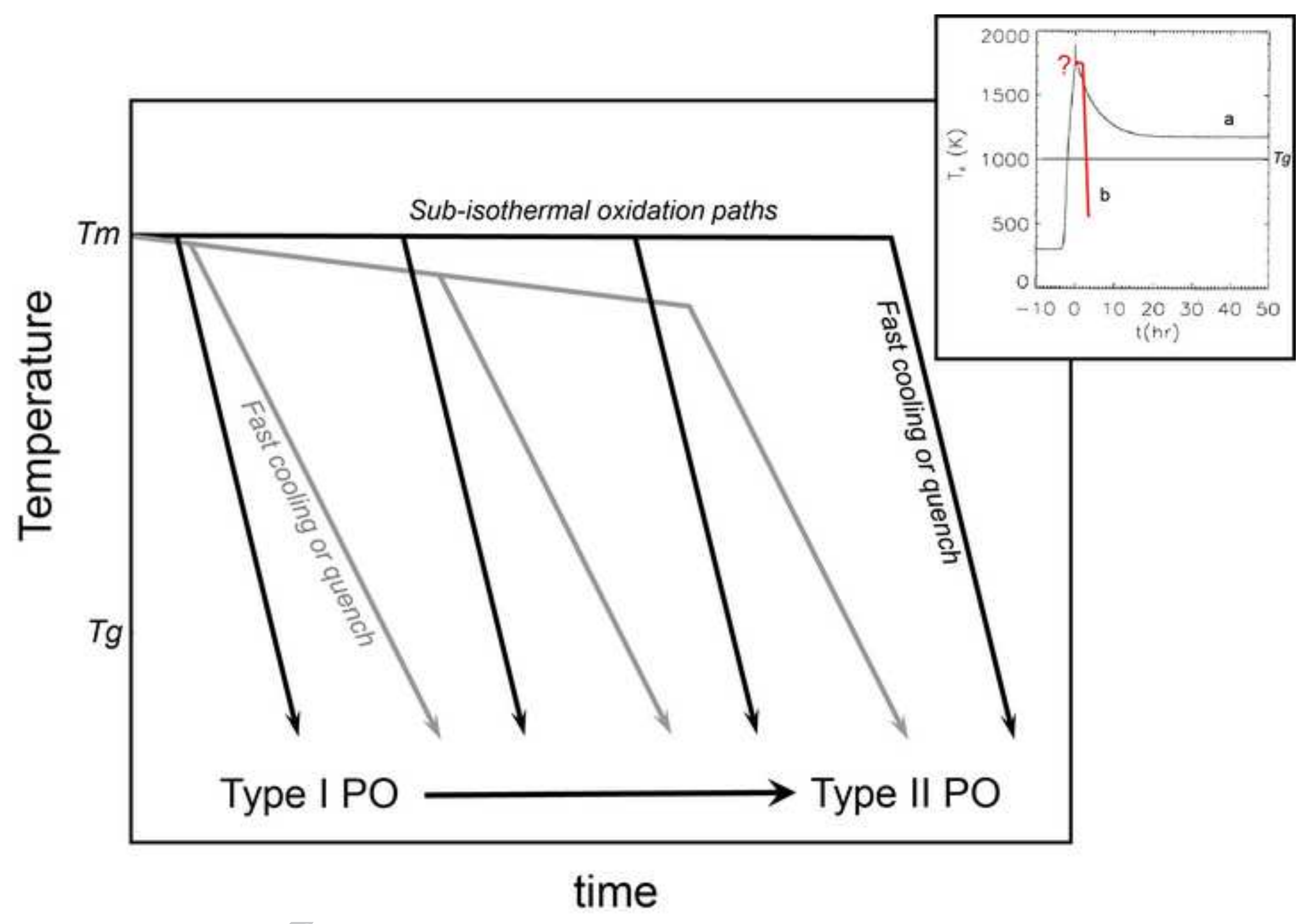

time 